\title{
Empirical investigations into performance and dynamics of agricultural firms
}

\author{
Dissertation \\ to obtain the Ph. D. degree \\ in the International Ph. D. Program for Agricultural Sciences in Göttingen \\ (IPAG) \\ at the Faculty of Agricultural Sciences, \\ Georg-August-University of Göttingen, Germany \\ presented by \\ Thelma Brenes Muñoz \\ born in Managua, Nicaragua
}

Göttingen, May 2015 
1. Name of supervisor: Prof. Dr. Stephan von Cramon-Taubadel

2. Name of co-supervisor: Prof. Dr. Bernhard Brümmer

Date of oral examination: May 7, 2015 
Es ist nicht das Wissen, sondern das Lernen, nicht das Besitzen, sondern das Erwerben, nicht das Dasein, sondern das Hinkommen, was den größten Genuß gewährt.

\section{Carl Friedrich Gauß}

No es el conocimiento, sino el acto de aprendizaje, y no la posesión, sino el acto de llegar allí, que concede el mayor disfrute.

\section{Carl Friedrich Gauß}


Table of Content

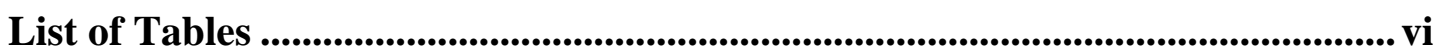

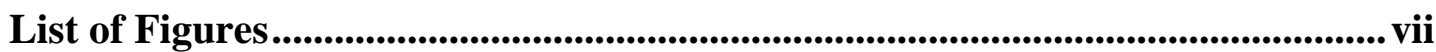

List of Appendix Tables................................................................................................viii

List of Appendix Figures .................................................................................

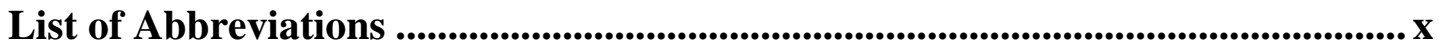

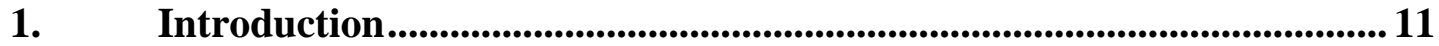

2. What influences the growth of organic farms? ........................................ 19

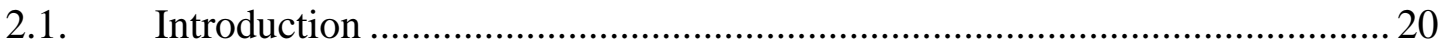

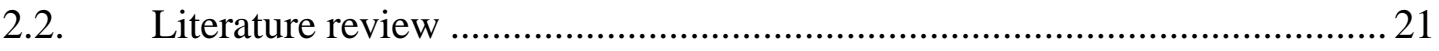

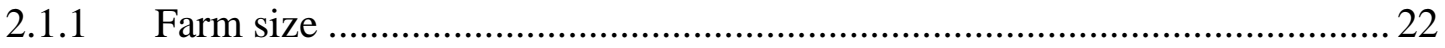

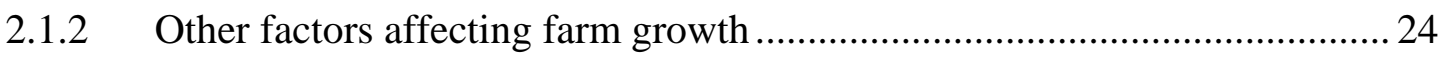

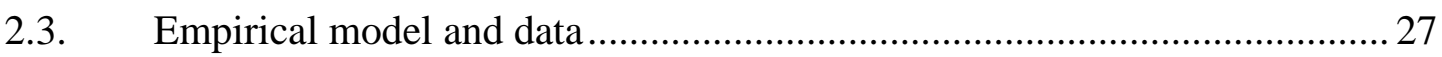

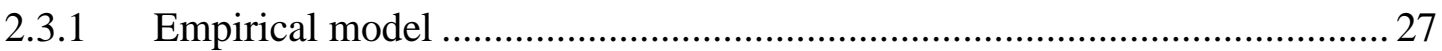

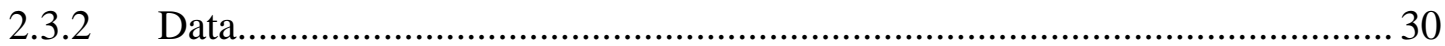

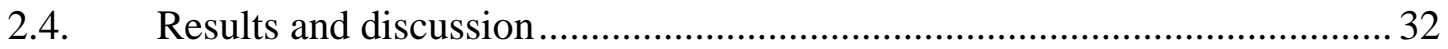

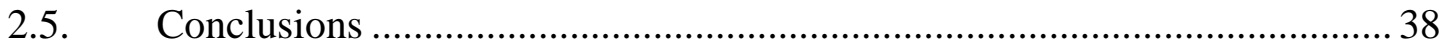

3. Technical efficiency in the Chilean agribusiness - a Stochastic Metafrontier Approach ............................................................................. 45

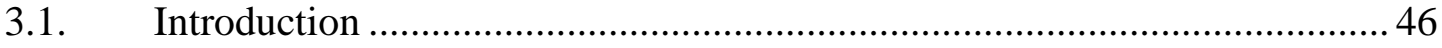

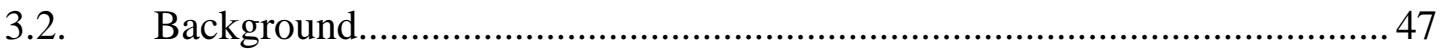

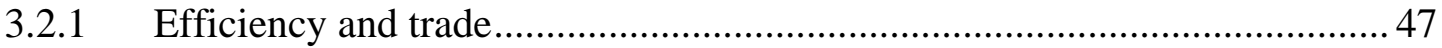

3.2.2 Background information on Chilean agribusiness ….................................. 50

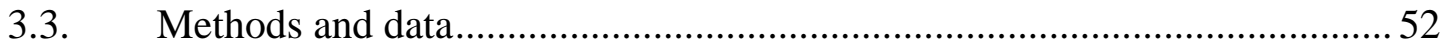

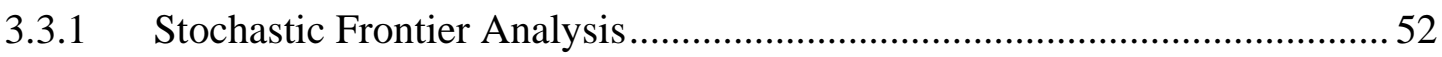

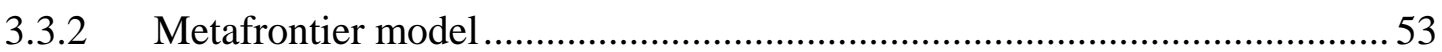

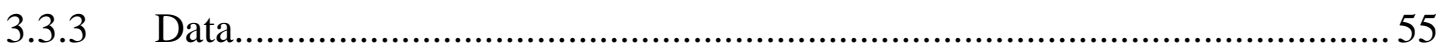




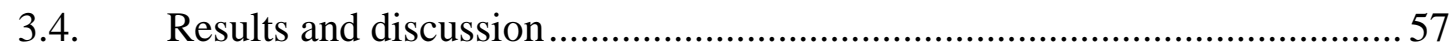

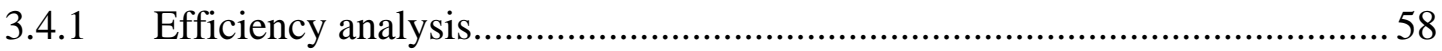

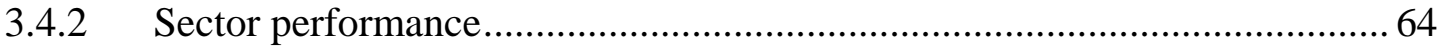

3.4.3 Performance of exporting sectors and firms.............................................. 66

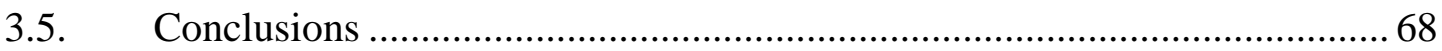

4. Testing the effect of firm performance on growth for the Chilean agribusiness .............................................................................................................. 79

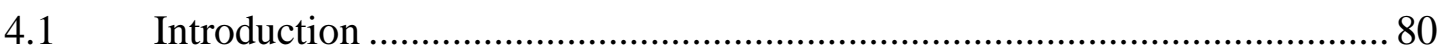

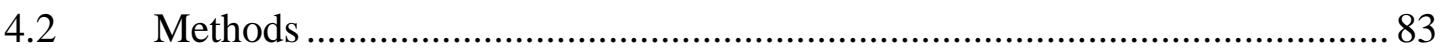

4.2.1 Estimating technical efficiency (TE) and meta-technology ratio (MTR) .... 83

4.2.2 Estimating the Penalized Quantile Regression with Fixed Effects (PFEQR)

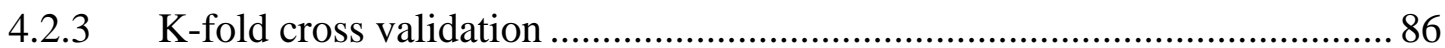

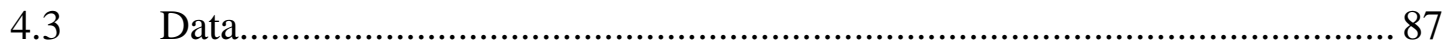

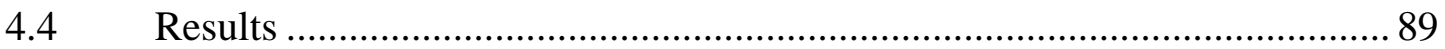

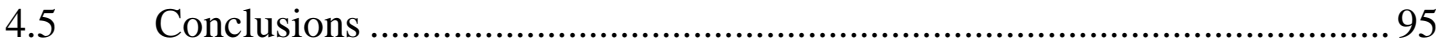

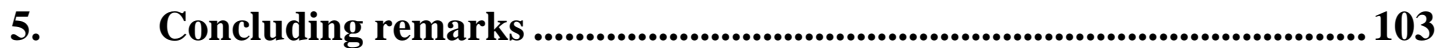

5.1 What influences the growth of organic farms in Southern Germany? ....... 103

5.2 Technical efficiency in Chilean agribusiness - a Stochastic Metafrontier

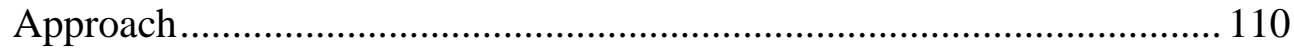

5.3 Testing the effect of firm performance on growth for the Chilean

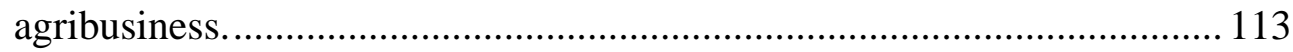

List of scientific presentations........................................................................ 117

Acknowledgements........................................................................................................ 118 


\section{List of Tables}

Table 2-1 Factor endowment of organic and comparable conventional farms in Germany, 1999-2000 24

Table 2-2 Definition of variables and descriptive statistics of organic farms, 1993-2005.

Table 2-3 SGMM estimation results for growth of organic farms in output and land, 1993-2005.

Table 2-4 Transition probability matrix for acreage changes in organic farming, 19932005.

Table 3-1 Number of observations by sector in the data set. 56

Table 3-2 Summary statistics of the Chilean agribusiness. 57

Table 3-3 Specification tests for model selection. 58

Table 3-4 Parameter estimates of the translog stochastic frontier model ${ }^{\dagger}$. 59

Table 3-5 Parameter estimates for the heteroscedasticity model. 61

Table 3-6 Mean MTR, TE ${ }^{G}$ and TE*$^{*}$ by sector. .63

Table 3-7 Scale-elasticities (SE) classification by sector. 63

Table 3-8 Share of exports and output of the largest firms. 66

Table 4-1 Number of observation by sector in the data set. 88

Table 4-2 Description of the variables. .88

Table 4-3 OLS, WG and quantile regression results of revenue growth. 91

Table 4-4 Pairwise T-tests of equivalence of the technical efficient coefficient at the different quantiles 93

Table 5-1 Comparison of coefficients for the lagged dependent variables of land and revenue. 108 


\section{List of Figures}

Figure 2-1 Predicted growth rates and farm size (in revenue) for organic farming. ..... 34

Figure 3-1 Group frontiers and Metafrontier. .54

Figure 3-2 TC and TEC development in the Chilean agribusiness 2002-2007. 64

Figure 3-3 $\mathrm{TE}^{\mathrm{G}}$ development for exporting and non-exporting firms in the Chilean agribusiness, 2001-2007. 67

Figure 4-1 Cross validation error corresponding to $\lambda$ values 87

Figure 4-2 Quantiles of the dependent variable, revenue growth rates. 89

Figure 4-3 Estimated effect of technical efficiency on revenue growth. 92

Figure 4-4 Estimated effect of MTR on revenue growth. 94 


\section{List of Appendix Tables}

Table A 1 T-Tests for pairwise comparisons column (d) Table 2-4............................ 44

Table A 2 T-Tests for pairwise comparisons column (e) Table 2-4............................ 44

Table A 3 Bonferroni test for TE* pairwise mean comparison. ................................. 76

Table A 4 PFEQR estimates for the meat sector...................................................... 100

Table A 5 PFEQR estimates for the fruit \& vegetables sector. .................................. 100

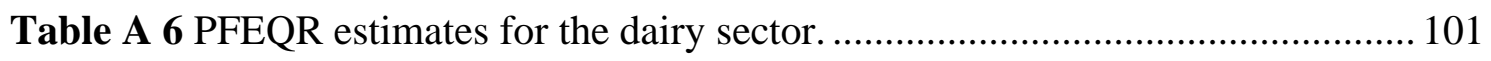

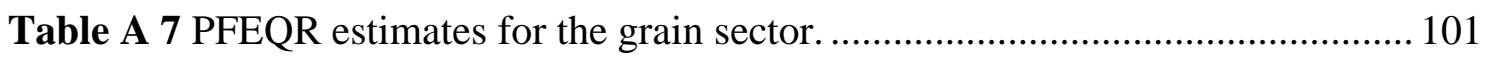

Table A 8 PFEQR estimates for the bakery sector. ................................................ 102 


\section{List of Appendix Figures}

Figure A 1 Distribution of technical efficiency (TE ${ }^{G}$ ) scores by sector for 2001, 2004 and 2007. .75

Figure A 2 Distribution of the meta-technology ratio (MTR) scores by sector for 2001, 2004 and 2007. .75

Figure A 3 Average $\mathrm{TE}^{\mathrm{G}}$ by sector in the Chilean agribusiness 2001-2007 77

Figure A 4 Average TC by sector in the Chilean agribusiness 2001-2007. .77

Figure A 5 TC with respect to firm size in the Chilean agribusiness. .78

Figure A 6 MTR with respect to firm size in the Chilean agribusiness. .78 


\section{List of Abbreviations}

UAA Utilized Agricultural Area

AWU Annual Agricultural Working Units

CD Cobb-Douglas

CLP Chilean Pesos

CV Cross Validation

DGMM Difference Generalized Method of Moments

ENIA Encuesta Nacional Industrial Anual - Annual National Industrial Survey

INE Instituto Nacional de Estadistica - National Institute of Statistics

ISIC International Standard Industrial Classification

LPE Law of Proportionate Effect

LRAC Long-Run Average Cost Curve

LU Livestock Units

MF Metafrontier

MTR Meta-Technology Ratio

ODEPA Oficina de Estudios y Políticas Agrarias

OECD Organization for Economic Co-operation and Development

OLS Ordinary Least Square

PFEQR Penalized Quantile Regression with Fixed Effects

RTS Returns to Scale

SE $\quad$ Scale Elasticities

SFA Stochastic Frontier Analysis

SGMM System Generalized Method of Moments Estimator

TE Technical Efficiency

TEC Technical Efficiency Change

TC Technical Change

WG Within Groups Estimation

WSR Weighted Sum of Absolute Residuals 


\section{Introduction}

\section{General Background}

Agricultural firms ${ }^{1}$ face decisions regarding the optimal input/output mix, the production techniques to be implemented in the production process and the scale of operation. These decisions determine the performance and the rate and direction of growth of the firm and, at the same time, of the whole industry. Yet the decisions are subject to external factors such as markets, policy framework and consumer preferences; factors which have changed profoundly during the last decades. This has resulted in an increased interest in the effects these changes have on individual firms and the behavior of firms under these new conditions. In this context, the present work analyzes which individual characteristics and external factors influence firm performance and firm growth, and how these two subjects are related for agricultural firms.

Certainly, the policy framework in a country sets the operating rules for the market and production activities (Happe, 2004). Agricultural and economic policies can either improve or deteriorate the functioning of the market and production sectors depending on the nature of the interventions and whether they create incentives for the mobility and allocation of production factors towards more efficient uses. Since the 1990s there have been major reductions in governmental distortions to agriculture and a greater emphasis on free markets and trade (Chavas, 2001; Anderson, 2010). Empirical evidence confirms that trade liberalization policies speed up the allocation of resources within and between firms, increasing the dynamics of an industry (Pavnick, 2002). With the increasing role of markets and the pressure to produce at lower costs, farming and food production have, in general, become more commercial and profit oriented (Lipton, 2005; Hazell and Wood, 2008). As a result, agriculture is now a competitive and thinmargin business in which a strong economic performance is crucial to remaining active in the market.

Consumer preferences have also changed and concerns about product quality, food safety, fairness and environmental impacts from food production have come to the fore (Henson and Reardon, 2005; Sexton, 2013). New market segments for differentiated products have flourished and some farmers have seen these market segments as a new

\footnotetext{
${ }^{1}$ We use the term agricultural firms in a generic sense to refer to firms operating in the agricultural sector, such as commercial farms or food processors.
} 
business opportunity. The market for organic products is one of them; its consumers are mainly driven by animal and environmental welfare of the production system (BravoPadilla, et al. 2013). The market for these products initially developed as an instrument to compensate producers for the internalization of negative externalities that would have otherwise come from a conventional production system (Stolze and Lampkin, 2009). This has also motivated some governments to provide financial assistance to producers for the additional costs of producing organically.

Initially, these market segments were seen as profitable for many producers due to the price-premium paid by consumers and the subsidies paid by governments. However, empirical analyses reveal that the low economic performance has forced some organic farms to get out of the business and reconvert to conventional production (for a review see Sahm et al., 2012). Other studies find a trend towards larger farm sizes in organic agriculture (Langer and Frederiksen, 2005; Best, 2008). These two developments together indicate that besides the plain processes of converting to organic or reconverting to conventional agriculture, there are also adjustments in the operation scale of organic farms which remain largely ignored. Understanding how this adjustment mechanism works is not only relevant to decision-makers who designed the policy support for those firms, but also for the firm's managers operating in this market segment. In this context, the present thesis contributes to identifying the magnitude of these individual adjustments, as well as their drivers and constraints.

Besides the increasing role of markets and new consumer preferences, the structure and organization of the agricultural industry has undergone significant changes during the last decades. It has become more diverse and some components within the industry have experienced significant growth. One of these changes concerns the development of food processors as an important component of the industry. Statistics from the WTO (2004) indicate that agricultural processed products have been the most dynamic element of agricultural trade since 1990. This shift from agricultural raw products to processed food can be observed across most regions and among a large majority of countries (ibid.). Among emerging economies, Chile is an exemplary case in adding value to its agricultural primary production. The food processing component arose in the late 1980s as a response to widescale discarding of fruit and within a period of 10 years it reached similar levels of export value as agricultural primary production (ODEPA, 2014). Moreover, much of the recent growth in Chilean food exports originates from the development of new sectors such as meat and dairy (OECD, 2008). The thesis will shed 
light on the performance of Chilean food processing firms, taking into consideration differences across the sectors in terms of technology, structure and engagement to international trade.

Against this background, the present work investigates the drivers of changes in size of agricultural firms operating in organic agriculture in Germany; subsequent analysis investigates the determinants of firm performance for food processors and the relationship between firm performance and growth in Chile.

\section{On the analysis of firm performance and firm growth}

To understand the remainder of this work, it is crucial to provide a clear definition of firm growth and performance. This section is not intended to provide an exhaustive literature review on these two subjects, but it aims to lay the foundations for the following chapters.

\section{Firm growth}

Firm growth is a multidimensional process that can be examined from several theoretical and empirical perspectives. McKelvie and Wiklund (2010) offer an extensive review on growth of individual businesses and summarize the literature into the following three streams:

o Firm growth as an outcome: this stream examines varying growth rates and increments or reductions of firm size as well as the drivers for these changes.

o The outcome of growth: this explores the changes that result within the organization as a consequence of growth. It focuses specially on the challenges of managing an increasingly large firm and examines the consequences of growth within a firm.

o Firm growth as a process: this deals with the process within the firm as it is growing, whether a firm grows via organic (internal) growth, mergers and acquisitions, or diversification, and analyzes how these decisions are taken.

Two of the studies presented in the remaining chapters can be categorized within the first stream of the literature described by McKelvie and Wiklund (2010). Within the context of this work, firm growth is defined as the changes in firm size over time. Specifically, this thesis explores the ability of the agricultural firms to increase their size based on their internal resources and takes into consideration potential external factors that contribute or hinder these dynamics. 


\section{Firm Performance}

Firm performance is a relative concept that can be defined in different ways. It can be measured in terms of productivity (the ratio of output(s) to input(s)), technical efficiency (relative to best possible output in the industry), or with respect to a firm's own performance over time (Coelli et al., 2005).

Technical efficiency offers the opportunity to estimate the firm's performance relative to maximum potential output, obtainable from a given set of inputs and a specific technology (Kumbhakar and Lovell, 2000). More importantly, it allows for measuring the shortfall of the observed output to the maximum feasible output and indicates the potential causes for this shortfall. The shortfall of the observed output for a firm is the technical inefficiency and is attributed to managerial inefficiency such as a firm's age or a manager's experience in addition to other factors that are not under the control of the producers.

Technical efficiency can be estimated through Data Envelopment Analysis (DEA) or Stochastic Frontier Analysis (SFA). DEA provides, through linear programming, a simple way to estimate technical efficiency by conducting a benchmarking assessment against the most efficient firms in the frontier. However, the main drawback is that it attributes all deviations from the production frontier to technical inefficiencies, without any consideration of random events (Coelli et al., 2005). SFA allows statistical noise to be distinguished from inefficiency, which is a pragmatic assumption for a real world application.

However, the results of these two methods do not allow for drawing comparisons between the efficiency of one sample relative to another and the subsequent implications of this (Coelli et al., 2005). In this context, Battese et al. (2004) and O'Donnell et al. (2008) propose the estimation of a Metafrontier function model (MF) for firms operating under different production possibilities. It can be estimated using either DEA or the SFA technique. The MF framework provides a decomposition of the efficiency term into two components: first, the distance of a firm to the group frontiers, related to the management and structure of the firm itself. Second, the technology gaps, that is, the distance of the groups to the common frontier that is influenced by the physical, social, or economic environment in which their production occurs. This decomposition is crucial when estimating the performance of a firm because it can shed 
light on the causes (internal or external factors) of why agricultural firms do not achieve their full efficiency.

\section{Following Chapters}

This thesis presents three selected studies on the topic of performance and dynamics of agricultural firms. It constitutes three empirical investigations which analyze the factors that determine firm performance, changes in firm size, as well as the extent to which firm performance influences firm growth in the context of the agricultural industry.

Chapter 2 analyzes the dynamics of agricultural firms engaged in organic agricultural production in Bavaria and Baden-Württemberg. This is one of the most developed regions in Germany with respect to a policy framework supporting organic farming and the share of German organic farms located in this region. The main objective in this chapter is to determine whether organic farms are changing their scale of operation and, if so, which factors contribute to - or stagnate - farm growth and to what extent. To answer these questions we use the System Generalized Methods of Moments (SGMM) estimator. The SGMM allows for including dynamics in the estimation of farm growth. That is, we can use previous farm size as a regressor and control for potential endogeneity, unobserved heterogeneity and persistency of the series. This chapter analyzes a unique panel data set of 453 organic farms over the period 1993 to 2005 and examines two dimensions of farm growth, in terms of agricultural land and in economic terms of output. The hypothesis tested is similar to that in empirical research of conventional agriculture: small farms show higher growth rates than their peers because they increase their scale of operation towards more efficient farm sizes. This chapter will test this hypothesis for the case of organic farming in South Germany and provide information about other factors that determine farm growth.

Chapter 3 analyzes the performance of agricultural firms in Chile. This chapter uses the data of 420 food processors over the period 2001 to 2007. As mentioned previously in this section, Chilean food processors are considered a successful case in adding value to agricultural primary production. However, within food processors there are groups which face different production opportunities and market structures. Furthermore, among food processors not all sectors have developed equally; some started earlier in processing agricultural products and entering international markets, others started later. We consider these differences as playing a decisive role when measuring the performance of firms. To determine the performance of the firms in this context, we 
estimate a Metafrontier function using Stochastic Frontier Analysis. These allow the identification of factors behind firms' inefficiency and decompose them into firm's internal factors such as managerial inefficiencies and external factors such as technological gaps.

Chapter 4 examines the relationship between firm performance and growth. This chapter is based on the data and estimates from Chapter 3. Specifically, it uses the estimates of technical efficiency relative to the group frontiers, the technology gaps and exporting status to model the changes in revenue for individual firms (firm growth). In this chapter, the primary variable of interest is technical efficiency as an indicator of firm performance. The hypotheses are that technical efficiency contributes to explain firm growth and that its effect is presumably heterogenous over the distribution of firm growth. This implies that the magnitude of effect can differ for firms experiencing negative growth to those with positive rates. To test the hypotheses, this chapter uses the Penalized Quantile Regression with Fixed Effects (PQRFE) method proposed by Koenker (2004). This method determines the effect of technical efficiency and the other covariates at different points on the conditional distribution of firm growth and hence, tests our hypotheses.

Chapter 5 presents the implications of the key findings from the three studies, the shortcomings of the analyses, as well as further research questions. 


\section{References}

Anderson, K. (2010). Globalization's effects on world agricultural trade, 1960-2050. Philosophical Transactions of the Royal Society B: Biological Sciences, 365(1554), 3007-3021.

Battese, G. E., O’Donnell, C. J., \& Rao, D. S. P. (2004). A metafrontier production function for estimation of technical efficiencies and technology gaps for firms operating under different technologies. Journal of Productivity Analysis, 21, 91103.

Best, H. (2008). Organic agriculture and the conventionalization hypothesis: A case study from West Germany. Agriculture and Human Values, 25(1), 95-106.

Bravo-Padilla, C., Cordts, A., Schulze, B., \& Spiller, A. (2013). Assessing determinants of organic food consumption using data from the German National Nutrition Survey II. Food quality and Preference, 28(1), 60-70.

Chavas, J. P. (2001). Structural change in agricultural production: Economics, technology and policy. Handbook of agricultural economics, 1, 263-285.

Coelli, T. J., Prasada Rao, D., \& O'Donnel, C. J. (2005). An introduction to efficiency and productivity analysis (2nd ed.). New York, NY: Springer.

Happe, K. (2004). Agricultural policies and farm structures-agent-based modelling and application to EU-policy reform. IAMO Studies on the Agricultural and Food Sector in Central and Eastern Europe 30, IAMO, Halle (Saale). Retrieved from: http://www.iamo.de/dok/sr_vol30.pdf

Hazell, P., \& Wood, S. (2008). Drivers of change in global agriculture. Philosophical Transactions of the Royal Society B: Biological Sciences, 363(1491), 495-515.

Henson, S., \& Reardon, T. (2005). Private agri-food standards: Implications for food policy and the agri-food system. Food policy, 30(3), 241-253.

Koenker, R., (2004). Quantile regression for longitudinal data. Journal of Multivariate $\begin{array}{lllllll}\text { Analysis, } & 91, & 74 & - & 89 . & \text { Retrieved } & \text { from: }\end{array}$ http://www.econ.uiuc.edu/ roger/research/panel/long.pdf

Kumbhakar, S. C., \& Lovell, C. K. (2000). Stochastic frontier analysis. Cambridge University Press.

Langer, V., Frederiksen, P., \& Jensen, J. D. (2005). The development of farm size on Danish organic farms-a comment to the conventionalisation debate. In Int. 
Scientific Conference on Organic Agriculture: Researching Sustainable Systems, Adelaide, Australia.

Lipton, M. (2005). The family farm in a globalizing world: The role of crop science in alleviating poverty (Vol. 40). Intl Food Policy Res Inst.

McKelvie, A., \& Wiklund, J. (2010). Advancing firm growth research: A focus on growth mode instead of growth rate. Entrepreneurship theory and practice, 34(2), 261-288.

O’Donnell, C.J., Rao, D.S.P., \& Battese, G.E. (2008). Metafrontier Frameworks for the study of firm level efficiencies and technology ratios. Empirical Economics, 34, 231-255.

Organisation for Economic Co-operation and Development (OECD). (2008). OECD Review of Agricultural Policies, Chile. ISBN 97892-64-04223-0.

Oficina de Estudios y Políticas Agrarias (ODEPA) (2014). Balanza comercial de productos silvoagropecuarios. Retrieved from: http://www.odepa.cl/balanzacomercial-de-productos-silvoagropecuarios/

Pavcnik, N. (2002). Trade Liberalization, Exit, and Productivity Improvements: Evidence from Chilean Plants. The Review of Economic Studies Limited, 69, 245276.

Sahm, H., Sanders, J., Nieberg, H., Behrens, G., Kuhnert, H., Strom, R., \& Hamm, U. (2012). Reversion of organic to conventional agriculture: a review. Renewable Agriculture and Food Systems 28 (3), 263-275.

Sexton, R. J. (2013). Market power, misconceptions, and modern agricultural markets. American Journal of Agricultural Economics, 95(2), 209-219.

Stolze, M. \& Lampkin, N. (2009). Policy for organic farming: Rationale and concepts. Food Policy 34 (3), 237-244.

McKelvie, A., \& Wiklund, J. (2010). Advancing firm growth research: A focus on growth mode instead of growth rate. Entrepreneurship theory and practice, 34(2), 261-288.

World Trade Organization (WTO). (2004) Trade and Trade Policy Developments, World Trade Report 2004, Geneva. Retrieved from: http://www.wto.org/english/news_e/pres04_e/press378_annex_e.pdf 


\title{
2. What influences the growth of organic farms?
}

\begin{abstract}
$^{2}$
Organic farming is one of the fastest-growing sectors of agriculture in Germany. The net increase in the number of hectares comes partly from the conversion of conventional farms, but also in part from the expansion of existing organic farms. So far, empirical research has focused on analyzing conversion to organic farming, and lately on reversion to conventional farming. However, changes in individual organic farm sizes have remained largely ignored by empirical researchers. It remains unclear what other factors besides increasing demand for organic products might influence growth of organic farms. The main objective in this study is to determine whether organic farms are changing their scale of operation and, if so, which factors contribute to - or stagnate - farm growth and to what extent. To answer these questions we use the System Generalized Methods of Moments (SGMM) estimator. This chapter analyzes a unique panel data set of 453 organic farms over the period 1993 to 2005. The results reveal that all farms increase area by a maximum of 10 ha and large farms change farm size more frequently than smaller ones. Increases in organic area are influenced by subsidies for organic farming, off-farm employment, and the farmer's age. Farm growth measured in terms of revenue is affected by farm size, land, capital, soil quality, and intensity of livestock production.
\end{abstract}

\footnotetext{
${ }^{2}$ This chapter is co-authored with Prof. Dr. Bernhard Brümmer and Dr. Sebastian Lakner and has been submitted to the German Journal of Agricultural Economics.
} 


\subsection{Introduction}

Organic farming has become one of the fastest-growing sectors of agriculture over the last two decades. This growth has been driven by the increase in consumer concern for the environmental and animal welfare effects of food production (Zander and Hamm, 2010; Bravo-Padilla, et al. 2013). The policy support for organic farming and the associated price premium for these products has also influenced the conversion of conventional producers to organic production (Nieberg and Strohm-Lömpcke, 2001; Nieberg et al., 2011; Kuhnert et al., 2013). In this context, the organic sector has experienced an impressive development in Germany. The country is the largest market for organically produced food in Europe (Sahota, 2014). Additionally, the total number of hectares (ha) farmed organically in Germany grew from 354,171 ha in 1996 to 1,089,000 ha in 2014, an increase of about $200 \%$ (BÖLW, 2015). The increase in hectares comes from conversion of conventional farms to organic agriculture and in part, presumably, from the acreage and output expansion of existing organic farms. This process of individual adjustment of farms has been largely ignored by previous studies about organic agriculture.

From the late eighties until today, organic farming grew particularly rapidly in the South German states of Bavaria and Baden-Württemberg. Roughly $53 \%$ of the organic farms and $31 \%$ of the total organic area in Germany are found in this region (Destatis BL, 2013). This development is partly the result of a comprehensive policy framework to provide financial support for conversion and maintenance of organic farms (Nieberg et al., 2011). These Federal States, among others, had the largest public expenditures for area payments and investment assistance to organic agricultural businesses from 1999 to 2007 (Nieberg et al., 2011).

The growth possibilities of organic farms are more troublesome and expensive than those of conventional agriculture. Organic farms face a particular barrier when expanding their operations: they must bridge a three-year conversion period during which they encounter low yields, high certification costs, and a higher demand for labor, without being able to capture price premiums for certified organic products. Moreover when changing farm size, organic farmers face challenges that are of less concern in conventional agriculture, such as improvement of soil fertility, crop rotation, and supply of organically produced inputs such as feed and manure for the new scale of operation. These additional costs may prevent farmers from taking advantage of economies of scales in the short term. To some extent, the subsidies paid contribute to 
compensate these costs. However, it remains unclear as to what other factors contribute to the individual development of organic farms in this region of Germany.

Empirical research so far has focused on analyzing the determinants of conversion to organic farming, and lately on reversion to conventional farming. However, change in individual farm sizes is another aspect of structural change in organic agriculture that has not been addressed in the literature. To the best of our knowledge, all previous studies on farm growth address only conventional agriculture. This research seeks to fill this gap by analyzing two dimensions of growth in organic farms in Bavaria and BadenWürttemberg: Utilized Agricultural Area (UAA) in hectares and agricultural revenue. Specifically, the following research questions are addressed: Are organic farms changing their scale of operation? If so, which factors influence the individual changes in size? Do these changes in farm size mainly occur in small or large farms? The results of this study will contribute to understanding the dynamics of one of the most developed regions in Germany with respect to organic agriculture.

This work is structured as follows: In section 2.2 we review the theory on firm and farm growth briefly, providing background information on the potential determinants of growth in the context of organic farming. Section 2.3 introduces the estimation procedure that we employ and describes the data and variables. Section 2.4 presents the results of the estimation and their interpretation. The final section presents conclusions that are relevant for organic farming in South Germany.

\subsection{Literature review}

Farm growth is a multidimensional event which can be analyzed from several theoretical perspectives. The most relevant approaches are: the stochastic approach introduced by Gibrat (1931) and known as the Law of Proportionate Effect (LPE), Penrose's theory (1959) based on human resources management, the learning process proposed by Jovanovic (1982), the evolutionary theory of Nelson and Winter (1982), and the path-dependence model of Balmann et al. (1996). This study focuses on the internal growth of farms to determine the factors that influence changes in their size. Empirical studies that analyze such changes use the LPE as a foundation. Gibrat (1931) finds that the size of firms in the French manufacturing sector follows a log-normal distribution, and that changes in a firm's size are the result of a large number of small, normally distributed shocks that are independent of previous firm size. 
Most empirical studies of conventional agriculture which have tested the LPE find that previous farm size is negatively related to future farm growth; namely, smaller farms have higher growth rates than their larger counterparts (Shapiro et al., 1987; Weiss, 1999; Rizov and Mathijs, 2003; Bakucs and Fertő, 2009; Gardebroek et al., 2010). This is explained by the long-run average cost curve (LRAC) when a farm expands its scale of operation. Previous studies in agriculture find evidence that the LRAC is L-shaped (Hall and Leveen, 1978; Kumbhakar, 1993); this means that the average costs decrease notably for small farms and become constant for large farm sizes when output increases. The former implies that economies of scales exist for small farms and that there is a wide range of farm sizes where average cost is approximately constant (Chavas, 2001).

\subsubsection{Farm size}

A prerequisite for consistent analysis of farm growth is a definition of farm size. There is no universally accepted definition of farm size. Measurements of farm size are either output- or input-based (Hallam, 1993; Weiss, 1998). Input-oriented measures are livestock units (LU) and acreage under cultivation. However, LU is a problematic measure when analyzing various farm types. Certainly, acreage is relevant since it provides a spatial perspective of farm size distribution, and without land, farm growth is only possible to a limited extent (Huettel and Margarian, 2009). Nevertheless, farm growth is not limited to acreage expansion, as it involves adjustments in other factor proportions and output quantities (Weiss, 1998). Output-based indicators, such as inflation-corrected sales capture those adjustments better than a single input measure (Hallam, 1993). Furthermore, output-based measures allow for comparison of farms that produce different products (Debertin, 2012). This is particularly important in organic agriculture because the farming system is more diverse than in conventional farming (Offermann and Nieberg, 2000). To provide a complete perspective of the growth process, we used land in UAA as an input-based measure for farm size and revenue from agricultural products as an output-based indicator.

Certainly, the conditions of the regional market determine the land availability (for purchase or lease). Compared with the rest of the country, transactions for agricultural land in Bavaria and Baden-Württemberg are limited in terms of the area. In 2003, the average size of each sale of agricultural land was 1.4 ha in Bayern and 0.9 ha in BadenWürttemberg, and all sales represented only $0.14 \%$ and $0.23 \%$, respectively, of the total agricultural land (Siegmund, 2004; Destatis, 2013). Therefore, farm growth mainly 
occurs via land lease. In 2005, farms that leased land annexed on average 17 ha to the owned land in Bayern (BStELF, 2012); in Baden-Württemberg it was 30 ha if the farmer was full-time and 8 ha for part-time farmers (StaLa, 2006). The prices for leased agricultural land were $259 € / \mathrm{ha}$ in Bayern and $219 € / \mathrm{ha}$ in Baden-Württemberg, the fourth and fifth-highest prices in Germany (Destatis, 2014) ${ }^{3}$. A study by Kuhnert et al. (2013) reveals that $21 \%$ of organic farmers in Germany feel constrained by the low availability of agricultural land and by failing to renew their land-lease contracts. The limited availability and high opportunity cost of agricultural land in the region increases the competition among conventional and organic farms for available land.

Acreage expansion is more expensive for organic farms than for conventional farms because farmers have to cope with investment costs to certify the additional land, to improve soil fertility, and to control for weeds and pests without using chemical pesticides or synthetic fertilizers. During the conversion period, farmers do not benefit from price premiums for organic produce, and yields are lower and more irregular. Additionally, certified organic inputs such as fodder, manure, and seed are becoming expensive and supply is often limited (Sahm et al., 2012; Kuhnert et al., 2013). These factors combined suggest that the slope of the LRAC for organic farms is lower than for conventional farms. This implies that the average costs for organic farms do not decrease as markedly as when conventional farms increase their scale of operation.

However, even if the slope of the LRAC is lower for organic farms, small organic farms still have greater economic incentives to adjust towards a more efficient farm size than their larger peers. Thus, the probability to expand the scale of operation should be higher for smaller farms. One important factor for the proper functioning of the previous mechanism is that small organic farms can cope with the initial costs of purchasing or leasing and then converting land into organic agriculture. If this is not the case and larger farms cope better with these costs, they would display higher growth rates. This result would contradict previous findings from conventional agriculture.

\footnotetext{
${ }^{3}$ This tendency continues: In 2013, leasing prices a hectare of agricultural reached $338 €$ in Bavaria and $246 €$ in Baden-Württemberg (Destatis, 2014).
} 


\subsubsection{Other factors affecting farm growth}

Although the LPE offers a starting point to analyze the effect of firm size on growth, its main limitation is that it disregards the effects of other factors. Results from previous empirical studies in the agricultural sector show that farm growth is also affected by the initial endowment of other factors such as capital, labor, and human capital (Upton and Harworth, 1987; Sumner and Leiby, 1987; Gale, 1994; Weiss, 1999; Kimhi, 2000; Juvancic, 2006; Gardebroek et al., 2010).

The production structure and factor endowment of organic farms differs from those in conventional agriculture. Table 2-1 shows the differences between organic farms and conventional farms from the German test farm network. Organic farms require about $17 \%$ more Annual Agricultural Working Units (AWU), and spend $140 \%$ more on hired labor than conventional farms (see Table 2-1). This is attributed to farming practices, such as weed control and preparation and application of soil amendments. These practices are particularly intensive during the conversion period. Besides this, organic farming requires additional documentation to comply with certification requirements and inspections. Farmers have to record practices and equipment used for each field, log equipment cleanout, grazing schedules, compost production, and field inputs among others. Indeed, $47 \%$ of the farmers who reverted to conventional agriculture remark that documentation workload was a very important factor contributing to their decision to revert (Kuhnert et al., 2013).

Table 2-1 Factor endowment of organic and comparable conventional farms ${ }^{\dagger}$ in Germany, 1999-2000.

\begin{tabular}{lcccc}
\hline Factor & Unit & Organic farms & $\begin{array}{c}\text { Comparable } \\
\text { conventional farms }\end{array}$ & $\begin{array}{c}\text { Percentage } \\
\text { difference }\end{array}$ \\
\hline Land & UAA & 60.2 & 60.1 & 0 \\
Labor & AWU/farm & 1.9 & 1.6 & 17 \\
Cost of hired labor & $€ /$ ha & 100.2 & 41.9 & 140 \\
Farm-owned capital & $€ /$ ha & $7,315.5$ & $9,480.4$ & -23 \\
\hline
\end{tabular}

$\dagger$ : This term refers to a subgroup of conventional farms from the German Test Farm Network and consists of the same farm-types as the group of organic farms in the network. They also have similar structural features with respect to land in UAA, location, and land tenure among others. Offermann and Nieberg (2001) provide an exhaustive definition of this concept.

Source: BML (2001), p. 61-63. 
Hired labor is particularly expensive in southern Germany. In 2007, the average gross salary per hour in Baden-Württemberg was $18.60 €$ and $18.05 €$ in Bayern, the third and fifth highest in Germany ${ }^{4}$ (Destatis, 2009). The higher demand for hired labor on organic farms combined with the opportunity cost that agricultural workers face in southern Germany may negatively influence farmers' decisions to expand their farmland. On the other hand, those farms with larger labor endowment require higher output growth to offset the labor costs.

Another factor, which presumably constrains farm expansion, is part-time farming. According to Kimhi (2000) and Weiss (1999), part-time farming can be considered the 'first step' outside of agriculture; however it can also prevent the cessation of farming operations by stabilizing a household's income (Sauer and Park, 2009). Weiss (1999) and Juvancic (2006) find that off-farm work promotes the restructuring of the farming sector by reducing both the probability of farm survival and the growth rates of farms. Considering the greater demand for labor among organic farms and the time-demanding documentation and certification workload, we expect part-time farmers to have fewer incentives to increase farm size in terms of land. On the other hand, farmers who depend exclusively on agricultural revenue are more affected by market prices than those who have their household's income secured. It is therefore probable that these farmers exhibit higher growth rates in terms of output.

Although organic agriculture is less capital-intensive than conventional agriculture (Table 2-1), capital is indispensable for expansion-particularly for the acquisition of new assets such as machinery and equipment. Capital investments improve productivity and increase the probability that a firm will remain active and prosper in the market (Heshmati, 2001; Gardebroek et al. 2010). Capital also has a positive effect on the technical efficiency of organic farms in Germany (Lakner et al. 2012; Tiedemann and Latacz-Lohmann, 2013). Therefore, organic farms with large capital endowment are expected to generate returns on their investments and exhibit higher output growth than their counterparts. Furthermore, capital intensive farms also require larger extensions of land to amortize their investments.

\footnotetext{
${ }^{4}$ In 2013, the gross salary per hour was $21.98 €$ in Baden-Württemberg and $21.24 €$ in Bavaria.
} 
Previous studies emphasize that farmer's education, experience, and managerial ability partly determines changes in farm size. Sumner and Leiby (1987) stress that human capital, represented as age and experience, is associated with more effective production management, lower interest rates for borrowed capital, and thus faster growth. This differs in organic agriculture as organic farming practices are unknown to the farmer prior to conversion from conventional agriculture (Sipiläinen and Oude Lansink, 2005). Therefore, the farmer's age may not adequately capture his or her experience in organic agriculture. Alternatively, Gale (1994) observes that the trajectory of farm size parallels the farmer life-cycle. He finds that during the years sequent to entry, young operators seek to expand farmland, machinery and equipment. When the farm approaches the desired size, growth diminishes and as farmers get older they decrease the size of their farms or abstain from making productive investments. Weiss (1999) and Juvancic (2006) have confirmed this pattern for Austria and Slovenia, respectively. We expect farmer's age to follow the life-cycle pattern proposed by Gale (1994).

Livestock production represents an important component of agricultural production (conventional and organic) in South Germany; $78 \%$ of the farms in Bavaria and $63 \%$ in Baden-Württemberg keep livestock in their holdings (Destatis, 2011). Previous studies in Germany find that intensification of livestock production increases technical efficiency of organic farms (Tiedemann and Latacz-Lohmann, 2011; Lakner et al., 2012). Presumably, this has a positive effect on the probability to grow in terms of output. Nonetheless, it may increase the productivity of land, and hence have a negative effect on acreage expansion.

A farm's growth is also influenced by its operating environment (e.g. marketing conditions and political factors). Offermann and Nieberg (2000) find that organic farmers who sold their products directly to consumers received double the price obtained through wholesale, and thus were more profitable than farms selling through other marketing channels. We therefore expect that direct marketing has a positive effect on farm growth via profitability.

Organic farms in Germany, and especially dairy and arable farms in the southern region, are highly dependent on policy support (Offermann et al., 2009). The most important policy support for organic farming in Germany is provided via agri-environmental measures (Stolze and Lampkin, 2009). To receive this support, farmers sign contracts for a minimum period of 5 years that provide payments per area to compensate for the 
additional costs and income foregone during the conversion period (EU commission, 2010). This financial assistance aims to promote conversion and the expansion of the area farmed organically. If the payments received compensate farmers for the additional costs of converting new farmland, these payments will have a positive effect on changes in farm size.

Furthermore, soil conditions increase output and technical efficiency in organic farming (Tiedemann and Latacz-Lohmann, 2013; Lakner et al., 2012). Therefore, higher soil quality presumably has a positive effect on farm growth in terms of output. This factor might have a negative effect when farm growth is measured in terms of agricultural land. This is primarily due to less area being demanded for the same output as land productivity increases.

We analyze the effect of the factors identified above, i.e. farm size, labor, and capital, on two dimensions of firm size: output and land. For this, we construct a dynamic model, using the LPE as a starting point. The next section describes the empirical specification and the data set used.

\subsection{Empirical model and data}

\subsubsection{Empirical model}

Based on the literature review above, we derive a growth model from a firm size equation and its relation to the size in the previous period:

$\ln S_{i t}=\alpha_{1} \ln S_{i t-1}+X_{i t-1} \beta+\gamma_{t}+a_{i}+u_{i t}$

where $\ln S_{i t-1}$ is the logarithm of farm size, and $\alpha_{1}$ is the relationship between firm size in two consecutive periods. $\mathrm{X}_{\mathrm{it}-1}$ represents a group of additional covariates, and $\gamma_{t}$ captures time effects common to all farms. $\mathrm{a}_{\mathrm{i}}$ captures unobserved and time-constant farm-specific effects, such as location (proximity to market) or differences in the initial levels of efficiency. $u_{i t}$ is a random disturbance term. To analyze different dimensions of farm growth, we estimate the model using two different dependent variablesnamely, farm size in hectares of UAA, and revenue from agricultural production. A description of the dependent variable and the covariates in $\mathrm{X}$ is presented in Table 2-2. 
The growth model is obtained by redefining the dependent variable as the first difference of the logarithm of farm size, on the left side of equation (2.1):

$\mathrm{G}_{\mathrm{it}} \equiv \ln S_{i t}-\ln S_{i t-1}=\alpha_{1} \ln S_{\mathrm{it}-1}+\mathrm{X}_{\mathrm{it}-1} \beta+\gamma_{\mathrm{t}}+\mathrm{a}_{\mathrm{i}}+\mathrm{u}_{\mathrm{it}}$

Therefore, farm growth is defined as the annual change in farm size. Analysis of the effect of farm size on growth consists of testing the null hypothesis $H_{0}: \alpha_{1}=0$, which implies that changes in size are independent of the size in the previous period. If $\alpha_{1}<1$, smaller farms grow faster than larger farms. Hypotheses for assessing the effects of the additional explanatory variables on farm growth are tested individually.

The lagged dependent variable on the right-hand side of equation (2.2) is correlated with the error term $\mathrm{a}_{\mathrm{i}}$, which violates the assumption of exogeneity. Estimating equation (2.2) by Ordinary Least Squares produces biased and inconsistent estimates. The Within Groups estimator will eliminate this source of bias by eliminating the farm fixed effects $a_{i}$. However, it fails to remove the endogeneity bias as the demeaned lagged dependent variable and the demeaned error term remains correlated (Bond et al., 2001).

Anderson and Hsiao (1981) propose a first-differenced generalized method of moments (DGMM) approach to obtain unbiased estimates. This procedure takes the first differences from equation (2.2) and uses all available lags of the dependent variable as instruments (Bond et al., 2001). However, the DIFGMM method performs poorly when the parameter $\alpha_{1}$ approaches unity (i.e. the size follows a random walk) because in this case, past levels of farm size provide little information on present changes (Roodman, 2009a).

To increase efficiency in the context of a near-random walk or persistent series, Arellano and Bover (1995) and Blundell and Bond (1998) each propose an augmented version of the DGMM-namely, the system generalized method of moments (SGMM), which uses a system of level and first-difference equations:

$$
\left[\begin{array}{c}
\Delta G_{i t} \\
G_{i t}
\end{array}\right]=\alpha\left[\begin{array}{c}
\Delta \ln S_{i t-1} \\
\ln S_{i t-1}
\end{array}\right]+\beta\left[\begin{array}{c}
\Delta X_{i t-1} \\
X_{i t-1}
\end{array}\right]+u_{i t}
$$


SGMM is based on the assumption that the first difference of the endogenous variable is uncorrelated with the unobserved (individual) effect. This makes it possible to use additional instruments, namely lags of the first difference of $\ln S_{i t}$, in the equation in levels.

To test the various assumptions of the SGMM model and to determine the most appropriate model specification, we perform several tests. Arellano and Bond (1991) propose a test to determine serial correlation on the residuals in first differences. Here, a negative serial correlation among the first differences was expected, since $\Delta u_{i t}$ relates to $\Delta u_{i t-1}$ through the common term $u_{i t-1}$. Thus, the $\operatorname{AR}(2)$ test will detect first-order serial correlation in levels between $u_{i t-1}$ in $\Delta u_{i t}$ and $u_{i t-2}$ in $\Delta u_{i t-2}$ (Roodman, 2009a). Additionally, we test the validity of the over-identifying restrictions with the Hansen test; the null hypothesis is that the instruments are valid (Bond et al., 2001). This test is robust to heteroscedasticity, but is weakened by the use of many instruments (lags), resulting in implausibly perfect $p$-values of 1.00. There are no clear guidelines on how many instruments one can use, but in any case, they should not exceed the number of observations (Roodman, 2009b).

The Hansen test evaluates the entire set of instruments used for the endogenous variables. Nevertheless, to test the validity of specific subsets of instruments, we use the difference-in-Hansen test. This is done by estimating the change in the Hansen test, when the subset of suspect instruments is added to the estimation set-up. The null hypothesis is that the examined instruments are exogenous (Roodman, 2009b). For the land growth model, revenue and payments for agri-environmental measures correlate with the error term. For revenue growth, the covariates capital, agricultural area and subsidies correlate with the error term. Thus, we treated these covariates in the same way as the lagged dependent variables and instrument them with further lags in levels and first differences. We estimate the two-step SGMM with the Windmeijer correction for finite samples; without this correction, the standard errors of the SGMM are severely biased downward (Roodman, 2009a).

Sample selection bias could occur if a particular group of farms has a higher probability of remaining in the data set than others. Correction for sample selection in the context of dynamic panel data is still incipient. To examine whether the patterns of missing observations has an effect on the underlying regressions, we perform the tests proposed by Verbreek and Nijman (1992). The tests consist of creating variables which capture 
the dynamics of the individuals and test their effect on the regression. These are: i) the number of years the farm participates in the panel, ii) a binary variable which equals zero at $t$ if the farm remains in the database in $t+1$, and changes to 1 if the farm exits in the subsequent period, iii) a dummy variable equals one for farms with less than 5 years of observations and equals zero otherwise. The results of these tests are discussed in following section.

Finally, to identify whether changes in size occur in small or large farms, we calculate a transition probability matrix. For this, we classify farm size in ha in $j$ groups and the change in hectares in $k$ categories. The matrix estimates the following equation, $p_{j k}=$ $\operatorname{Pr}\left(\Delta h a_{t}=k \mid S_{t-1}=j\right)$, the probability of a farm being in category $k$ in period $t$, given that it was in group $j$ in period $t-1$. The conditional probability uses the following formula:

$p_{j k}=n_{j k} / \sum_{j=1}^{n} n_{j k}$

where $n_{j k}$ denotes the number of farms which were in category $j$ in period $t-1$ and are in group $k$ in period $t$.

\subsubsection{Data}

The analysis is based on a unique 13-year panel data set provided by the firm Land Data $\mathrm{GmbH}$, a service firm for agricultural accountancy. It consists of 2759 observations from $i=453$ organic farms, from 1993 until 2005, located in the Federal States of Bavaria and Baden-Württemberg. The information is drawn from an unbalanced panel dataset comprising incumbent farms (with observations over the entire 13 years), dropouts (farms that exited the dataset before 2005), and newcomers (farms that entered after 1993). The data set does not provide information on whether the dropouts ceased to operate, reverted to conventional agriculture, or changed their bookkeeping company. Despite this limitation, the dataset provides accurate information on the changes in the size of individual organic farms. $90 \%$ of the farms either increased or decreased their acreage during the sample period. Similarly, all of them exhibit changes in agricultural revenue. Furthermore, all farms in the sample received agri-environmental payments for organic farming. To obtain these payments, farmers sign a contract for a minimum of 5 years during which they commit to farm organically. This restricts farmers from reverting to conventional agriculture before 5 years has elapsed. In addition, the average age of farmers who dropped out of the data set was relatively young at 42 years old. It is 
therefore more likely that the dropouts in the data set stopped hiring the accountancy service, rather than reverting to conventional agriculture or giving up their holdings. The effects of ignoring attrition are discussed in the next section.

Table 2-2 presents descriptive statistics for all of the variables that we employ. On average, organic farms make use of 50 ha of UAA, 1.6 AWUs, and earn $86770 €$ per year from agricultural revenue. As revenue is in constant prices, this variable represents the output generated by farms. Most organic farmers are full-time, their average age is 43 years, and they receive an average of $11000 €$ per year in agri-environmental payments for organic farming. The average livestock intensity is $1 \mathrm{LU} / \mathrm{ha}$.

Table 2-2 Definition of variables and descriptive statistics of organic farms, 19932005.

\begin{tabular}{|c|c|c|c|c|c|c|}
\hline \multirow{2}{*}{ Variable } & \multirow{2}{*}{ Unit } & \multirow{2}{*}{ Definition } & \multirow{2}{*}{ Mean } & \multicolumn{3}{|c|}{$\begin{array}{l}\text { Standard deviation } \\
\end{array}$} \\
\hline & & & & Overall & Within & Between \\
\hline \multicolumn{7}{|c|}{ Dependent variables } \\
\hline Revenue $\mathrm{G}_{\mathrm{it}}$ & $\%$ & Change of agricultural revenue & 0.10 & 0.29 & 0.26 & 0.20 \\
\hline Land $\mathrm{G}_{\mathrm{it}}$ & $\%$ & $\begin{array}{l}\text { Change of Utilized Agricultural } \\
\text { Area }\end{array}$ & 0.02 & 0.11 & 0.09 & 0.10 \\
\hline \multicolumn{7}{|c|}{ Variables regarding farm size } \\
\hline Revenue $_{\text {it }-1}$ & $1000 €$ & $€$ Revenue from agricultural revenue & 86.77 & 76.13 & 21.61 & 69.96 \\
\hline Land $_{\text {it }-1}$ & Hectare & $\begin{array}{l}\text { e Utilized Agricultural Area, owned } \\
\text { and rented }\end{array}$ & 49.77 & 31.90 & 6.57 & 32.75 \\
\hline \multicolumn{7}{|l|}{$\begin{array}{l}\text { Explanatory } \\
\text { variables }\end{array}$} \\
\hline Capital $_{\text {it }-1}$ & $1,000 €$ & $€$ Annual depreciation & 17.98 & 13.05 & 3.53 & 13.00 \\
\hline Labor $_{\text {it }-1}$ & AWU & $\begin{array}{l}\text { Annual Agricultural Work Units } \\
\text { (AWU) }\end{array}$ & 1.63 & 0.75 & 0.26 & 0.82 \\
\hline Part-Time $_{i t-1}$ & $0 / 1$ & $\begin{array}{l}\text { Dummy }=1 \text { if the farmer has a } \\
\text { part-time job, } 0 \text { otherwise }\end{array}$ & 0.12 & 0.32 & 0.10 & 0.31 \\
\hline Age $_{\text {it }-1}$ & Years & Farm operator age, in years & 43.44 & 8.50 & 2.75 & 8.42 \\
\hline $\begin{array}{l}\text { Livestock } \\
\text { Intensity }_{\mathrm{it}-1}\end{array}$ & $\mathrm{LU}^{\mathrm{a}} / \mathrm{ha}$ & Livestock Units (LU) per hectare & 1.08 & 0.72 & 0.22 & 0.69 \\
\hline Subsidies $_{\mathrm{it}-1}$ & $1,000 €$ & $\begin{array}{l}\text { Agri-environmental payments for } \\
\text { organic farming }\end{array}$ & 11.44 & 6.82 & 6.14 & 2.68 \\
\hline $\begin{array}{l}\text { Direct } \\
\text { Marketing }_{i t-1}\end{array}$ & $0 / 1$ & $\begin{array}{l}\text { Dummy }=1 \text { if the farms has its } \\
\text { own farm shop, } 0 \text { otherwise }\end{array}$ & 0.09 & 0.30 & 0.18 & 0.21 \\
\hline $\begin{array}{l}\text { Soil } \\
\text { Quality } \\
\text { it -1 }\end{array}$ & $\mathrm{EMZ}^{\mathrm{b}}$ & Soil quality index & $3,511.91$ & $1,236.81$ & 444.27 & $1,236.78$ \\
\hline Years & Years & Vector of years dummies & - & & - & \\
\hline
\end{tabular}


Considering the panel structure of the data set, we divide the overall standard deviation into between and within variation. The between standard deviation shows the spread in the mean values between firms, while the within standard deviation indicates the deviation from each individual's averages. Table 2-2 shows that the growth rates of revenue have a larger variation within each farm than between them. This is contrary to land growth, which has a larger dispersion between farms. For the econometric estimation, we used the natural logarithms of all variables. All monetary variables were deflated and are in constant prices of the year 2000. We used the standard agricultural price indices from official statistics available from BMELV (2006).

\subsection{Results and discussion}

We find that the individual increases of organic farms totaled 2540 ha, and the decreases totaled 511 ha for the sample period. The decreases in acreage were mostly small; $78 \%$ of the farms that reduced their size lost 5 ha or less. The increases were more evenly distributed, with $47 \%$ of the farms that grew gaining up to 5 ha, $20 \%$ growing between 5 and 10 ha, and $33 \%$ gaining more than 10 ha.

Table 2-3 presents the results for the two econometric estimations, growth of agricultural revenue and growth of land. The outcomes of the Arellano-Bond test for $\mathrm{AR}(1)$ in the first differences in columns (a) and (b) show that the residuals are negatively autocorrelated, corresponding to the first-differencing process inherent in the SGMM method. The AR(2) tests did not reject the null hypotheses of autocorrelation in the second differences, which is a required assumption for consistent results. 
Table 2-3 SGMM estimation results for growth of organic farms in output and land, 1993-2005.

\begin{tabular}{|c|c|c|}
\hline \multirow[b]{2}{*}{ Explanatory variables } & \multicolumn{2}{|c|}{ Dependent variables } \\
\hline & $\begin{array}{l}\text { Revenue } G_{\text {it }} \\
\text { (a) }\end{array}$ & $\begin{array}{l}\text { Land } G_{i t} \\
\text { (b) }\end{array}$ \\
\hline $\log$ Revenue $_{\text {it }-1}$ & $\begin{array}{c}-0.422 * * * \\
(0.051)\end{array}$ & $\begin{array}{c}0.027 \\
(0.024)\end{array}$ \\
\hline $\log \operatorname{Land}_{\mathrm{it}-1}$ & $\begin{array}{l}0.179 * * \\
(0.072)\end{array}$ & $\begin{array}{c}0.082 \\
(0.061)\end{array}$ \\
\hline $\log$ Capital $_{\text {it }-1}$ & $\begin{array}{l}0.100 * * \\
(0.041)\end{array}$ & $\begin{array}{r}-0.038 \\
(0.025)\end{array}$ \\
\hline $\log$ Labor $_{\text {it }-1}$ & $\begin{array}{l}0.218 \text { *** } \\
(0.049)\end{array}$ & $\begin{array}{r}-0.030 \\
(0.026)\end{array}$ \\
\hline Part-Time $_{\text {it }-1}$ & $\begin{array}{r}-0.057 \\
(0.057)\end{array}$ & $\begin{array}{c}0.028 * \\
(0.016)\end{array}$ \\
\hline Age $_{\text {it }-1}$ & $\begin{array}{c}0.005 \\
(0.010)\end{array}$ & $\begin{array}{c}0.009 * \\
(0.005)\end{array}$ \\
\hline $\operatorname{Age}_{i t-1}^{2}$ & $\begin{array}{c}-7.37-05 \\
(1.127-04)\end{array}$ & $\begin{array}{c}-1.005-04 * \\
(5.900-05)\end{array}$ \\
\hline $\log$ Livestock Intensity $_{\mathrm{it}-1}$ & $\begin{array}{l}0.085 * * * \\
(0.026)\end{array}$ & $\begin{array}{c}-0.030 * * \\
(0.013)\end{array}$ \\
\hline $\log$ Subsidies $_{\mathrm{it}-1}$ & $\begin{array}{c}0.012 \\
(0.013)\end{array}$ & $\begin{array}{c}0.020 * \\
(0.011)\end{array}$ \\
\hline Direct Marketing $_{\mathrm{it}-1}$ & $\begin{array}{c}0.035 \\
(0.037)\end{array}$ & $\begin{array}{c}0.015 \\
(0.014)\end{array}$ \\
\hline $\log$ Soil Quality ${ }_{\mathrm{it}-1}$ & $\begin{array}{l}0.079 * * \\
(0.041)\end{array}$ & $\begin{array}{c}-0.008 \\
(0.011)\end{array}$ \\
\hline Observations & 1,579 & 1,579 \\
\hline No. Instruments & 136 & 28 \\
\hline F-Test & $\begin{array}{c}5.85 \\
{[0.00]}\end{array}$ & $\begin{array}{c}2.19 \\
{[0.03]}\end{array}$ \\
\hline Arellano-Bond test AR(1) & $\begin{array}{c}-5.14 \\
{[0.00]}\end{array}$ & $\begin{array}{c}-6.56 \\
{[0.00]}\end{array}$ \\
\hline Arellano-Bond test AR(2) & $\begin{array}{c}0.77 \\
{[0.44]}\end{array}$ & $\begin{array}{l}-1.34 \\
{[0.18]}\end{array}$ \\
\hline Hansen test of over-identification restrictions & $\begin{array}{c}114.69 \\
{[0.46]}\end{array}$ & $\begin{array}{c}4.64 \\
{[0.59]}\end{array}$ \\
\hline $\begin{array}{l}\text { Diff.-in-Hansen tests of exogeneity of GMM } \\
\text { instrument for the level equation }\end{array}$ & $\begin{array}{l}73.44 \\
{[0.46]}\end{array}$ & $\begin{array}{c}3.86 \\
{[0.27]}\end{array}$ \\
\hline
\end{tabular}

Corrected standard errors in parentheses; $p$-values in square brackets; significance levels: $* * * / * * / *$ denote significance at the 1,5 , and $10 \%$ levels, respectively.

Results were generated using xtabond2 from Roodman (2003).

The estimated coefficients in Table 2-3 indicate that the returns to farm size are negative and less than equi-proportionate when farm size is measured in terms of output. Therefore, the hypothesis that changes in farm size are independent of the size in the previous period is rejected for this estimation. According to the results in Table 2-3, the elasticity of farm growth with respect to farm size in the previous period is - 0.42, i.e. a farm that is $1 \%$ smaller will, on average, have a rate of growth that is $0.42 \%$ higher. 
These results are consistent with previous findings in the agricultural sector. Shapiro et al. (1987) and Gardebroek et al. (2010) also find that large farms grow slower than small farms when farm size is measured in economic terms of output (e.g. gross sales). Figure 2-1 illustrates the estimated growth values with respect to farm size and shows that smaller organic farms achieve higher growth rates than their peers. The result in Figure 2-1 implies that small farms are increasing output to a larger extent than large farms; as predicted by economic theory.

Figure 2-1 Predicted growth rates and farm size (in revenue) for organic farming ${ }^{5}$.

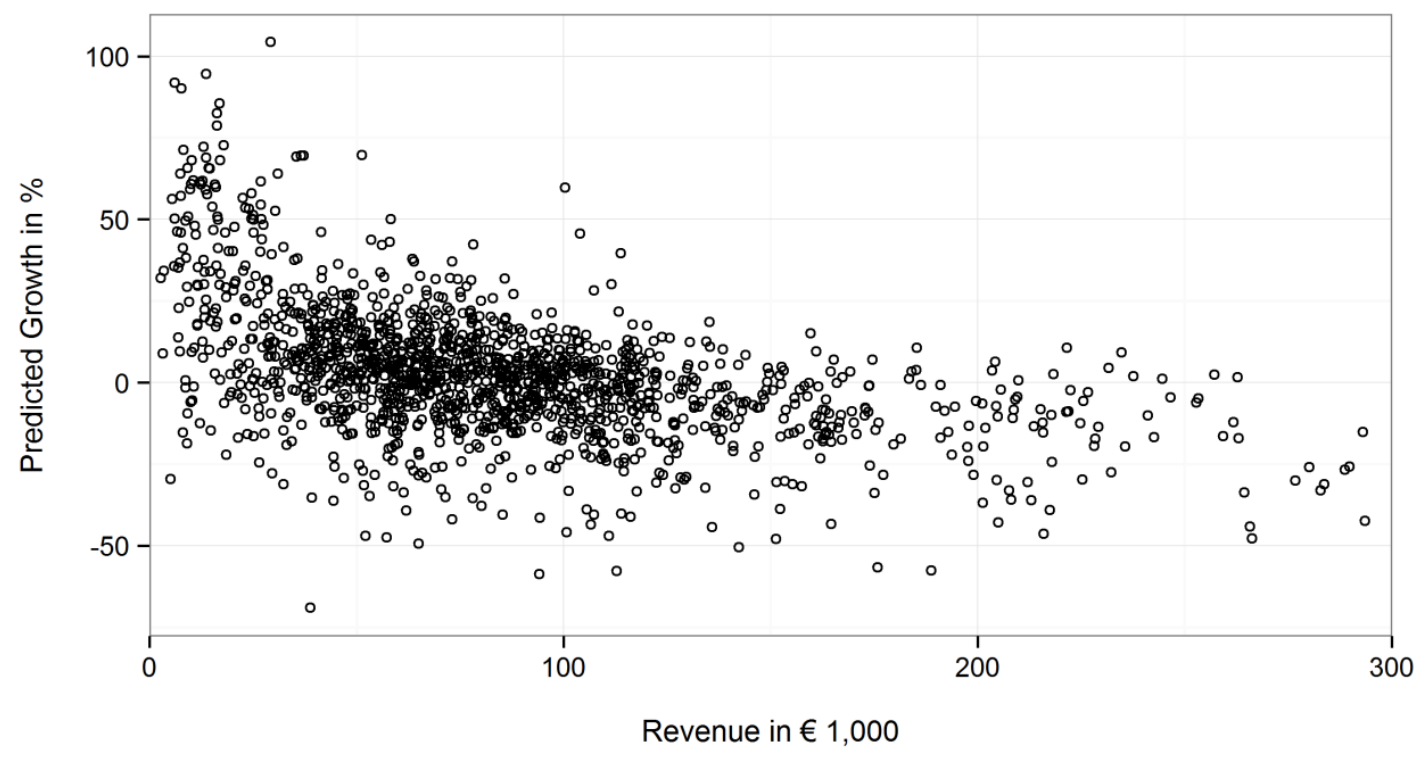

Source: based on data from Land Data GmbH 1993-2005, Author’s own calculations.

We do not find the same tendency when we measure farm size in terms of land. The results in column (b) of Table 2-3 indicate that previous farm size (measured in terms of agricultural area) does not have a significant effect on farm growth. This result contradicts previous studies in conventional agriculture which find that small farms grow at higher rates than larger ones, when farm size is measured in hectares (Shapiro et al., 1987; Rizov and Mathijs, 2003). Furthermore, the positive sign of the coefficient in Table 2-3 column (b) does not coincide with the negative relationship suggested by empirical research and economic theory. To provide a detailed analysis about the absolute changes in agricultural land by predefined farm size categories, we present the results of the transition probability matrix. Table $2-4$ shows the transition probabilities of changing the number of hectares in $t$ depending on the size of the farm in $t-1$. As an example, the first row in Table 2-4 indicates that the smallest farms $(<10$ ha) have a

\footnotetext{
${ }^{5}$ The predicted growth rates are the estimated values from equation (2) with respect to revenue.
} 
$9.5 \%$ probability of reducing their agricultural land area between 10 ha and 0.5 ha in the next year, $67 \%$ probability of not changing their size and $20 \%$ probability to increase their acreage between 0.5 to 10 ha for the following period. Note that the row in Table 2-4 sums up to 1.0 .

Table 2-4 Transition probability matrix for acreage changes in organic farming, 1993-2005 ${ }^{\dagger}$.

\begin{tabular}{cccccccc}
\hline $\begin{array}{l}\text { Farm Size } \\
\text { (ha) }\end{array}$ & $>-20$ & -20 to -10 & -10 to -0.5 & 0 & 0.5 to 10 & 10 to 20 & $>20$ \\
(a) & (b) & (c) & (d) & (e) & (f) & (g) \\
\hline$<10$ & 0.0 & 0.0 & 9.5 & 66.7 & 19.1 & 4.8 & 0.0 \\
10 to 20 & 0.0 & 0.0 & 16.5 & 56.7 & 26.8 & 0.0 & 0.0 \\
20 to 30 & 0.3 & 0.0 & 22.5 & 41.3 & 34.1 & 0.6 & 1.2 \\
30 to 40 & 0.0 & 0.5 & 21.0 & 40.7 & 36.7 & 1.2 & 0.0 \\
40 to 50 & 0.3 & 0.3 & 26.3 & 31.9 & 38.2 & 2.0 & 1.0 \\
$>50$ & 0.4 & 1.7 & 26.5 & 20.7 & 40.7 & 7.0 & 3.0 \\
\hline
\end{tabular}

${ }^{\dagger}$ : Pairwise T-tests revealed significant differences between farm size categories. The results of pairwise tests are presented in the Appendix of this chapter. For column (d), see Table A 1 and for column (e) see Table A 2.

Source: Author's own calculations

The results in Table 2-4 column (d) show that small farms ( $<10$ ha) have a $67 \%$ chance of not changing farm size within the next year. This percentage drops to $21 \%$ if the farm has more than 50 ha. The group differences in column (d) are statistically significant from each other, except for two pairwise comparisons ${ }^{6}$. This result provides evidence that the probability to change the scale of operation is higher for categories with larger farm sizes. This result also indicates that small farms are not adjusting their scale of operation in terms of land as expected by economic theory. The persistence of farms in a determined size category is a frequent event observed in empirical literature. As described by Huettel and Margarian (2009) and Chavas (2001), this is related to the reluctance of farms to exit the sector or to grow and is explained by the initial farm size structure conditions in the region, sunk costs, uncertain future revenues, and the presence of imperfect markets for labor and capital.

Additionally, the results in Table 2-4 column (e) show that the increases in land occur by a maximum of 10 ha. The probability of increasing acreage by 10 ha is statistically different between most size categories ${ }^{7}$; it increases with increasing farm size. Explanations for this development are that, firstly, large organic farms cope better with the investment cost for acquiring and converting new area into organic than their

\footnotetext{
${ }^{6}$ see Table A 1 in the Appendix of this chapter.

${ }^{7}$ see Table A 2 in the Appendix
} 
smaller peers; secondly, uncertainty for future revenues due to irregular yields, potential changes in the policy support and market conditions; thirdly, if organic farms have a limited supply of organically certified inputs (Sahm et al., 2012; Kuhnert et al. 2013), it is reasonable that increases in farm size are modest; finally, purchasing or renting additional land and converting it into organic is a long-term investment, whereas the policy support and growing demand for organic products are external factors which are not under farmers' control and can change in the mid-term.

The SGMM estimations reveal which additional factors besides size influence changes in the scale of operation of organic farms. Table 2-3 indicates that the land variable has a positive effect on changes in revenue, as the elasticity value for land is 0.18. Furthermore, farms with $1 \%$ more capital have, on average, a $0.10 \%$ higher rate of growth in terms of revenue. This outcome can be explained by the effect of capital on productivity and efficiency (Lakner et al., 2012; Tiedemann and Latacz-Lohmann, 2013), which enables farms to produce more output with less inputs.

Organic farms with $1 \%$ more labor endowment exhibit, on average, a $0.22 \%$ higher rate of growth in revenue. Labor has no significant effect on acreage expansion. Parttime farming has a significant and positive impact on land growth; organic holdings operated by part-time farmers report $2.8 \%$ higher growth rates than full-time farmers. This is surprising because previous studies by Weiss (1999) and Juvancic (2006) find that part-time farming reduces the probability of survival and growth. However, in the case of organic farming in South Germany, the former suggests that off-farm employment does not only stabilize a household's income on smaller farms, it enables them to invest in additional agricultural area.

Farmer's age has a non-linear effect on growth of land; it has a positive effect when farmers are younger than 45 years old and then becomes negative. This result is consistent with the life-cycle pattern found by Gale (1994), Weiss (1999), and Juvancic (2006). Furthermore, we find evidence that farms that on average have $1 \%$ higher livestock intensity (LU/ha) show $0.09 \%$ higher growth in revenue; thus, this factor increases the revenue of organic farms via gains in productivity. The result of the land growth model shows that an increase of $1 \%$ in the LU/ha decreases acreage growth by $0.03 \%$, implying that intensification of livestock production reduces the demand for additional agricultural area. 
Subsidies for organic farming have a significant and positive effect on growth of agricultural land. This indicates that support payments contribute to offset the lower and irregular yields and the additional costs during the conversion period of new farmland. The support payments did not have a significant effect on growth of revenue.

Soil quality has a positive effect on the growth in terms of output, and no impact on the change in land. The coefficient shows that farms with $1 \%$ higher soil quality show, on average, $0.08 \%$ higher growth in revenue. This can be explained by the positive effect of soil quality on technical efficiency in organic farming (Tiedemann and LataczLohmann, 2013; Lakner et al. 2012), contributing to the reduction of inefficiency sources and an increase in output. Furthermore, farms in favorable soil conditions can more readily adjust their production programme to fit market demands. Direct marketing has no significant impact on farm growth, neither when measured in revenue nor when measured in agricultural land.

Results from previous studies indicate that farm size and growth have a negative relationship (Shapiro et al., 1987; Weiss, 1999; Rizov and Mathijs, 2003; Bakucs and Fertő, 2009; Gardebroek et al., 2010). If small, slow-growing farms are less likely to remain in the data set than large farms; over time we observe that only small farms perform well. Thus, an analysis based on incumbent farms (those who remain in the data set) alone will be biased. Nevertheless, this is not the case in the present study. The analysis includes yearly newcomers and dropouts. Furthermore, the Verbreek and Nijman-tests did not find significant evidence of the three variables we created. The was no significant effect of the variable with the number of years the farm participates in the panel, the revenue growth estimation, $t(453)=-0.0048, p$-value $=0.51$ and the land growth regression, $t(453)=0.0002, p$-value $=0.98$. The dummy variable indicating whether the farm exits in the subsequent period was also not significant, $t(453)=-$ 0.0076, $p$-value $=0.79$ and $t(453)=0.0153, p$-value $=0.22$. Finally, the effect of the dummy variable for firms with less than 5 years of observations was not significant, $t(453)=0.0149, p$-value $=0.57$ (revenue growth) and $t(453)=-0.0027, p$-value $=0.78$ (land growth). Additionally, farmers who have dropped out in the sample are young (42 years old) and all receive support payments, committing them to maintain organic farming for a minimum of 5 years. Thus, these results do not show evidence for the existence of attrition bias and reinforce the assumption that most dropouts did not cease 
operations or revert to conventional farming, but more likely stopped hiring the bookkeeping services.

\subsection{Conclusions}

We find that most organic farms in southern Germany have changed their farm size during the period of study. Therefore, the overall increase in area farmed organically in this region does not only come from conversion of conventional farms, but also from acreage expansion of the existing organic farms. The evidence shows that acreage expansion occurred in adjustments of less than 10 ha, regardless of the farm size. The acreage increase is partly driven by subsidies for environmental measures, indicating that the political support for organic agriculture in this region has not only stimulated the conversion of conventional farms, but also the individual growth of organic farms. Other determinants of acreage growth are off-farm income, farmer's age, and intensity of livestock production. Large organic farms cope better with the competitive conditions of the regional market and presumably have the additional capital to finance the costs for converting new farmland into organic. This study reveals that previous findings on land growth from conventional agriculture differ from the case of organic farms in South Germany.

The results of the revenue growth estimation reveal that small organic farms have higher growth rates of revenue than their counterparts. This result is consistent with previous studies stating that average costs of production decrease more rapidly for small farms than for large farms when output increases. Moreover, any improvement in output and reduction in costs has a larger impact in proportional terms for small farms than it does for large ones. We also find evidence that capital, labor, intensity of livestock production and soil quality have a significant positive impact on revenue growth in organic farming. This is particularly important for small organic farms with limited possibilities to expand acreage, since output increase can be achieved through efficient allocation of the previous factors and improvements in current technology.

Unfortunately, this study could not take into account the effects of variables pertaining to farm survival or the reversion of organic farms to conventional agriculture, two important aspects of structural change in the organic sector. Once relevant data are made available on farms that ceased to operate or reverted to conventional agriculture, future studies can address these research issues. 


\section{References}

Anderson, T.W., \& Hsiao, C. (1981). Estimation of dynamic models with error components. Journal of the American Statistical Association 76 (375), 598-606.

Arellano, M. \& Bond, S. (1991). Some tests of specification for panel data: Monte Carlo evidence and an application to employment equations. Review of Economic Studies 58 (2), 277-297.

Arellano, M. \& Bover, O. (1995). Another look at the instrumental-variable estimation of error-components models. Journal of Econometrics 68 (1), 29-52.

Bakucs, L.Z. \& Fertö, I. (2009). The growth of family farms in Hungary. Agricultural Economics. 40(S), 789-795.

Balmann, A., Odening, M., Weikard, H. \& Brandes W. (1996). Path dependence without increasing returns to scale and network externalities. Journal of Economic Behavior and Organization 29 (1), 159-172.

BStELF (2012). Bavarian Agricultural Report 2012 (in German). Retrieved May 25 May, Bavarian State Ministry for Food, Agriculture and Forestry (BStELF) 2014. Retrieved from: http://www.agrarbericht-2012.bayern.de/landwirtschaft-laendlicheentwicklung/pachtverhaeltnisse.htm

Blundell, R. \& Bond, S. (1998). Initial conditions and moment restrictions in dynamic panel data models. Journal of Econometrics 87 (1), 115-143.

BMELV (2006). Statistical Yearbook on Food. Agriculture and Forestry (in German).

Federal Ministry for Food, Agriculture and Consumer Protection (BMELV). Bremerhaven: NW-Verlag.

BML (2001). Agricultural Report of the Federal Government 2011. Data Appendix (in German. Berlin: Federal Ministry for Agriculture (BML), 61-63.

BÖWL (Bund Ökologische Lebensmittelwirtschaft) (2015). Zahlen - Daten - Fakten: Die Bio-Branche 2013. Berlin: BÖLW.

Bond, S., Hoeffler, A. \& Temple, J. (2001). GMM estimation of empirical growth models. London: Centre for Economic Policy Research (CEPR) Discussion Paper No. 2048.

Bravo-Padilla, C. P., Cordts, A., Schulze, B., \& Spiller, A. (2013). Assessing determinants of organic food consumption using data from the German National Nutrition Survey II. Food quality and Preference, 28(1), 60-70. 
Chavas, J. P. (2001). Structural change in agricultural production: Economics, technology and policy. Handbook of agricultural economics, 1, 263-285.

Debertin, D. (2012). Agricultural Production Economics, Second Edition. New York: Macmillan Publishing Company.

Destatis (2009). Income and Labour Costs (in German). Wiesbaden: Federal Statistical Office (Destatis).

Destatis (2011). Animal Production on Farms (in German), Agricultural Census 2010, Series 3, Issue 2.1.3. Wiesbaden: Federal Statistical Office (Destatis).

Destatis (2013). Prices for purchasing agricultural land (in German). Wiesbaden: Federal Statistical Office (Destatis).

Destatis (2014). Rental prices for arable land 1999-2013 (in German), database of the Federal Statistical Office Germany. Wiesbaden. Available at https://wwwgenesis.destatis.de, (last accessed 03.November 2014)

Destatis BL (2013). Regional Database, Statistical Offices of the German Federal States (Destatis BL). Düsseldorf. Retrieved from: https://www.regionalstatistik.de/genesis/online/logon

EU Commission. (2010). Agriculture and Rural Development. Agri-environment measures. Retrieved February 1, 2014. Retrieved from: http://ec.europa.eu/agriculture/envir/measures/index_en.htm

Gale, F. (1994). Longitudinal analysis of farm size over the farmer's life cycle. Review of Agricultural Economics 16 (1), 113-123.

Gardebroek, C., Turi, K.N. \& Wijnands, J. (2010). Growth dynamics of dairy processing firms in the European Union. Journal of Agricultural Economics 41 (34), 285-291.

Gibrat, R. (1931). Les Inégalités Économiques. Paris: Librairie du Recueil Sirey.

Hall, B. F., \& LeVeen, E. P. (1978). Farm size and economic efficiency: The case of California. American Journal of Agricultural Economics, 60(4), 589-600.

Hallam, A. (ed.) (1993). Size, Structure, and the Changing Face of American Agriculture. Boulder, CO. Westview Press Inc.

Heshmati, A. (2001). On the growth of micro and small firms: Evidence from Sweden. Small Business Economics 17 (3), 213-228. 
Huettel, S. \& Margarian, A. (2009). Structural change in the west German agricultural sector. Agricultural Economics 40 (Supplement), 759-772.

Jovanovic, B. (1982). Selection and the evolution of industry. Econometrica 50 (3), 649-670.

Juvancic, L. (2006). Determinants of farm survival and growth in Slovenia (19912000). Paper presented at the 96th EAAE Seminar Causes and Impacts of Agricultural Structures. Tänikon (Switzerland): January 10-11, 2006.

Kimhi, A. (2000). Is part-time farming really a step in the way out of agriculture? American Journal of Agricultural Economics 82 (1). 38-48.

Kuhnert, H., Behrens, G., Hamm, U., Müller, H., Nieberg, H., Sanders, J. \& Strohm, R. (2013). Ausstiege aus dem ökologischen Landbau: Umfang - Gründe Handlungsoptionen. Johann Heinrich von Thünen-Institut. Retrieved from: http://www.ti.bund.de/fileadmin/dam_uploads/Institute/BW/bw_de/bw_de_downlo ads/Ausstieg_2013.pdf

Kumbhakar, S. C. (1993). Short-run returns to scale, farm-size, and economic efficiency. The Review of Economics and Statistics, 336-341.

Lakner, S., von Cramon-Taubadel, S. \& Brümmer, B. (2012). Technical efficiency of organic pasture farming in Germany: The role of location economics and of specific knowledge. Renewable Agriculture and Food Systems 27 (3), 228-241.

Nelson, R. \& Winter, S. (1982). An Evolutionary Theory of Economic Change. Cambridge, MA: Harvard University Press.

Nieberg, H., Kuhnert, H. \& Sanders, J. (2011). Förderung des ökologischen Landbaus in Deutschland - Stand, Entwicklung und internationale Perspektive. 2., überarbeitete und aktualisierte Auflage, Special Issue No. 347. Braunschweig: vTI, Johann Heinrich von Thünen-Institut.

Nieberg, H. \& Strohm-Lömpcke, R. (2001). Promotion of Organic Farming in Germany: Development and Perspectives for the Future. German Journal for Agricultural Economics 50 (7), 410-421

Offermann, F. \& Nieberg, H. (2000). Economic Performance of Organic Farms in Europe. Organic Farming in Europe: Economics and Policy. Stuttgart-Hohenheim: University of Hohenheim, Department of Farm Economics.

Offerman, F. \& Nieberg, H. (2001). Economic Performance of Organic Farms in Selected European Countries: Situation, Development and Determinants (in 
German). German Journal of Agricultural Economics (Agrarwirtschaft) 50 (7), 421-427.

Offermann, F., Nieberg, H. \& Zander, K. (2009). Dependency of organic farms on direct payments in selected EU member states: Today and tomorrow. Food Policy 34 (3), 273-279.

Penrose, E. (1959). The Theory of the Growth of the Firm. New York: Oxford University Press.

Rizov, M. \& Mathijs, E. (2003). Farm survival and growth in transition economies: Theory and empirical evidence from Hungary. Post Communist Economies 15(2), $227-242$.

Roodman, D. (2003). XTABOND2: Stata Module to Extend xtabond Dynamic Panel Data Estimator. Statistical Software Components. Boston College Department of Economics.

Roodman, D. (2009a). How to do xtabond2: An introduction to difference and system GMM in Stata. Stata Journal 9, 86-136.

Roodman, D. (2009b). A note on the theme of too many instruments. Oxford Bulletin of Economics and Statistics 71 (1), 135-158.

Sahm, H., Sanders, J., Nieberg, H., Behrens, G., Kuhnert, H., Strom, R., \& Hamm, U. (2012). Reversion of organic to conventional agriculture: a review. Renewable Agriculture and Food Systems 28 (3), 263-275.

Sahota, A. (2014). The global market for organic food and drink. Willer, H. \& Lernoud, J. (Eds.): The World of Organic Agriculture. Statistics and Emerging Trends 2014. Ifoam, Bonn, 125-131.

Sauer, J. \& T. Park (2009). Organic farming in Scandinavia: Productivity and market exit. Ecological Economics 68 (8-9), 2243-2254.

Shapiro, D., Bollman, R. D. \& Ehrensaft, P. (1987). Farm size and growth in Canada. American Journal of Agricultural Economics 69 (2), 477-483.

Siegmund, K. (2004). Deutscher Bodenmarkt weiter zweigeteilt: Enorme Dynamik in den neuen Länder. Bodenmarkt 1, 4-9. Berlin. Retrieved from: http://www.bodenmarkt.info/g/BM-Ex/daten/1-3/1-3-1/BM1_Siegmund.pdf

Sipiläinen, T. \& Oude Lansink, A. (2005). Learning in organic farming: An application on Finnish dairy farms, paper presented at the 2005 International Congress. 
Copenhagen, Denmark: European Association of Agricultural Economists, August 23-27, 2005.

StaLa (Statistisches Landesamt Baden-Württemberg) (2006). Der Grundstücksmarkt in Baden-Württemberg. In Statistisches Monatsheft Baden-Württemberg 11/2006, S. 32-36.

Retrieved from: http://www.statistik.badenwuerttemberg.de/veroeffentl/Monatshefte/PDF/Beitrag06 _11_07.pdf

Stolze, M. \& Lampkin, N. (2009). Policy for organic farming: Rationale and concepts. Food Policy 34 (3), 237-244.

Sumner, D. A. \& Leiby, J.D. (1987). An econometric analysis of the effects of human capital on size and growth among dairy farms. American Journal of Agricultural Economics 69 (2), 465-470.

Tiedemann, T. \& Latacz-Lohmann, U. (2011). Development of productivity in organic and conventional Agriculture: An empirical analysis. German Journal of Agricultural Economics 60 (2), 101-118.

Tiedemann \& Latacz-Lohmann, U. (2013). Production risk and technical efficiency in organic and conventional agriculture - The case of arable farms in Germany. Journal of Agricultural Economics 64 (1), 73-96.

Upton, M. \& Harworth, S. (1987). The growth of farms. European Review of Agricultural Economics 14 (4), 351-366.

Verbeek M. \& Nijman, T.E. (1992). Testing for selectivity bias in panel data models. International Economic Review 33 (3), 681-703.

Weiss, C. (1998). Size, growth, and survival in the Upper Austrian farm sector. Small Business Economics 10 (4), 305-312.

Weiss, C. (1999). Farm growth and survival: Econometric evidence for individual farms in Upper Austria. American Journal of Agricultural Economics 81 (1), 103-116.

Zander, K. \& Hamm, U. (2010). Consumer Attitudes towards Ethical Attributes of Organic Food (in German). German Journal for Agricultural Economics 59 (4). 246-257. 


\section{Appendix}

Table A 1 T-Tests for pairwise comparisons for holding farm size column (d) Table $2-4^{\dagger}$.

\begin{tabular}{cccccc}
\hline Farm size & $<10$ ha & 10 to 20 ha & 20 to 30 ha & 30 to 40 ha & 40 to 50 ha \\
\hline 10 to 20 ha & $0.82(0.37)$ & & & \\
20 to 30 ha & $5.68(0.02)$ & $10.65(0.00)$ & & \\
30 to 40 ha & $6.03(0.01)$ & $12.34(0.00)$ & $0.03(0.87)$ & \\
40 to 50 ha & $10.69(0.00)$ & $27.79(0.00)$ & $6.14(0.01)$ & $6.01(0.01)$ & \\
$>50$ ha & $19.53(0.00)$ & $74.97(0.00)$ & $44.37(0.00)$ & $49.66(0.00)$ & $13.26(0.00)$ \\
\hline
\end{tabular}

$\uparrow: p$-values in parentheses

Table A 2 T-Tests for pairwise comparisons for increasing acreage column (e)

Table 2-4

\begin{tabular}{cccccc}
\hline Farm size & $<10$ ha & 10 to 20 ha & 20 to 30 ha & 30 to 40 ha & 40 to 50 ha \\
\hline 10 to 20 ha & $0.71(0.40)$ & & & & \\
20 to 30 ha & $2.84(0.09)$ & $2.85(0.09)$ & & & \\
30 to 40 ha & $3.93(0.05)$ & $5.53(0.02)$ & $0.52(0.47)$ & & \\
40 to 50 ha & $4.50(0.03)$ & $6.50(0.01)$ & $1.12(0.29)$ & $0.17(0.68)$ & \\
$>50$ ha & $6.10(0.01)$ & $12.52(0.00)$ & $4.26(0.04)$ & $1.82(0.18)$ & $0.58(0.45)$ \\
\hline
\end{tabular}

$\dagger: p$-values in parentheses 


\title{
3. Technical efficiency in the Chilean agribusiness - a Stochastic Metafrontier Approach
}

\begin{abstract}
$^{8}$
The agribusiness industry is one of the most important and competitive sectors in Chile. This study models technical efficiency in Chilean agribusiness between 2001 and 2007 by taking into consideration the differences between the meat, fruit \& vegetables, dairy, milling and bakery sectors. We analyze firm data incorporating 2,940 observations using the Stochastic Metafrontier approach. We observe dynamic developments in the sectors with a stronger export-orientation for meat, fruit \& vegetables and dairy. We can show that meat and fruit \& vegetables firms in particular have experienced positive technological change, whereas dairy firms exhibit a slight decrease in efficiency and technical change. The milling and bakery sectors, which mainly produce for the domestic market, display consistently stable efficiency and technical change. The results confirm that an in-depth analysis of these sectors is necessary to evaluate the competitiveness of the agribusiness industry in Chile.
\end{abstract}

\footnotetext{
${ }^{8}$ This chapter is co-authored with Prof. Dr. Bernhard Brümmer and Dr. Sebastian Lakner and has been submitted to the Journal Agribusiness.
} 


\subsection{Introduction}

Chile, one of the strong emerging economies in Latin America, has a long tradition of liberal trade policies. Chile has free trade agreements with other countries, regions, and free-trade areas ${ }^{9}$, all of which highlight a strong trade orientation in Chile's economic policy. Between 2003 and 2013, Chile's exports grew by an annual average rate of $2.4 \%$ in volume terms and $11.6 \%$ in value terms (World Bank, 2014). In 2014, Chilean agribusiness accounted for $22 \%$ of Chilean total exports in value terms (Chilean Central Bank, 2014). Throughout the last 15 years, the industry has successfully overcome various challenges and new sectors have started to trade on international markets. As a result, the agribusiness industry has constantly been able to increase its exports, with the exception of 2009 when the world economic crisis reached the Chilean economy. The economic crisis mainly affected the sector of fruit \& vegetables. Nevertheless, the Chilean agribusiness industry managed to average an export value growth rate of $10 \%$ for the period 2004 - 2014 (Chilean Central Bank, 2014).

Classical Ricardian trade theory would suggest that comparative advantage in an industry (in the absence of direct policy intervention) leads to increased exports of that industry on the world market. Consequently, the export share of an industry on the world market "reveals" its competitive advantages (Balassa, 1965). However, recently, starting from the firm heterogeneity approach by Melitz (2003), the role of productivity differences has been added as an important element in explaining participation in international trade. Firm heterogeneity models suggest that aggregate country-level average productivity is inaccurate because only a small share of the firms within the exporting industries engage in exporting (Bernard et al., 2007). In the case of Chile, the impressive export growth and the absence of policy interventions reflect an improvement in the comparative advantage of the Chilean agribusiness. Hence, the objective of this paper is to investigate the technical efficiency of the Chilean agribusiness by taking into consideration the heterogeneity within the industry.

Interestingly, there is little empirical literature analyzing the productivity and efficiency of the agribusiness and food industries (Lundvall and Battese, 2000, Singh et al., 2001, Chaaban et al., 2005, Roudaut, 2006, Setiawan et al., 2012). Moreover, it is commonly analyzed at an aggregate level as a small part of the 'manufacturing industry'. However, agribusiness differs from other manufacturing industries in that the supply of raw

\footnotetext{
9 European Union, Mexico, Canada, South-Korea, Central America, the Mercosur-states, Singapore, Japan, China, India, New Zealand, Colombia, Venezuela, Ecuador, Bolivia, Peru, and the USA.
} 
materials strongly depends upon weather conditions and seasonality of production; in most cases, the raw materials can only be stored for a limited time. Furthermore, previously there has not been a distinction between the different sectors within the agribusiness regarding their production and sector structures. An efficiency measurement based on the whole agribusiness industry can be misleading. Therefore, our study fills this gap by examining the Chilean agribusiness and analyzing how the existing intra-sector heterogeneity in production structures, factor endowment and trade exposure influences technical efficiency (TE) and technical change (TC). We also provide an overview of the development of the agribusiness sectors between 2001 and 2007.

The remainder of this work is organized as follows. Section 3.2 provides background information on the potential effects of trade liberalization and the five sectors analyzed in this paper. Section 3.3 describes econometric estimation and the data employed. Section 3.4 presents the results of the estimation and their interpretation. Finally, in Section 3.5 we summarize the results and draw conclusions for the Chilean agribusiness industry.

\subsection{Background}

\subsubsection{Efficiency and trade}

Firms and consumers benefit from free trade through static welfare gains. There are adjustments in the structure of consumption and production in response to international price ratios. For the production, these changes occur as onetime adjustments in the output of industries whose prices changed due to trade liberalization. As Chile started its free-trade agenda decades ago, the welfare gains from these static effects have most likely already been reaped. Therefore, the dynamic effects of liberalized trade on efficiency and productivity are the present focus of this research. Recent empirical research finds that openness facilitates more competition and restricts price mark-ups resulting from market power. It also results in higher investments, productivity growth and improves exploitation of economies of scale, at least if appropriate domestic policies accompany the liberalization (Pavcnik, 2002; OECD, 2010).

A recent theory on trade emphasizes the importance of the heterogeneity of firms in explaining the dynamic effects of free trade. Melitz (2003) identifies differences in firms' productivity as a new source of gain from trade and establishes that trade exposure induces most productive firms to export, while forcing less productive firms to 
exit the industry. The reallocation of resources from low to high-productive firms contributes to an aggregate productivity increase. Empirical studies of firm heterogeneity and trade provide evidence that international trade is concentrated, that is, only a very small number of firms dominate exports (Bernard et al., 2007). These firms also tend to be largest in the industry, an outcome that arises from increasing returns to scale (Ciuriak, 2014). Secondly, exporters export - on average - a small share of the firm output (Bernard and Jensen, 1995). Furthermore, firms' characteristics determine decisions on export volume (intensive margin of trade) and the set of trade partners or products (extensive margin); this explains much of the variation in aggregate trade flows (Bernard et al., 2007). Thus, firms' heterogeneity and performance are crucial aspects to consider when explaining engagement in international trade and its impact in a given industry.

Finally, trade liberalization and the corresponding increased level of competition have several potential dynamic effects on industry, which can be described as follows:

- Rodrik (1995) and Pavcnik (2002) list a number of important channels through which trade liberalization improves industry performance. All these channels start from the assumption that the industry is characterized by substantial heterogeneity prior to trade liberalization. Learning by doing, in particular 'learning by exporting', contributes both to higher rates of adoption of new technologies, and to better utilization of the potential of existing technology (gains in technical efficiency).

- $\quad$ Stronger competition caused by external competitors and price pressures within domestic industries hinders market power. This influences the sectoral output by pushing firms to exert more efforts (i.e., gains in technical efficiency). Tybout et al. (1991) support this argument by proving that output levels and average efficiency levels of Chilean manufacturing plants rise for those industries facing significant reductions in protection after trade liberalization. Finally, the Hicksian 'quiet life' of the monopolist is harder to maintain in the presence of global competition.

- In the same vein, increases in competitive pressures can be expected to increase the rate of structural change within the industry. As discussed above, Melitz (2003) identifies that trade exposure accelerates the reallocation of economic resources and market shares toward more productive firms. The effect of this structural change is an improvement in the aggregate productivity. Pavcnik (2002) 
analyzes plant productivity of Chilean manufacturing industries during a period of adjustments toward trade liberalization from 1979 - 1986. Her results show strong evidence that trade liberalization increases aggregate productivity in the exportoriented and import competing sectors in comparison to the non-traded goods sectors.

- $\quad$ On the other hand, we observe different kinds of technological spill-overs from exporting firms to non-exporting firms via labor and product markets. For the case of the agricultural sector in Chile, Fleming and Abler (2013) show technological spill-overs from non-traditional crops, which are mainly produced for export, to the traditional crops, which are consumed on the domestic market. Their results find trade exposure positively correlated with yield, suggesting that trade has a positive effect on farm productivity.

- $\quad$ Firms acting in a globalized market are better able to exploit increasing returns to scale, if these play a role in the industry at hand. Firms are also better able to utilize their installed capacities. Nevertheless, the relatively low degree of processing in the Chilean agribusiness suggests that the impact of scale improvements on growth is rather limited. Typically, economies of scale increase with the degree of processing.

- Resource use efficiency might improve in a liberalized economy because liberalization frequently lowers the expected returns to rent-seeking activities. However, existing rent-seeking activities, even if targeted, might not completely vanish, but re-emerge in different areas (e.g., public procurement). The share of resources devoted to such wasteful activities will be influenced more strongly by the general level of governance in a country (Dijkstra, 2000). Since Chile, in almost all quantification attempts, shows relatively low levels of corruption, the impact of this last channel is likely limited.

Hence, most of the previous dynamic effects of liberalization are likely to materialize in the form of efficiency improvements. However, the magnitude of these effects is determined by the intra-sector heterogeneity. Therefore, we use the differences within the industry as a basis to analyze the technical efficiency of the Chilean agribusiness industry. 


\subsubsection{Background information on Chilean agribusiness}

The agribusiness industry involves several links in the food production chain including inputs suppliers, processors and retailers. The export value of this industry accounts for $22 \%$ of total Chilean exports (Chilean Central Bank, 2014). In this study, we center our analysis on the largest sectors: meat, fruit \& vegetables, dairy, milling and bakery. These sectors account for $71 \%$ of total agribusiness firms in 2007 and $46 \%$ of the industry revenue (INE, 2007). These sectors also have sufficient observations available for the entire period of interest (see section 3.3).

The development of the meat sector in Chile has been driven by a continuous increase in domestic demand. Pork and chicken meat consumption increased $25 \%$ and $14 \%$ respectively from 2001 to 2007. Accordingly, pork and poultry production tripled between 1990 and 2008 (ODEPA, 2011). In 1997, Chile started to export significant volumes of meat and in 2002 it achieved a trade surplus for the first time (ODEPA, 2014a). In particular, during the period of this research (2001 - 2007), the volumes of exported meat grew, on average, $32 \%$ annually. Nowadays, Chile mainly produces and processes poultry meat (47\%) and pork meat (32\%) (ODEPA, 2014b). According to ODEPA (2011), these developments have also contributed to technological improvements in the meat processing sector. Two aspects were crucial for the development of meat export: firstly, improvements in access to export markets through preferential tariffs, and secondly, a high sanitary and phytosanitary status of the country. For example, Chile is free from foot and mouth disease and bovine spongiform encephalopathy.

The fruit \& vegetables sector is one of the strongest exporting sectors in Chile. It enjoyed a phase of accelerated growth in the 1980s, with an average growth rate in export volumes of $38 \%$ (Chilealimentos, 2013). However, this had slowed down to $9 \%$ during the period of our study (2001 - 2007). The focus of processing activities in the fruit \& vegetables sector is on canned products (40 to $50 \%$ ), dehydrated products (20 to $30 \%$ ), frozen foods (15\%), and juices and oils (Chilealimentos, 2013; ODEPA, 2011). Generally, this sector has up-to-date technologies; this condition is strongly influenced by the recent development of firms processing oil products (olive and avocado oil) (ODEPA, 2012).

Rising milk prices in the domestic market during the 1990s resulted in an increase in national production (ODEPA, 2011). Analogous to the meat sector, the development in the primary sector stimulated production and exports of processed dairy products. Dairy 
exports have increased steadily since 2001. In 2004, Chile became a net exporter of dairy products (ODEPA, 2014b). Mexico and Venezuela acquire nearly $70 \%$ of dairy exports, although in recent years Cuba and China have increased their shares (ODEPA, 2011). The milk processing sector is very concentrated: The four largest firms ${ }^{10}$ purchase $75 \%$ of the raw milk in the country and export $78 \%$ of total Chilean dairy exports. On the other hand, the primary dairy sector is fragmented with about 12,000 dairy farmers in the country (ODEPA, 2009).

The milling sector is oriented to the domestic market. It has been re-activated in recent years by the increased demand for processed cereal and meal products for human consumption and prepared animal feeds for different growing sectors: pork, poultry, and salmon. For this reason, milling has made technological investments to improve quality and extraction rates; the average extraction rate for flour increased from 68 \% in 1995 to approximately 78 \% in 2005 (Fundacion Chile, 2005). The milling sector imports wheat from Argentina and the USA to cope with the increasing demand for higher quality and larger volumes of flour (ibid.).

The main buyers from milling firms are bakeries. The bakery sector is highly fragmented, yet it is one of the most important in economic terms. In 2006, sales were calculated at 1,000 million US Dollars in bakery products and 25,000 direct jobs were generated. Increased purchasing power has increased demand and variety of these products in recent years, forcing bakery firms to update technology. However, the rising costs of energy and wheat flour have decreased profit margins (Fundacion Chile, 2007).

These five sectors have developed and modernized at varying rates and times. Fruit \& vegetables was a pioneer for breaking into international trade, whereas meat and milk began to trade significant volumes two decades later. Therefore, an aggregate efficiency measurement for the Chilean agribusiness is likely to be distorted, as firms face different technologies and production opportunities according to their sector. Additionally, the structure and trade orientation varies between sectors. This also has an effect on firm efficiency. Finally, the Metafrontier approach enables us to measure efficiency levels for firms under different technologies relative to the entire industry, allowing us to capture the firms’ efficiency differences across sectors.

\footnotetext{
${ }^{10}$ Two of them are subsidiaries of multinational dairy companies, i.e. Fonterra and Nestlé.
} 


\subsection{Methods and data}

We use the Metafrontier model within the Stochastic Frontier Analysis (SFA) developed by Battese et al. (2004) and O'Donnell et al. (2008). This approach provides a framework to estimate the deviations between the observed outputs and the group or sector frontiers. Similarly, deviations can be estimated between the observed outputs and the Metafrontier (or industry frontier). Both sets of deviations can be estimated as a single data-generating process.

\subsubsection{Stochastic Frontier Analysis}

We use a stochastic frontier analysis approach to investigate the efficiency differences and the impact of potential determinants of technical efficiency in Chilean agribusiness. The basic stochastic frontier model can be defined as follows (Aigner et al., 1977, Meeusen and van den Broeck, 1977):

$y_{i t}=f\left(x_{j i t}, \beta_{i}\right) * \exp \left\{w_{i t}\right\} \quad$ with $w_{i t}=v_{i t}-u_{i t}$

$y_{i t}=f\left(x_{j i t}, \beta\right) * \exp \left\{v_{i t}-u_{i t}\right\}$,

where output $y_{i t}$ is the sum of revenues of the $i$-th firm at time $t$, and $x_{j i t}$ denotes $j=$ four inputs. These are: total labor $\left(x_{1}\right)$, cost of raw materials $\left(x_{2}\right)$, total operating costs $\left(x_{3}\right)$, capital $\left(x_{4}\right)$ and a dummy variable for exporting firms $\left(D_{1}\right)$ at $t$. The functional form $f(\cdot)$ is specified as a translog function. $\beta$ represents a vector of parameters to be estimated, and $w_{i t}$ is the composed error term, $w_{i t}=v_{i t}-u_{i t}$. The first component $v_{i}$ is defined as a pure random error (white noise), independently and identically distributed as $N\left(0, \sigma_{v}^{2}\right)$ (Aigner et al., 1977). The second error-term $u_{i}$ is a systematic and nonnegative random variable for the $i$-th firm (Schmidt and Sickles, 1984), which is assumed to be under the firm's control. We assume a half normal distribution for the inefficiency term, $u_{i} \sim N^{+}\left(0, \sigma_{\text {uit }}\right)$, where we allow for heteroscedasticity by modeling $\sigma_{\text {uit }}=\exp \left(z_{j i t} \rho_{j}\right)$. The Z-variables include the inputs and additional potential drivers of technical efficiency.

The inference in the stochastic frontier model is based on maximum-likelihood estimates that are obtained in terms of the parameterization of $\sigma_{v}^{2}+\sigma_{u}^{2} \equiv \sigma^{2}$ and $\gamma=\sigma_{u}^{2} /\left(\sigma_{v}^{2}+\sigma_{u}^{2}\right)$, where $\gamma$ lies between zero and one. Thus, if $\gamma=0$, all deviations are due to noise, while $\gamma=1$ means all deviations are due to technical 
inefficiency. An output-oriented measure of technical efficiency (TE) for any $i$-th individual firm is given by:

$T E=\frac{q_{i}}{q_{i}^{*}}=\frac{f\left(x_{i k} ; \beta\right) \exp \left(v_{i}-u_{i}\right)}{f\left(x_{i k} ; \beta\right) \exp \left(v_{i}\right)}=\exp \left(-u_{i}\right) \in[0,1]$.

The estimation of equation (3.1) depends on the assumption that both error components are homoscedastic. However, it is possible that both errors are affected by heteroscedasticity (Caudill et al., 1995). Thus, the inefficiency term would vary according to the size of the firm; larger firms often exhibit more variation in input allocation than smaller firms. Since the data show a large variation in terms of inputs and outputs, we are using the heteroscedasticity model (Wang and Schmidt, 2002) for a production frontier framework. The main estimation of the heteroscedasticity model is described as follows: $\sigma_{u_{i t}}=\exp \left\{z_{i t} \rho_{j}\right\}$, where $z_{i t}$ is a matrix of $j$ explanatory variables of the variance of inefficiency term $\sigma_{u_{i t}}$ for firm $i$ in period $t$; $\rho$ is a vector of length $j$ of parameters to be estimated, reflecting the impact of the variable $z_{i t}$ on technical inefficiency. A positive (negative) estimate of $\rho$ indicates that the corresponding variable leads to a larger (smaller) variance of the inefficiency term, i.e. a smaller (larger) technical efficiency. The model was estimated by means of MaximumLikelihood (see Coelli et al., 2005)

\subsubsection{Metafrontier model}

The estimation of technical efficiency is based on the assumption that all firms have access to homogenous technology. In order to incorporate technology differences within Chilean agribusiness, we use the stochastic Metafrontier (MF) framework (Battese et al., 2004). Unlike the stochastic frontier specified above, the MF is a deterministic frontier, defined by the condition that it envelops the maximum outputs predicted by a set of estimated group-specific stochastic frontiers (Figure 3-1). 
Figure 3-1 Group frontiers and Metafrontier.

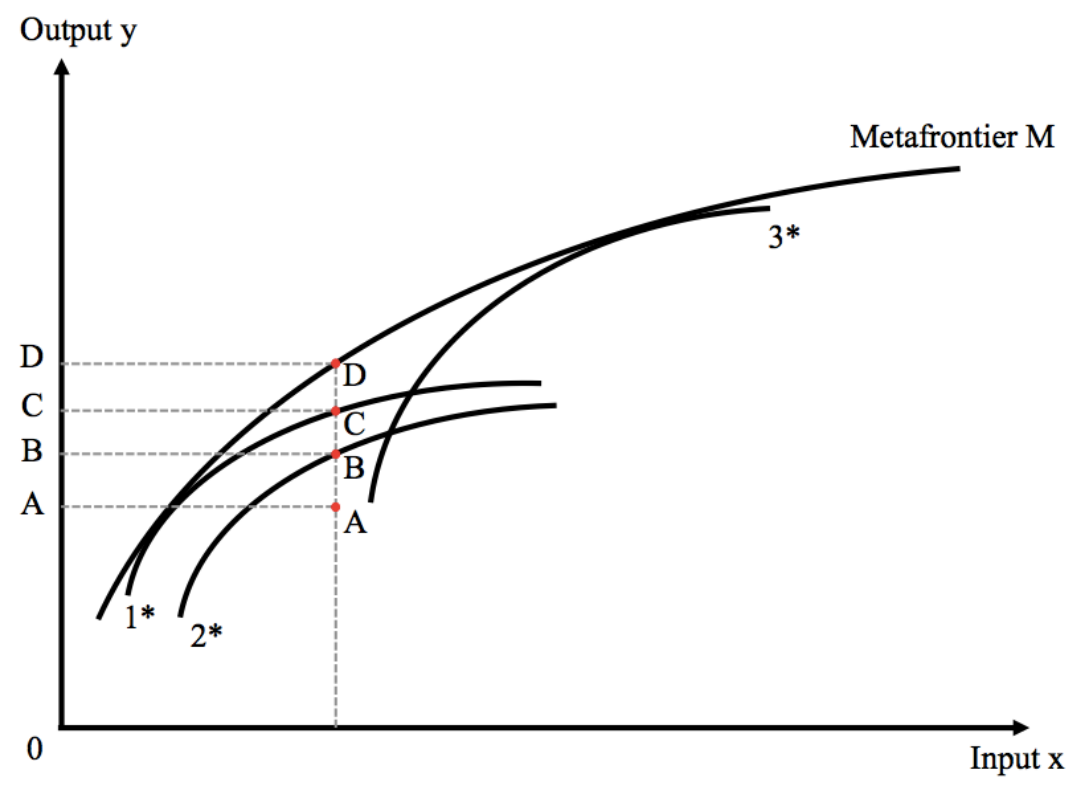

Source: own presentation based on O’Donnell et al., 2008 p. 236

For a given observation A belonging to group 2 in Figure 3-1, we can estimate its technical efficiency relative to its given group frontier $\left(2^{*}\right)$. Its technical efficiency $\left(T E_{A}\right)$ for a given set of inputs $x$ would be $T E_{A}=O A / O B$. For the same observation $A$, the total technical efficiency $T E_{A} *$ in relation to the MF would be $T E_{A} *=O A / O D$, assuming that the observed firm $\mathrm{A}$ has access to the joint technology. The metatechnology ratio (MTR) (O’Donnell et al., 2008) is defined as the ratio of the distances between the group-specific frontier $* 2$ and $\mathrm{M}: M T R=0 \mathrm{~B} / O D$.

The stochastic MF model is based on the group-specific frontier for group G:

$y_{i t}(G)=f\left(x_{j i t}(G), \beta(G)\right) * \exp \left\{v_{i t}(G)-u_{i t}(G)\right\}$

with a given output $y$ and for the inputs $x(j=4)$ of firms $i$. The group-specific parameter $\beta(G)$ is estimated for the different groups $G=1,2, \ldots, N$.

The MF is then defined as: $y_{i t}^{*}=f\left(x_{j i t}, \beta^{*}\right)$

subject to $x_{j i t}, \beta^{*} \geq x_{j i t}, \beta^{G}$, where $\beta^{*}$ is a vector of parameters for the Metafrontier. These parameters for the deterministic MF can be estimated by mathematical programming techniques, such as linear programming to minimize the sum of deviations between $y_{i t}^{*}$ and $y_{i t}(G)$, or by using quadratic programming to minimize the 
sum of squared deviations (Battese et al., 2004). In our case, the results from both techniques are similar; hence we only present the linear programming results.

The firm's individual MTR is then expressed as follows:

$M T R_{i t}=\frac{e^{x_{i t}^{\prime} \beta^{G}}}{e^{x_{i t}^{\prime} \beta^{*}}}$

The firm's individual technical efficiency to the Metafrontier, $T E_{i t}^{*}$ is defined as:

$T E_{i t}^{*}=T E_{i t}^{G} \times M T R_{i t}$

The model is estimated using the package sfamb for OxMetrics 6.3 (Brümmer, 2001). Standard errors for the parameters of the Metafrontier can be obtained by statistical simulation; we conduct 5,000 replications of the simulations.

\subsubsection{Data}

We use data from the 'Annual National Industrial Survey (ENIA)', which was conducted between 2001 and 2007 by the National Institute of Statistics in Chile (INE). The ENIA surveys the full population of manufacturing establishments with 10 or more employees (INE, 2007), based on information provided by the Internal Revenue Service. The data set covers the manufacturing of food products (division 15 of the International Standard Industrial Classification (ISIC)). The divisions are defined by the United Nations (2002) based on similarities in (i) produced goods, (ii) the uses to which the goods are put, and (iii) the inputs, the process and the technology of production. Finally, firms are classified according to the production activity, which accounts for most of the value added.

There were not enough observations for statistical analysis of some sectors; hence, the final data set consists of the following five sectors: (1) production and processing of meat and meat products, (2) processing and preserving of fruit \& vegetables, (3) manufacture of dairy products, (4) manufacture of grain mill products and (5) manufacture of bakery products. Table 3-1 shows the final structure of data set by sector. 
Table 3-1 Number of observations by sector in the data set.

\begin{tabular}{lcrl}
\hline $\begin{array}{c}\text { ISIC } \\
\text { Classes }\end{array}$ & Observations & Firms & Description of the sector \\
\hline 1511 & 301 & 43 & $\begin{array}{l}\text { Production, processing and preserving of meat and meat } \\
\text { products }\end{array}$ \\
1513 & 217 & 31 & Processing and preserving of fruit \& vegetables \\
1520 & 161 & 23 & Manufacture of dairy products \\
1531 & 434 & 62 & Manufacture of grain mill products \\
1541 & 1,827 & 261 & Manufacture of bakery products \\
\hline & $\mathbf{2 , 9 4 0}$ & $\mathbf{4 2 0}$ & Total \\
\hline
\end{tabular}

Source: Author's own calculation

Table 3-2 presents the descriptive statistics for the overall sample and for the individual sectors. Output is measured in terms of revenue from all manufactured products. Labor represents the average number of workers per year in a firm. Raw materials describe the value of products which are bought to be processed, for instance, fruits, raw milk, grains, flour, etc. We also estimate the operating costs as the sum of expenses for fuel, water, and electricity used in the production process. Finally, capital is measured as the value of capital stock (land, vehicles, machinery, and buildings) minus the accumulated depreciation. The studies of Jorgenson (1989) and Diewert (2003) provide an overview of the different methodological approaches to appropriately estimate the capital of a production unit. We found the value of fixed assets to be the most reliable proxy for capital. All monetary variables are measured in 2007 constant prices. Operating costs and raw materials are deflated by the Wholesale Price Index, revenue from exports is deflated using the Export Food Index, and revenue from domestic sales is deflated by the Consumer Price Index. The variable capital is deflated by the Gross Fixed Capital Formation. All indexes were provided by the Central Bank of Chile.

The average revenue for agribusiness firms is 4,270 million Chilean Pesos (CLP\$). Meat and dairy firms are the largest firms in terms of output, followed by fruit \& vegetables firms, milling firms and bakeries. Raw material is the main input factor in each of the sectors. Meat and dairy firms have the highest use of raw materials and capital. The differences between these two sectors consist of meat firms being more labor intensive and having lower operating costs than dairy firms. The fruit \& vegetables sector has the second highest labor and operating cost intensity; however, it produces distinctly less output than meat and dairy firms. On the other hand, milling firms have low labor and operating cost intensity, and their output is similar to that produced by fruit \& vegetables firms. Table 3-2 depicts the outward orientation of each 
sector, for instance, $64 \%$ of fruit \& vegetables firms export. The share of exporting firms is also relatively high in the meat and dairy sectors, but low in the milling and baking sectors.

Table 3-2 Summary statistics of the Chilean agribusiness.

\begin{tabular}{|c|c|c|c|c|c|c|}
\hline Variables & Meat & $\begin{array}{c}\text { Fruit \& } \\
\text { Vegetables }\end{array}$ & Dairy & Milling & Bakery & Overall \\
\hline & \multicolumn{6}{|c|}{ Mean (Standard deviation) } \\
\hline Revenue (CLP\$ 10 Mio.) & $\begin{array}{c}1,450 \\
(2,130)\end{array}$ & $\begin{array}{c}697 \\
(1,030)\end{array}$ & $\begin{array}{c}1,640 \\
(4,000)\end{array}$ & $\begin{array}{l}532 \\
(621)\end{array}$ & $\begin{array}{c}95 \\
(683)\end{array}$ & $\begin{array}{c}427 \\
(1,420)\end{array}$ \\
\hline Labor (No. of workers) & $\begin{array}{l}219 \\
(310)\end{array}$ & $\begin{array}{c}212 \\
(280)\end{array}$ & $\begin{array}{c}176 \\
(351)\end{array}$ & $\begin{array}{c}49 \\
(56)\end{array}$ & $\begin{array}{c}36 \\
(122)\end{array}$ & $\begin{array}{c}78 \\
(192)\end{array}$ \\
\hline Raw Materials (CLP\$ 10 Mio.) & $\begin{array}{c}1,080 \\
(1,590)\end{array}$ & $\begin{array}{c}439 \\
(637)\end{array}$ & $\begin{array}{c}1,040 \\
(2,730)\end{array}$ & $\begin{array}{c}456 \\
(518)\end{array}$ & $\begin{array}{c}44 \\
(287)\end{array}$ & $\begin{array}{c}294 \\
(944)\end{array}$ \\
\hline Operating Costs (CLP\$ 10 Mio.) & $\begin{array}{r}29 \\
(46)\end{array}$ & $\begin{array}{c}31 \\
(50)\end{array}$ & $\begin{array}{c}40 \\
(104)\end{array}$ & $\begin{array}{c}11 \\
(14)\end{array}$ & $\begin{array}{c}4 \\
(22)\end{array}$ & $\begin{array}{c}12 \\
(38)\end{array}$ \\
\hline Capital (CLP\$ 10 Mio.) & $\begin{array}{c}557 \\
(991)\end{array}$ & $\begin{array}{c}381 \\
(666)\end{array}$ & $\begin{array}{c}551 \\
(1660)\end{array}$ & $\begin{array}{c}160 \\
(235)\end{array}$ & $\begin{array}{c}32 \\
(247)\end{array}$ & $\begin{array}{c}159 \\
(607)\end{array}$ \\
\hline Share of exporting firms (\%) & 24.9 & 63.6 & 21.1 & 9.5 & 0.4 & 10.1 \\
\hline Determinants of technical efficiency & & & & & & \\
\hline Share of skilled workers (\%) & 0.13 & 0.12 & 0.16 & 0.12 & 0.24 & 0.20 \\
\hline Share of non-productive labor (\%) & 0.30 & 0.62 & 0.46 & 0.42 & 0.31 & 0.37 \\
\hline Dummy for contract manufacturer $(0 / 1)$ & 0.57 & 0.46 & 0.48 & 0.59 & 0.78 & 0.69 \\
\hline Dummy for export fiscal incentives $(0 / 1)$ & 0.06 & 0.35 & 0.02 & 0.03 & 0.00 & 0.04 \\
\hline
\end{tabular}

Source: Author's own calculation

The share of skilled workers (workers with training) is relatively uniform over all sectors, except for the bakery firms. This sector requires workers with specific training. The share of workers in administrative, sales, and management tasks (non-productive labor) is highest for fruit \& vegetables firms. About half of the firms in the five sectors are 'contract manufacturers', that is, they process food for third parties. This practice is more frequent in bakery, milling, and meat firms and it is expected to increase performance, since they benefit from economies of scales and know-how by servicing multiple contractors. Finally, fruit \& vegetables firms receive the most fiscal incentives for exporting. Fiscal incentives consist of tax rebates for exporting; exporters receive a refund of $19 \%$ of the Free on Board value of exports.

\subsection{Results and discussion}

This section begins by presenting the standard tests for selecting the functional form of the production function and the inefficiency approach. We then show the results of the group frontiers and Metafrontier as well as the technological progress on all sectors. Finally, we present the development of technical efficiency of exporting and non- 
exporting firms.

\subsubsection{Efficiency analysis}

Table 3-3 shows the standard test results to evaluate the general specifications of each model. The first test rejects the null hypothesis of no technical efficiency for each sector. The second test rejects the null hypothesis that the production function has a Cobb-Douglas (CD) functional form for all groups. Similarly, both constant returns to scale (RTS) and no impact on the variance of inefficiency by the firm-specific factors are soundly rejected. Finally, the data show evidence against a homogenous technology, indicating that an MF approach is a superior approach to compare firm performance across the sectors.

Table 3-3 Specification tests for model selection.

\begin{tabular}{|c|c|c|c|c|c|c|}
\hline \multirow[b]{2}{*}{ Null-hypothesis } & \multicolumn{5}{|c|}{ Test-value } & \multirow{2}{*}{$\begin{array}{l}\text { Critical } \\
\text { value }\end{array}$} \\
\hline & Meat & $\begin{array}{c}\text { Fruit \& } \\
\text { vegetables }\end{array}$ & Dairy & Milling & Bakery & \\
\hline $\begin{aligned} \mathrm{H}^{1}: & \text { No inefficiency } \\
& \rho_{j}=0, j=0,1, \ldots, 29\end{aligned}$ & $71.77 * *$ & $136.34^{* *}$ & $106.98 * *$ & $112.36^{* *}$ & $68.11^{* *}$ & 3.84 \\
\hline $\begin{array}{ll}\mathrm{H}^{2}: & \text { CD-production function } \\
& \beta_{t t}=\beta_{j j}=\beta_{j k}=0\end{array}$ & $119.67^{* *}$ & $222.09 * *$ & $222.87 * *$ & $129.91^{* *}$ & $161.66^{* *}$ & 25.00 \\
\hline $\begin{aligned} \mathrm{H}^{3}: & \text { Linear homogeneity } \\
& \text { (constant returns to scale) } \\
& \sum \beta_{j}=1 ; \sum \beta_{j k}=0 \text { for } j= \\
& 1,2,3,4\end{aligned}$ & $98.57 * *$ & $50.45 * *$ & $111.33^{* *}$ & $32.94 * *$ & $55.77 * *$ & 11.07 \\
\hline $\begin{aligned} \mathrm{H}^{4}: & \text { No Heteroscedasticity } \\
& \rho_{j}=0, j=1,2, \ldots, 19\end{aligned}$ & $67.05 * *$ & $50.15^{* *}$ & $39.76^{* *}$ & $119.41^{* *}$ & $97.22 * *$ & 15.51 \\
\hline $\begin{array}{l}\mathrm{H}^{5} \text { : Homogenous tech. across } \\
\text { sectors }\end{array}$ & & & $685.51^{* *}$ & & & \\
\hline
\end{tabular}

Table 3-4 displays the first order parameter estimates of the translog stochastic frontier for the five sectors and for the overall food industry in Chile. 
Table 3-4 Parameter estimates of the translog stochastic frontier model ${ }^{\dagger}$.

\begin{tabular}{|c|c|c|c|c|c|c|}
\hline Parameters & Meat & $\begin{array}{c}\text { Fruit \& } \\
\text { Vegetables }\end{array}$ & Dairy & Milling & Bakery & $\begin{array}{c}\text { Meta } \\
\text { frontier }\end{array}$ \\
\hline Constant & $-0.084 * * *$ & 0.061 & 0.080 & $0.080 * * *$ & $-0.233^{* * *}$ & $0.170 * * *$ \\
\hline Labor & $0.274 * * *$ & 0.072 & $0.257 * * *$ & $0.226 * * *$ & $0.223 * * *$ & 0.085 \\
\hline Raw Material & $0.699 * * *$ & $0.672 * * *$ & $0.521 * * *$ & $0.699 * * *$ & $0.716^{* * *}$ & $0.706^{* * *}$ \\
\hline Operating Cost & $0.080^{* * *}$ & 0.160 & $0.253 * * *$ & $0.117 * * *$ & $0.078 * * *$ & $0.184 * * *$ \\
\hline Capital & 0.012 & $0.088^{*}$ & 0.067 & $0.029 *$ & $0.080 * * *$ & $0.128 * * *$ \\
\hline Time & $0.024 * * *$ & $0.021 *$ & 0.017 & $0.024 * * *$ & $0.042 * * *$ & $0.036 * *$ \\
\hline Export & $0.058 * *$ & $0.035^{*}$ & $0.148 * * *$ & -0.071 & 0.103 & $0.085^{*}$ \\
\hline $0.5 \times(\log \text { labor })^{2}$ & 0.094 & $0.113^{*}$ & $0.266 * * *$ & $0.369 * * *$ & $0.324 * * *$ & $0.437 * * *$ \\
\hline $0.5 \times(\log \text { raw material })^{2}$ & $0.237 *$ & $0.269 * * *$ & $0.179 * * *$ & $0.215^{* * *}$ & $0.381 * * *$ & $0.435 * * *$ \\
\hline $0.5 \times(\log \text { operating cost })^{2}$ & $0.079 * * *$ & $0.181^{*}$ & 0.029 & $0.062 * * *$ & $0.034 * * *$ & $0.308 * * *$ \\
\hline $0.5 \times(\log \text { capital })^{2}$ & $0.067 * * *$ & $0.064^{*}$ & -0.019 & -0.005 & $0.020 * * *$ & $0.116 * * *$ \\
\hline $0.5 \times(\text { time })^{2}$ & $0.013^{* *}$ & 0.010 & -0.005 & 0.001 & 0.002 & 0.006 \\
\hline $\log$ labor $\times \log$ raw material & -0.031 & $-0.120^{* *}$ & $-0.070 * * *$ & $-0.228 * * *$ & $-0.361 * * *$ & $-0.304 * * *$ \\
\hline $\log$ labor $\times \log$ operating cost & $-0.086 * *$ & $-0.151 *$ & $0.035^{*}$ & $-0.060 *$ & 0.031 & -0.071 \\
\hline $\log$ labor $\times \log$ capital & 0.028 & 0.069 & $-0.076^{* *}$ & 0.036 & 0.021 & 0.009 \\
\hline $\log$ labor $\times$ time & -0.005 & -0.006 & $-0.039 * * *$ & 0.001 & $-0.033 * * *$ & $-0.029 * *$ \\
\hline $\log$ raw material $\times \log$ operating cost & $-0.067 * *$ & 0.002 & $-0.142 * * *$ & $-0.055^{* *}$ & -0.060 & $-0.113^{* * *}$ \\
\hline $\log$ raw material $\times \log$ capital & $-0.110 * * *$ & $-0.124 * * *$ & $-0.036 * *$ & -0.033 & -0.014 & $-0.089 * * *$ \\
\hline $\log$ raw material $\times$ time & -0.004 & -0.012 & -0.005 & 0.010 & $0.015^{*}$ & 0.001 \\
\hline $\log$ operating cost $\times \log$ capital & 0.020 & -0.022 & $0.094 * * *$ & $0.030^{*}$ & 0.004 & $-0.046^{* *}$ \\
\hline $\log$ operating cost $\times$ time & -0.008 & 0.003 & $0.024 * *$ & -0.008 & $0.009 * *$ & 0.002 \\
\hline $\log$ capital $\times$ time & 0.011 & 0.003 & -0.004 & -0.004 & 0.002 & $0.014 *$ \\
\hline $\ln \sigma_{v}$ & -1.970 & -1.928 & -2.424 & -2.210 & -1.703 & \\
\hline$\gamma$ & 0.621 & 0.894 & 0.955 & 0.877 & 0.471 & \\
\hline Log Likelihood & 131.261 & 43.513 & 85.491 & 168.297 & 423.883 & \\
\hline
\end{tabular}

Significance levels: $* * * / * * *$ denote significance-level of alpha at the 1,5 , and $10 \%$ levels, respectively.

$\dagger$ : The parameters are evaluated at the sample mean.

Source: Author's own calculation

The $\gamma$ values indicate that there is a large share of inefficiency in the joint error-term for dairy, fruit \& vegetables, and milling and low inefficiency in the meat and bakery sectors. Since the input variables are normalized with their respective means, the estimated coefficients in Table 3-4 can be interpreted as the partial output elasticities at the sample mean. At the sample mean, the models fulfil the monotonicity condition, since all parameter estimates are positive. The results correspond to the cost structure within the agribusiness industry, where the most important production factor is raw material, followed by labor, operating costs and capital. 
The cost of raw materials shows high output elasticity in all sectors. The magnitudes of the elasticities vary from 0.71 for bakery to 0.52 for dairy firms. The results of the raw material elasticities are similar to other studies on processing food industries in India, the USA, and Ivory Coast (Singh et al. 2001; Roudaut, 2006; Ollinger, et al. 2005).

Labor is the second most important production factor; it has a significant effect on all sectors with the exception of fruit \& vegetables. The output-elasticity varies from 0.07 for fruit \& vegetables firms to 0.27 for bakery firms. The low output-elasticity of labor on fruit \& vegetables firms is explained by the seasonality of the work: $73 \%$ of workers are temporarily employed for four to six months per year (ODEPA, 2012). Additionally, firms in the fruit \& vegetables sector use about the same amount of labor as meat firms; nevertheless, they produce $52 \%$ less output. Therefore, the results point out that a further increase in the labor force (when it is already used intensively) does not significantly affect production. The coefficient of labor interacted with time is negative for dairy and bakery, indicating an overuse of this input factor in both sectors. This result is explained by the $80 \%$ increase in the number of workers over the study period in dairy firms, and $18 \%$ in bakery.

Operating costs have a significant effect on all sectors, with the exception of the fruit \& vegetables sector. The strongest effect is found on dairy firms (0.25) as a result of the intensive use of energy and fuels for the pasteurization and cooling of the dairy products. The coefficient of operating cost interacted with time is positive and significant for dairy and bakery firms, revealing that technological change saves operating costs.

Capital has a significant effect on those sectors with lower capital endowment (fruit \& vegetables, milling, and bakery), while it shows no effect on meat and dairy firms. This result suggests that when capital is not used intensively, it has a significant effect on firm productivity. The effect is also larger for fruit \& vegetables and bakery firms, where the complexity of the production process and product design is greater. This indicates that capital investment in modern technologies is decisive for a higher degree of processing. A $10 \%$ increase in capital would increase output between $0.1 \%$ and $0.9 \%$. This is in line with Singh et al. (2001) and Roudaut (2006), who also find similar effects from capital in agribusiness firms. 
The parameter estimate of the time variable is interpreted as the rate of technical change (TC) at the sample mean. The parameters $t$ and $t^{2}$ are both positive and significant for meat, indicating that the rate of TC increased notably over time. The parameter $t^{2}$ is not significant for the remaining sectors. The $t$ coefficient for bakery firms denotes an average TC rate of $4 \%$. Fruit \& vegetables and milling firms have similar TC rates of about $2 \%$, while dairy firms show no technological progress. The large TC and the positive elasticity of capital in the bakery sector is due to recent investments in fixed assets such as modern machinery and ovens to cope with the increasing prices of energy and flour (Fundacion Chile, 2007). Moreover, improvements in basic technologies for small and medium bakery firms will probably have a larger effect than in the other sectors.

Interestingly, exports have a larger effect on sectors that have begun to export more recently (meat and dairy) and less on fruit \& vegetable firms, which have constituted an established export sector since the 1980s. Exporting dairy firms are $14 \%$ more productive than their counterparts; the effect of exporting is $5 \%$ for meat firms and $3 \%$ for firms operating in the fruit \& vegetables sector.

Table 3-5 shows the estimated parameters for the heteroscedasticity model:

Table 3-5 Parameter estimates for the heteroscedasticity model.

\begin{tabular}{lccccc}
\hline \multirow{2}{*}{ Parameter } & \multicolumn{4}{c}{ Coefficients } \\
\cline { 2 - 6 } & Meat & $\begin{array}{c}\text { Fruit \& } \\
\text { vegetables }\end{array}$ & Dairy & Milling & Bakery \\
\hline Constant & $-3.178^{* * *}$ & $-1.871 * * *$ & $-0.871 * * *$ & $-1.854 * * *$ & $-3.292 * * *$ \\
Labor & 0.028 & -0.070 & $0.719 * *$ & $0.759 * * *$ & $1.233 * * *$ \\
Raw Materials & $-0.854 * * *$ & $-0.919 * * *$ & $-0.695 * * *$ & $-0.925 * * *$ & $-1.454 * * *$ \\
Operating Costs & $0.816 * * *$ & 0.557 & -0.064 & $0.328 * *$ & 0.072 \\
Capital & -0.137 & 0.326 & $0.506 * * *$ & 0.087 & $0.194 * * *$ \\
Share of skilled labor & -0.726 & $-3.204 * * *$ & -0.094 & $-0.844 * * *$ & -0.275 \\
Share of non-productive labor & -1.083 & 0.428 & $-1.785 * * *$ & -0.137 & $-0.851 * *$ \\
Contract manufacturer (0/1) & $1.253 * * *$ & -0.117 & -0.056 & $0.245 * * *$ & $0.708 * * *$ \\
Export fiscal incentives (0/1) & $-2.800 * * *$ & 0.543 & $0.974 *$ & $-0.491 *$ & $0.909 * * *$ \\
\hline
\end{tabular}

$* * * / * * / *$ denote significance level of alpha at the 5 and $10 \%$ levels, respectively. Source: Author's own calculation

The effect of the variables on the inefficiency term shows a similar direction in the five sectors:

- Firms with a higher use of raw materials exhibit higher TE.

- An increase in labor leads to lower TE in the dairy, milling, and bakery sectors.

- Operating costs are also a source of inefficiency for meat and milling firms.

- An increase in capital reduces TE in the dairy sector and to a smaller extent in bakeries. 
Since capital is measured as capital stock minus accumulated depreciation, an increase in capital indicates investments in the production capacity. Therefore, this outcome points to organizational challenges when acquiring new equipment or machinery, leading to errors in the production flow in the short-run and hence a reduction in efficiency. Diaz and Sanchez (2008) find similar results in the Spanish manufacturing sector.

The proportion of skilled labor in the production process increases TE in both fruit \& vegetables and milling firms. Meanwhile, the share of non-productive labor increases $\mathrm{TE}$ in dairy and bakery firms. The firm management and sales workers appear to be more important in those two sectors. Processing food for other firms (contract manufacturing) unexpectedly decreases TE for meat, milling and bakery firms. It is assumed that contract manufacturers benefit from specialization and know-how of the production process. However, the gains from specialization vanish if the product range is too ample, because it increases possible sources for error in the production process. The fiscal incentives for exporting have mixed effects across the sectors. The incentives increase efficiency on meat and milling firms, but have a decreasing effect on efficiency in dairy and bakery firms.

The estimated technical efficiencies for the group frontiers (TE ${ }^{G}$ ), the MTR, and the technical efficiency relative to the Metafrontier (TE*) are shown in Table 3-6 ${ }^{11}$. The results reveal that, on average, firms efficiently manage their own technology set $\left(\mathrm{TE}^{\mathrm{G}}\right)$. In particular, meat and bakery firms have lower standard deviations for $\mathrm{TE}^{\mathrm{G}}$ than the other sectors, implying less dispersion in their efficiency levels. The moderate average MTR indicates that there is an important share of firms within each sector requiring new technologies to increase productivity. Both MTR and $\mathrm{TE}^{\mathrm{G}}$ are combined into the technical efficiency measure against the Metafrontier (TE*); the highest average TE* is achieved by the meat and bakery sectors due to their high $\mathrm{TE}^{\mathrm{G}}$ and MTR. A share of firms with low $\mathrm{TE}^{\mathrm{G}}$ and MTR in the milling, dairy, and fruit \& vegetables sectors negatively affects the sectors' performances. The results reveal that firms in Chilean agribusiness make efficient use of the technologies they have available, however substantial efficiency gains throughout the overall industry could come from the adoption of new technologies.

\footnotetext{
${ }^{11}$ Figure A 1 and Figure A 2 in the Appendix of this chapter show the distributions of TE and MTR.
} 
Table 3-6 Mean MTR, TE ${ }^{\mathrm{G}}$ and TE* by sector.

\begin{tabular}{lcccccc}
\hline \multirow{2}{*}{ Sector } & \multicolumn{2}{c}{$\begin{array}{c}\text { Technical Efficiency } \\
\mathbf{( T E}^{\mathbf{G}} \mathbf{)}\end{array}$} & \multicolumn{2}{c}{$\begin{array}{c}\text { Meta-technology ratio } \\
\text { (MTR) }\end{array}$} & \multicolumn{2}{c}{ Total Efficiency (TE*) } \\
& Mean & Std. Dev. & Mean & Std. Dev. & Mean $^{\dagger}$ & Std. Dev. \\
\hline $\begin{array}{l}\text { Meat } \\
\text { Fruit \& }\end{array}$ & 0.926 & 0.087 & 0.761 & 0.147 & 0.705 & 0.148 \\
vegetables & 0.850 & 0.142 & 0.712 & 0.197 & 0.607 & 0.199 \\
Dairy & 0.859 & 0.168 & 0.739 & 0.171 & 0.629 & 0.181 \\
Milling & 0.852 & 0.131 & 0.759 & 0.160 & 0.649 & 0.173 \\
Bakery & 0.934 & 0.060 & 0.748 & 0.113 & 0.698 & 0.106 \\
\hline
\end{tabular}

$\dagger$ : Pairwise comparison by the Bonferroni test revealed significant differences between the sectors. We could not reject the null hypothesis for mean differences between meat and bakery, fruit \& vegetables and dairy, and milling and dairy. All other mean values were statistically significantly different from each other. The pairwise tests are presented in Table A 3 in the Appendix of this chapter.

Source: Author's own calculation

To investigate the share of firms that operate with increasing, constant or decreasing returns to scale (RTS), we approximated the z-values for the scale elasticities using the delta-method (Greene, 2008). We tested for constant RTS and classified observations with $\mathrm{p}<0.05$ as decreasing RTS and with $\mathrm{p}>0.95$ as increasing RTS (Table 3-7):

Table 3-7 Scale-elasticities (SE) classification by sector.

\begin{tabular}{lccrrr}
\hline Indicator & Meat & $\begin{array}{c}\text { Fruit \& } \\
\text { Vegetables }\end{array}$ & Dairy & Milling & Bakery \\
\hline Observations with decreasing RTS (\%) & 0.0 & 18.4 & 3.1 & 4.8 & 0.8 \\
Observations with constant RTS (\%) & 24.6 & 42.4 & 24.2 & 26.7 & 16.8 \\
Observations with increasing RTS (\%) & 75.4 & 39.2 & 72.7 & 68.4 & 82.5 \\
\hline
\end{tabular}

Source: Author's own calculation

We find that the majority of firms within the defined sectors operate with increasing RTS, with the exception of fruit \& vegetables. In this sector, about $20 \%$ of the firms exhibit decreasing RTS. These companies operate with three times more workers and double the capital than the average firm in fruit \& vegetables. Furthermore, the largest firms operating with diseconomies of scale can be related to the seasonality of production and its effect on the capacity utilization rate. ODEPA (2012) reports that the average utilization rate is $76 \%$ during harvest season (four to six months) while throughout the rest of the year it decreases to $30 \%$. This has an adverse effect on larger firms with more installed capacity.

Increasing RTS is also an incentive to grow by increasing firm size, or by mergers and acquisitions. Based on the share of firms with increasing RTS in four of the five sectors, we expect structural changes within the Chilean agribusiness (except for fruit \& vegetables). 


\subsubsection{Sector performance}

In the following section we discuss the development of technical change (TC) and technical efficiency change (TEC) for each sector over time, displayed in Figure 3-2:

Figure 3-2 TC and TEC development in the Chilean agribusiness 2002-2007 ${ }^{12}$.
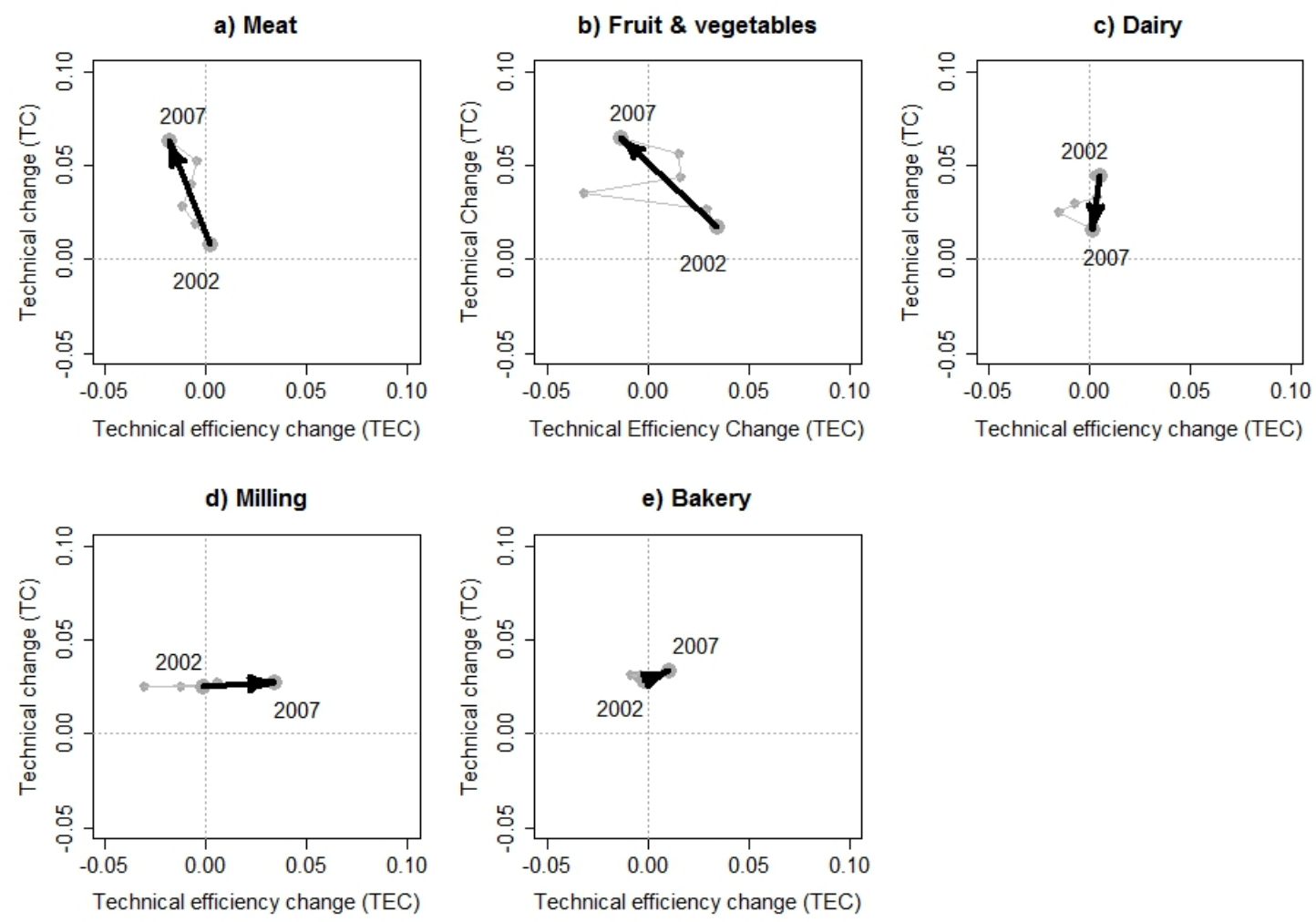

Source: Author’s own calculation

The results in Figure 3-2a show that the meat sector has experienced a significant TC from almost no TC at the beginning of the period to $6 \%$ through to the period end. The adoption of new technologies has contributed to increasing output (the average output per firm grew $33 \%$ over the period) and taking advantage of economies of scale (this sector has the highest share of firms operating with increasing RTS.) However, the development of TEC displays a negative trend, indicating that - on average - $\mathrm{TE}^{\mathrm{G}}$ levels have decreased over time. This suggests that some firms are pushing out the frontier by acquiring more productive technologies, while others remain stagnant. Thus, the distance between stagnant firms and the advancing frontier becomes wider over time. Hadley (2006) and Jin et al. (2010) find similar results. The flattening out of the $\mathrm{TE}^{\mathrm{G}}$ distribution through time also supports this result.

\footnotetext{
${ }^{12}$ See also Figure A 3 and Figure A 4 in the Appendix for TE and TC development in levels.
} 
Fruit \& vegetables firms exhibited significant technical progress; the average rate of TC went from $1 \%$ in 2001 to $7 \%$ in 2007 (see Fig. 2b). The TC was mainly driven by small and medium firms, while large firms experience zero or even negative technological progress ${ }^{13}$. According to ODEPA (2012), firms which make the largest contribution to the aggregate output (canned and dehydrated producers) have technology that is older than ten years, while olive oil firms have very recent technology (less than five years). Furthermore, the largest firms operate with diseconomies of scale, which can be related to the seasonality of production as discussed in the previous section. The fruit \& vegetables sector also displays a negative TEC over the period mentioned above, corresponding to the accelerated upward shift of the production frontier. All things considered, the moderate performance of the fruit \& vegetables sector $\left(\mathrm{TE}^{*}\right)$ is caused by a decrease in the efficiency levels and the largest firms show poor TC and low MTR. Finally, the results demonstrate that small and medium firms in the sector have developed dynamically, whereas large operators require improvements in efficiency management and technology.

Dairy firms exhibit technological progress at a slightly decreasing rate, changing from $5 \%$ to $2 \%$ between 2001 and 2007 (Fig. 2c). The results also reveal that TC decreases as firm size increases, indicating that the main drivers of TC are small and medium firms. These firms are mainly non-exporters and exhibit an average TC of $5 \%$ per year, whereas the largest firms (exporters) have no technological progress. This is because the largest dairy firms underwent significant technological improvements before the observed period, during the 1990s, after dairy multinationals (Nestlé, Fonterra and Parmalat) entered the Chilean market (Torrealba, 1999). Consequently, the results show that small and medium dairy processors are forced to improve their technologies to remain competitive in the market.

The results indicate that the TC development in the milling sector is more stable in comparison to the previously mentioned sectors, about $2 \%$ annually (Fig. 2d). Interestingly, in this sector the TEC shows a positive shift from $-2 \%$ to $3 \%$ within the period analyzed, which suggests that a constant and stable technological progress allows firms to focus on improving the efficiency. Milling firms also have higher MTR than their counterparts in the dairy and fruit \& vegetables sectors. Consequently, the simple and standardized production technology in the milling sector leaves little room for large

\footnotetext{
${ }^{13}$ Figure A 5 and Figure A 6 in the Appendix provides information on the TC and MTR with respect to firm size.
} 
differences in the individual technical inefficiencies.

Bakery firms show a continuous and stable TC of $3 \%$ per year, whereas TEC exhibits a modest development from $-5 \%$ to $1 \%$ over the study period (Fig. 2e). The bakery sector is highly fragmented, with a large number of buyers and sellers, and thus produces a tight market. This explains the efficient management of the current technology $\left(\mathrm{TE}^{\mathrm{G}}\right)$ by most firms, which finally contributes to a high TE* average. The sector performance is also influenced by the share of firms operating at increasing RTS. These findings indicate that the competitive market structure has contributed to the development and overall performance of the sector.

\subsubsection{Performance of exporting sectors and firms}

In this section we focus on the sectors with the highest share of exporting firms: fruit \& vegetables, meat, and dairy. We present and discuss descriptive statistics on exporting firms and then compare the development of TE between exporting and non-exporting firms.

Table 3-8 Share of exports and output of the largest firms.

\begin{tabular}{lccccc}
\hline Sector & $\begin{array}{c}\text { Export share of } \\
\text { the four largest } \\
\text { firms (\%) }\end{array}$ & $\begin{array}{c}\text { Output share of } \\
\text { the four largest } \\
\text { firms in the } \\
\text { sector (\%) }\end{array}$ & $\begin{array}{c}\text { Average share of } \\
\text { exports in firm's } \\
\text { total output (\%) }\end{array}$ & $\begin{array}{c}\text { Average output } \\
\text { (CLP\$ 10 Mio.) }\end{array}$ \\
\cline { 5 - 6 } $\begin{array}{l}\text { Meat } \\
\text { Fruit \& }\end{array}$ & 84 & 36 & 18 & 3,070 & $\begin{array}{c}\text { Non- } \\
\text { exporters }\end{array}$ \\
vegetables & 67 & 45 & 54 & 882 & 374 \\
Dairy & 95 & 83 & 1 & 5,610 & 572 \\
\hline
\end{tabular}

Source: Author's own calculation

The data in Table 3-8 confirm that exports are dominated by a small number of firms. Concentration is high in the dairy sector, where the four largest firms export $95 \%$ of the aggregate exports and $83 \%$ of the sectoral output. In comparison, the meat and fruit \& vegetables sectors exhibit a moderate concentration of exports and domestic sales. Empirical studies of firm heterogeneity and trade also point out that exporters often only export a small share of their output (Bernard et al., 2007). In the Chilean agribusiness, this is valid for the dairy and meat sectors. Nevertheless, fruit \& vegetable firms export, on average, $54 \%$ of their output. The last column in Table 3-8 also confirms previous findings that exporters tend to be larger than non-exporters.

Figure 3-3 presents the development of technical efficiency in exporting and nonexporting firms within the observed period of study. 
Figure 3-3 $\mathrm{TE}^{\mathrm{G}}$ development for exporting and non-exporting firms in the Chilean agribusiness, 2001-2007.

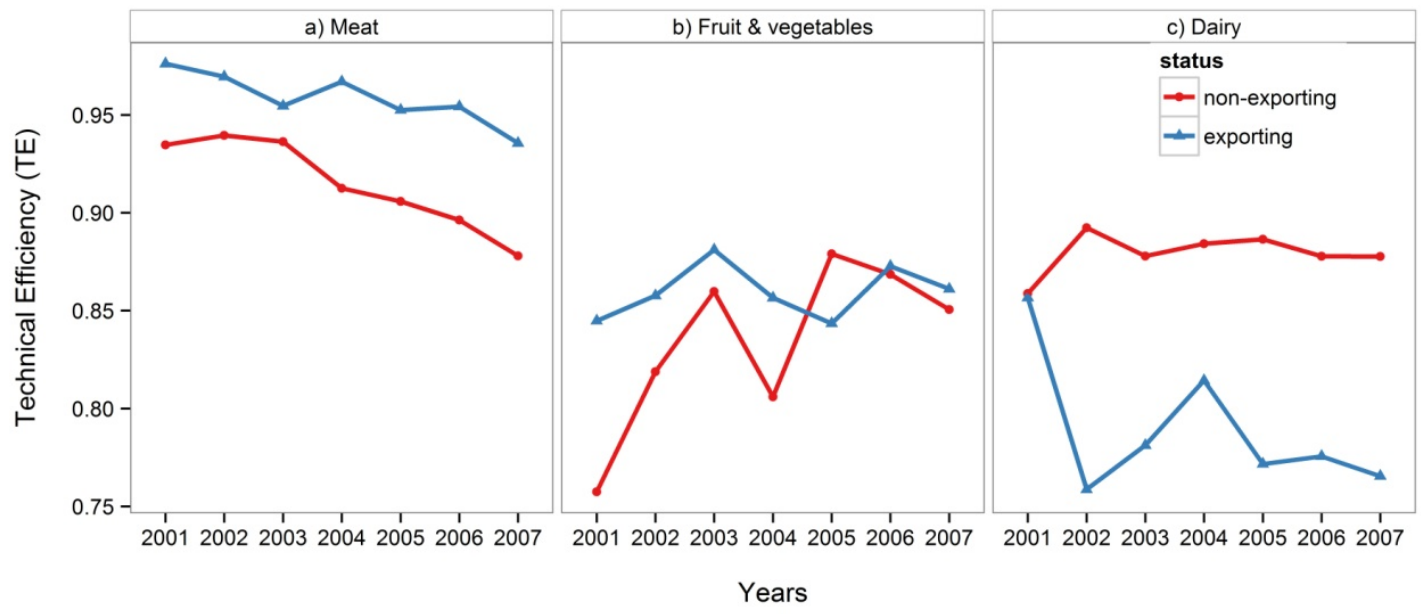

Source: Author's own calculation

The results show substantial differences with respect to technical efficiency between exporting and non-exporting firms.

a) In the meat sector, exporting firms exhibit consistently higher $\mathrm{TE}^{\mathrm{G}}$ levels in comparison to non-exporting firms. This corresponds with the recent export orientation of the sector and the exposure to international competition. At regional and international markets, Chile competes with its neighboring countries: Brazil, Argentina, and Uruguay, which are among the world's largest meat exporters. These results are consistent with Melitz's approach (2003) which states that the most productive firms are more likely to export.

b) Similarly, in the fruit \& vegetables sector, exporting firms have higher efficiency levels from the beginning of the observed period until 2004. However, in 2005 the non-exporting firms catch-up to the exporters and by the end of the period under scrutiny, both groups exhibit the same level of efficiency. This catching-up effect also reveals the 'technological spill-over' effect stemming from the export oriented firms, as previously observed by Fleming and Abler (2013) in Chilean agriculture.

c) The results of the dairy sector are unexpected; the level of $\mathrm{TE}^{\mathrm{G}}$ is the same at the beginning of the period for exporting and non-exporting firms when Chile was still a net importer of dairy products. After 2002, exporting firms show lower $\mathrm{TE}^{\mathrm{G}}$ levels than their counterparts, creating a constant gap between the groups. The average efficiency level of the four largest firms is 0.75 whereas the remaining firms average 0.88 . The heteroscedasticity model supports this 
finding and shows decreases in technical efficiency for firms with large capital endowment and fiscal incentives for exporting (see Table 3-5). These results are not consistent with Meltiz's approach. In this case, it appears that large dairy exporters are taking advantage of their market power. Fahlbusch (2014) reports that the New Zealander multinational, Fonterra, has a moderate degree of market power in most export destinations and is able to charge an optimal mark-up of about $8 \%$ of the price. Finally, the results reveal that the benefits from exporting have not yet been transferred to non-exporting firms because of the market structure of the dairy sector.

\subsection{Conclusions}

The agribusiness industry is one of the most important sectors in Chile. However, studies on efficiency and analysis on a disaggregated level are scarce. In this study, we make use of firm panel data to analyze their technical efficiency and determine which sectors use resources efficiently and the impact of international trade therein. We use the Metafrontier approach to compare the technical efficiency between sectors and determine different potential sources of inefficiency. Based on our knowledge, there has been no previous investigation at this level of disaggregation using MF. We find several important results that are relevant for the Chilean agribusiness.

In general, the results support theoretical models, suggesting that the heterogeneity in structure and production characteristics defines sectoral performance and the magnitude of effects of exposure to international trade. The results also reveal that an average performance measurement for the whole Chilean agribusiness industry can be misleading since the performance, structure, and development differ among the sectors. Exporting sectors show a more dynamic development with respect to technical change and technical efficiency, for instance, the meat sector has been the most efficient coinciding with its recent export orientation. Technological change in this sector was the highest among all five sectors, which also brought advantages in the exploitation of economies of scale. The results of the fruit \& vegetables sector show that large companies being less efficient and innovative hampers the productivity of this sector. Nevertheless, small and medium non-exporting firms improve the average performance of the sector catching up on the efficiency levels of their counterparts. Furthermore, we find strong evidence that the structure of the dairy sector prevents the transfer of the benefits of international trade to non-exporting firms. The milling and bakery sectors 
have more stable technological progress than the previously mentioned sectors; however, they can still achieve the same level of efficiency as the exporting sectors due to strong competition in the domestic market.

The results of the overall industry reveal that the sectors are efficient with respect to the technologies they currently use. However, if they were to further improve their technologies, significant gains in efficiency could be made. The Chilean agribusiness firms, except for fruit \& vegetable firms, operate at suboptimal size; this implies that they can further exploit economies of scale. Furthermore, the sectors exposed to international trade achieve higher rates of technological progress than those that trade mostly domestically. We find evidence that exposure to international trade contributes to a better utilization of current technologies if firms operate under strong competition. Finally, imperfect competition within a given sector creates efficiency losses even if international trade is occurring. Finally, if Chile wants to position itself on the global market as a food power, it should further develop competitive advantages in its agribusiness industry and improve current technologies.

We acknowledge that the economic development of Chile (especially its copperindustry) and the development of the Chilean Peso certainly affect the competitiveness of the agribusiness sector, especially for the export-oriented sectors. However, the time horizon of this data set is too short to create strong evidence on the interaction of firm efficiency and the Peso-US Dollar exchange rates. Further research on this topic will require a longer study period to analyze these potential effects. 


\section{References}

Aigner, D., Lovell, C.A.K. \& Schmidt, P. (1977). Formulation and Estimation of Stochastic Frontier Function Analysis Models. Journal of Econometrics, 6, 21-37.

Balassa, B. (1965). Trade Liberalisation and "Revealed” Comparative Advantage, The Manchester School, 33 (2), 99-123.

Battese, G.E., Rao, D.S.P. \& O’Donnell, C.J. (2004). A Metafrontier Production Function for Estimation of Technical Efficiencies and Technology Gaps for Firms Operating Under Different Technologies, Journal of Productivity Analysis, 21, 91103.

Bernard, A. \& Jensen B. (1995). Exporters, Jobs, and Wages in U.S. Manufacturing: 1976-87. Brookings Papers on Economic Activity: Microeconomics, 1995, 67112.

Bernard, A., Jensen, B., Redding, S. \& Schott, P. (2007). Firms in International Trade, Journal of Economic Perspectives, 21(3), 105-130.

Brümmer, B. (2001). Stochastic Frontier Analysis using SFAMB for Ox, Manual at the Institute for Agricultural Economics, Christian-Albrechts-University, Kiel, Germany.

Brümmer, B. (2010). Foundations of Stochastic Frontier Analysis. Unpublished Manuscript form the PhD-Course 'Efficiency Analysis - stochastic approach', March 15-19, 2010, Georg-August University Göttingen.

Caudill, S.B., Ford, J.M. \& Gropper, D.M. (1995). Frontier Estimation and Firmspecific Inefficiencies measures in the presence of Heteroscedasticity. Journal of Business \& Economic Statistics, 13 (1), 105-111.

Chaaban, J., Réquillart, V., \& Trévisiol, A. (2005): The Role of Technical Efficiency in Takeovers: Evidence from the French Cheese Industry, 1985-2000; Agribusiness, $21(4), 545-564$.

Chilealimentos (2013). Exportaciones Alimentos Elaborados 1990-2012. Santiago: Chilealimentos. Retrieved from: http://www.chilealimentos.com/2013/phocadownload/Estadisticas/exportacion\%20 1981\%20a\%202013\%20version\%20final.pdf

Chilean Central Bank. (2014). Bases de datos estadisticos. Retrieved from: http://si3.bcentral.cl/Siete/secure/cuadros/home.aspx 
Ciuriak, D., Lapham, B., Wolfe, R., Collins-Williams, T. \& Curtis, J. (2014), Firms in International Trade: Trade Policy Implications of the New New Trade Theory. Global Policy. doi: 10.1111/1758-5899.12183

Coelli, T.J., Rao, D.S.P., O’Donnell, C.J., \& Battese G.E. (2005). An Introduction to Efficiency and Productivity Analysis (2.E.), Springer, New York.

Diaz, M.A., \& Sanchez, R. (2008). Firm size and productivity in Spain: a stochastic frontier analysis, Small Business Economics, 30 (3), 315-323.

Diewert, W.E. (2003). Measuring Capital, Working Paper 9526 des National Bureau of Economic Research (NBER), Cambridge, Retrieved from: http://www.nber.org/papers/w9526

Dijkstra, A. (2000). Trade Liberalisation and Industrial Development in Latin America. World Development, 28 (9), 1567-1582.

Fahlbusch, M. (2014). Price Formation and the Measurement of Market Power on the International Dairy Markets, Dissertation at the Agricultural Faculty, Georg-August University Göttingen, Retrieved from: http://hdl.handle.net/11858/00-1735-00000022-5E42-C

Fleming, D.A., \& Abler, D.G. (2013). Does agricultural trade affect productivity? Evidence from Chilean farms, Food Policy, 41, 11-17 (http://dx.doi.org/10.1016/j.foodpol.2013.04.004)

Fundacion Chile (2005). Una vision para el sector triguero en Chile. Santiago de Chile. Retrieved from: http://www.odepa.cl/odepaweb/serviciosinformacion/publica/VisionTrigoFunChile.pdf

Fundacion Chile (2007). Estudio de Competitividad para la Industria de la Panadería tradicional Chilena: Diseño, Difusión y Transferencia de un Plan de Reducción de Brecha Competitivar Retrieved from: http://www.fechipan.cl/pdf/estudio_Diagnostico_Competitividad.pdf

Greene, W.H. (2008). Econometric Analysis (6.A), Pearson, Prentice Hall, New Jersey, USA.

Hadley, D. (2006). Patterns in Technical Efficiency and Technical Change at the Farmlevel in England and Wales, 1982-2002. Journal of Agricultural Economics, 57, 81-100.

INE (Instituto Nacional de Estadisticas) (2007). Antecedentes metódologicos de la Encuesta Naciona Industrial Anual (ENIA). Santiago, Chile. 
Jin, S. Q., Ma, H. Y., Huang, J. K., Hu, R. F. \& Rozelle S. (2010). Productivity, efficiency and technical change: measuring the performance of China's transforming agriculture. Journal of Productivity Analysis, 33 (3), 191-207.

Jorgenson, D.W. (1989). Capital as a Factor of Production, pp. 1-35 in Technology and Capital Formation, D.W. Jorgenson and R. Landau (eds.), Cambridge MA: The MIT Press.

Kodde, D. A., \& Palm F. C. (1986). Wald Criteria for Jointly Testing Equality and Inequality Restrictions, Econometrica, 54, 1243-1248.

Kumbhakar, S.C., Amundsveen, R., Kvile, H.M., \& Lien, G. (2014). Scale economies, technical change and efficiency in Norwegian electricity distribution, 1998-2010, Journal of Productivity Analysis, online published in Dec. 2014, doi: 10.1007/s11123-014-0427-6.

Lundvall, K., \& Battese, G.E. (2000). Firm Size, Age and Efficiency: Evidence from Kenyan Manufacturing Firms, The Journal of Development Studies, 36 (3), 146163.

Meeusen, W., \& van den Broeck, J. (1977). Efficiency Estimation from Cobb-Douglas. International Economics Review, 18 (2), 435-444.

Melitz, M.J., (2003). The Impact of Trade on Intra-Industry Reallocations and Aggregate Industry Productivity. Econometrica, 71, 1695-1725.

O’Donnell, C.J., Rao, D.S.P., \& Battese, G.E. (2008). Metafrontier Frameworks for the study of firm level efficiencies and technology ratios. Empirical Economics, 34, 231-255.

ODEPA (Oficina de Estudios y Politicas Agrarias) (2009). Situación del sector lechero y perspectivas. Boletin Mercados Agropecuarios Nr. 208. Santiago de Chile.

ODEPA (2011). Identificación y análisis de las fortalezas y restricciones del crecimiento agroalimentario chileno al año 2017. Santiago, Chile.

ODEPA (2012). Actualizacion del catastro de la agroindustria hortofrutícola chilena. Santiago, Chile.

ODEPA (2014a). Balanza comercial de productos silvoagropecuarios. Retrieved from: http://www.odepa.cl/balanza-comercial-de-productos-silvoagropecuarios/

ODEPA (2014b). Avance por grupo de productos. Retrieved from: http://www.odepa.cl/avance-por-grupos-de-productos/ 
OECD (2010). Trade and Agriculture Directorate: Benefits of Trade Liberalization, document from Organization of Economic Co-operating and Development (OECD), Retrieved from: http://www.oecd.org/about/0,3347,en_2649_36442957_1_1_1_1_1,00.html

Ollinger, M. E., MacDonald, J. M., \& Madison, M. (2005). Technological Change and Economies of Scale in U.S. Poultry Processing. American Journal of Agricultural Economics, 87 (1), 116-129.

Pavcnik, N. (2002). Trade Liberalization, Exit, and Produtivity Improvements: Evidence from Chilean Plants. The Review of Economic Studies Limited, 69, 245276

Rodrik, D. (1995). Trade and industrial policy reform. In: J. Behrman and T.N. Srinivasan (Eds), Handbook of development economics, vol. 3 B, 2925-2982.

Roudaut, N. (2006). Influences of the business environment on manufacturing firms technical efficiencies: the Côte d'Ivoire case, Journal of Productivity Analysis, 25 (1-2), 93-109.

Schmidt, P. \& Sickles, R.C. (1984). Production frontiers and panel data. Journal of Business and Economic Statistics, 2, 367-374.

Setiawan, M., Emvalomatis, G., \& Oude Lansink, A. (2012). The relationship between technical efficiency and industrial concentration: Evidence from the Indonesian food and beverages industry, Journal of Asian Economics, 23 (4), 466-475

Singh, S., Coelli, T.J., \& Fleming, E. (2001). Performance of Dairy Plants in the Cooperative and Private Sectors in India, Annals of Public and Cooperative Economics, 72 (4), 453-479.

Torrealba, F. (1999). La inversion en el sector agroindustrial chileno. Serie Reformas Económicas 46, ECLAC, Santiago, Chile.

Tybout, J.R., J. de Melo \& V. Corbo. (1991). The effects of trade reforms on scale and technical efficiency: New evidence from Chile, Journal of International Economics, 31, 231-250.

United Nations. (2002). International Standard Industrial Classification of All Economic Activities. Series M, Nr. 4, Rev. 3.1, New York

Wang, H.-J., \& Schmidt, P. (2002). One-Step and Two-Step Estimation of the Effects of Exogenous Variables on Technical Efficiency Levels. Journal of Productivity Analysis, 18, 129-144. 
Technical efficiency in the Chilean agribusiness - a Stochastic Metafrontier Approach

Worldbank (2014). World Development Indicators, Retrieved from: http://wdi.worldbank.org/table/6.1 


\section{Appendix}

Figure A 1 Distribution of technical efficiency $\left(\mathrm{TE}^{\mathrm{G}}\right)$ scores by sector for 2001, 2004 and 2007.

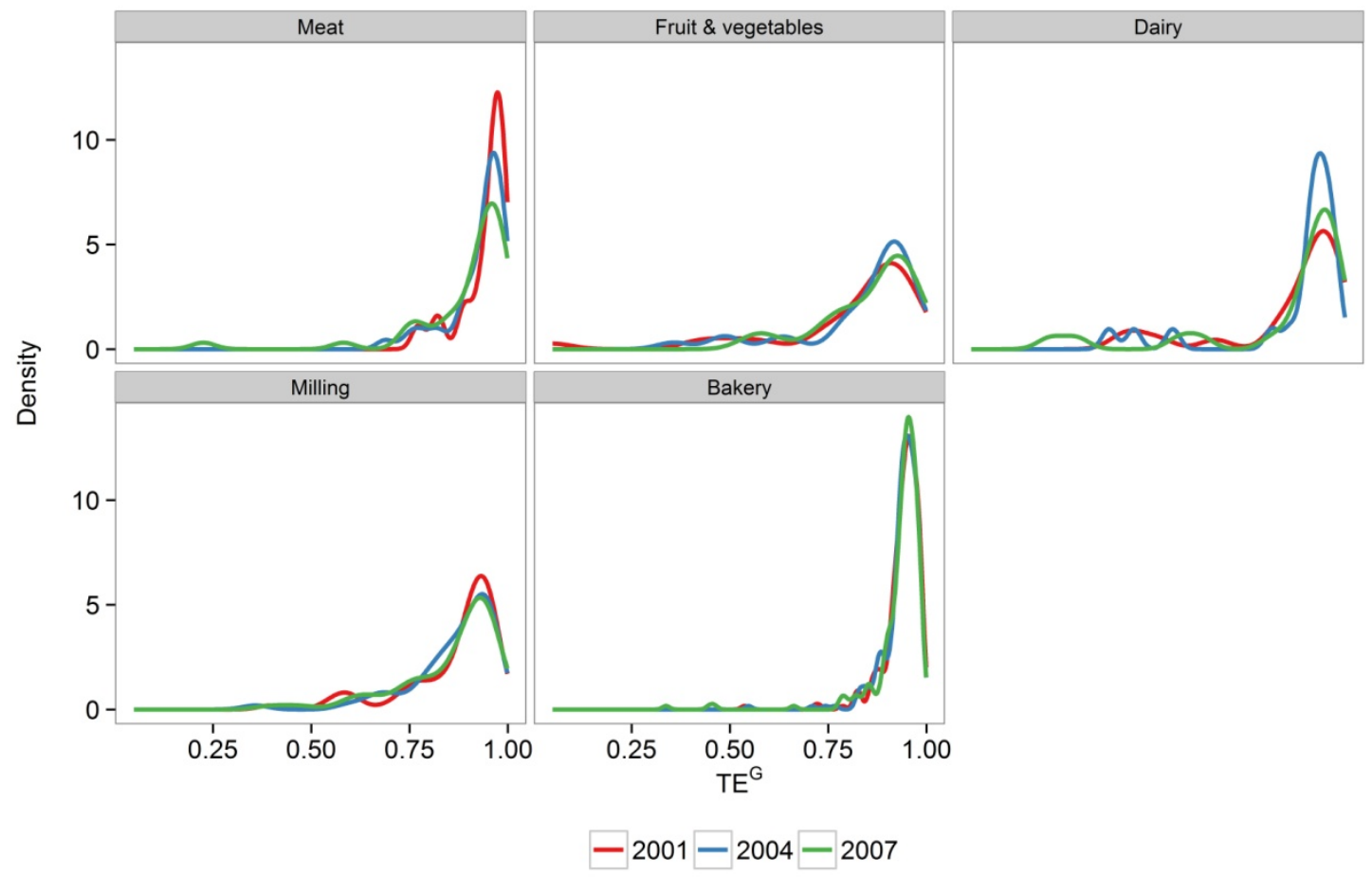

Source: Author’s own calculations

Figure A 2 Distribution of the meta-technology ratio (MTR) scores by sector for 2001, 2004 and 2007.
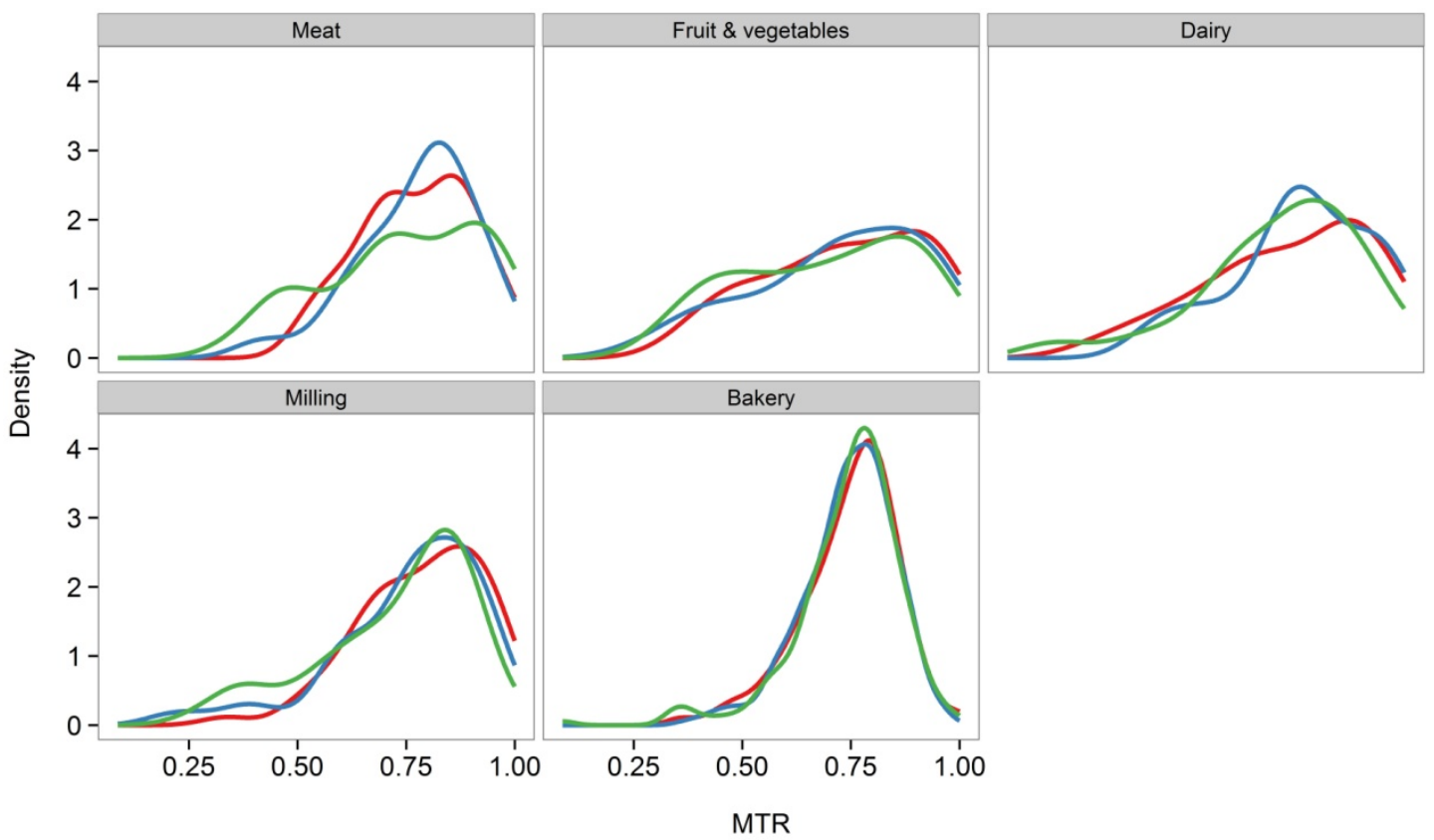

$-2001-2004-2007$

Source: Author's own calculations 
Technical efficiency in the Chilean agribusiness - a Stochastic Metafrontier Approach

Table A 3 Bonferroni test for TE* pairwise mean comparison.

\begin{tabular}{|c|c|c|c|c|}
\hline & Meat & Fruit \& vegetables & Dairy & Milling \\
\hline \multicolumn{5}{|c|}{ Mean differences, $p$-value in italics } \\
\hline \multirow[t]{2}{*}{ Fruit \& vegetables } & -0.10 & & & \\
\hline & 0.00 & & & \\
\hline \multirow[t]{2}{*}{ Dairy } & -0.08 & 0.02 & & \\
\hline & 0.00 & 1.00 & & \\
\hline \multirow[t]{2}{*}{ Milling } & -0.06 & 0.04 & 0.02 & \\
\hline & 0.00 & 0.00 & 1.00 & \\
\hline \multirow[t]{2}{*}{ Bakery } & -0.01 & 0.09 & 0.07 & 0.05 \\
\hline & 1.00 & 0.00 & 0.00 & 0.00 \\
\hline
\end{tabular}

$\mathrm{H}_{0}$ : means between groups are equal.

Bartlett's test for equal variances among all groups: $\chi^{2}=376.95 p$-value: 0.00

Source: Author's own calculations 
Figure A 3 Average $\mathrm{TE}^{\mathrm{G}}$ by sector in the Chilean agribusiness 2001-2007.

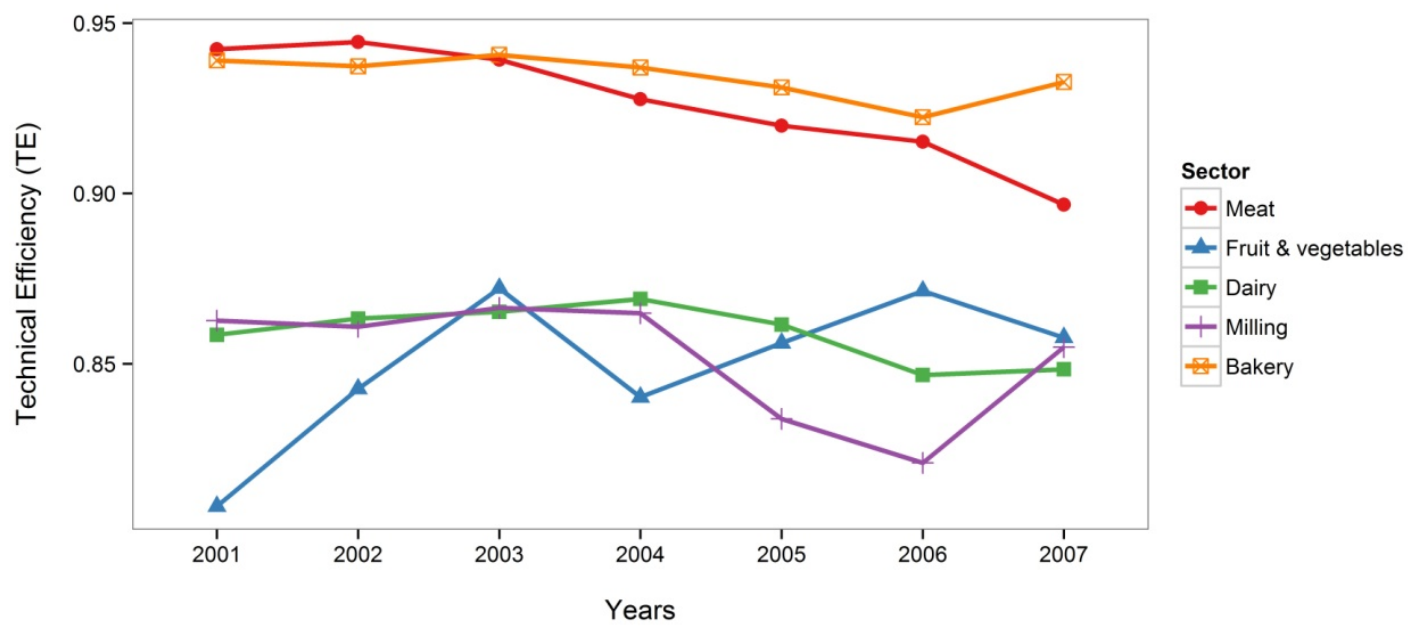

Source: Author’s own calculations

Figure A 4 Average TC by sector in the Chilean agribusiness 2001-2007.

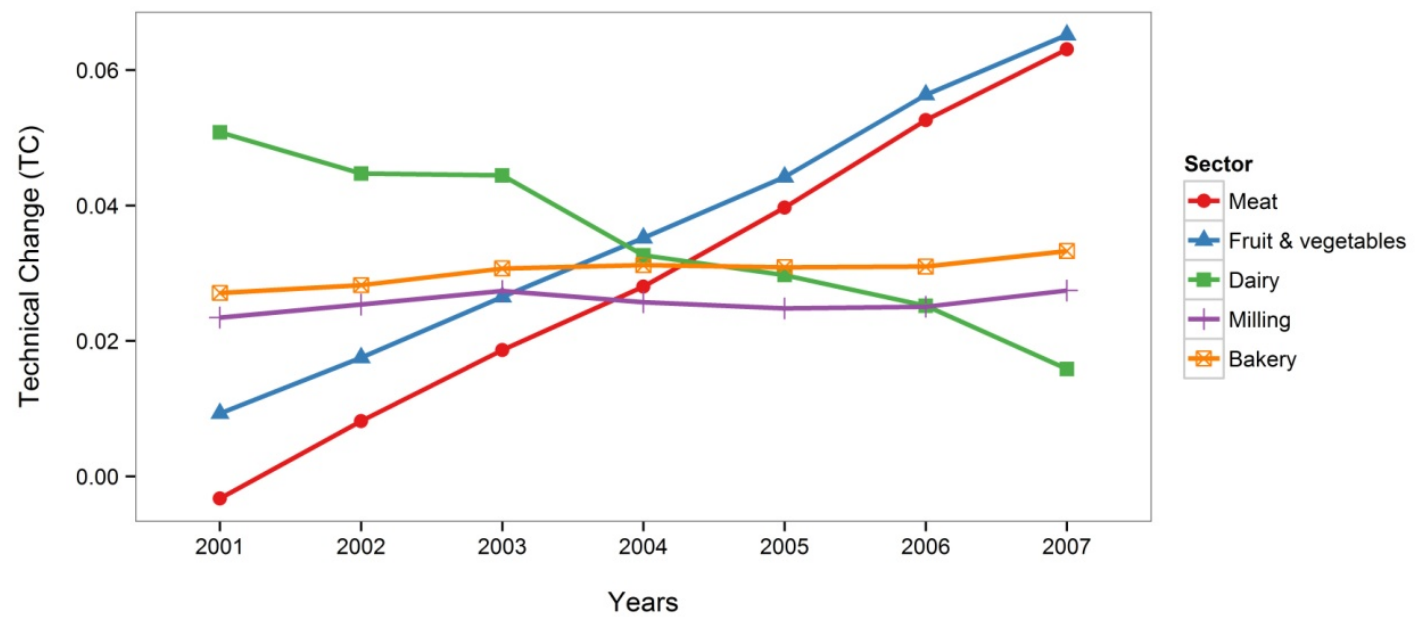

Source: Author's own calculations 
Figure A 5 TC with respect to firm size in the Chilean agribusiness.

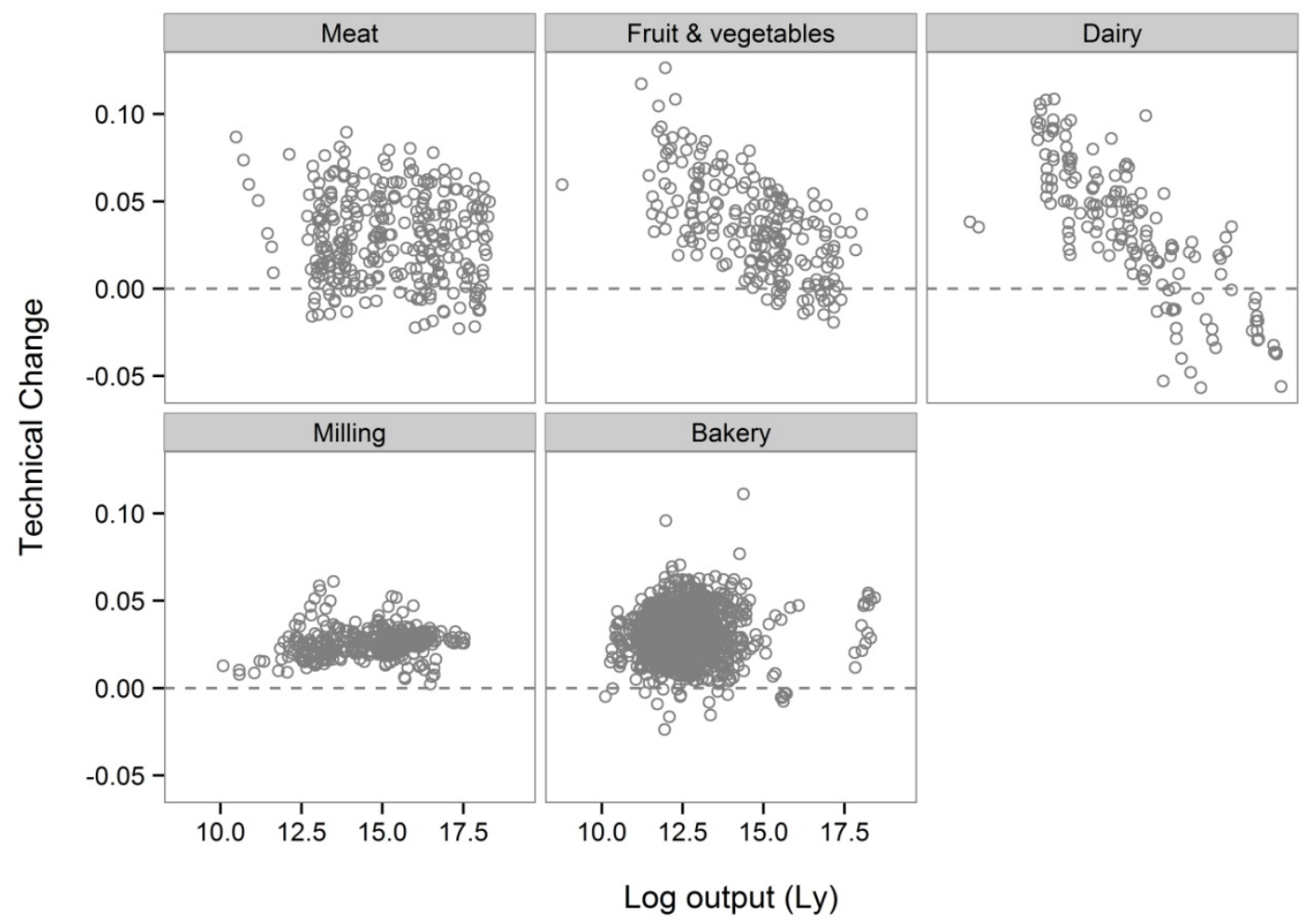

Source: Author's own calculations

Figure A 6 MTR with respect to firm size in the Chilean agribusiness.

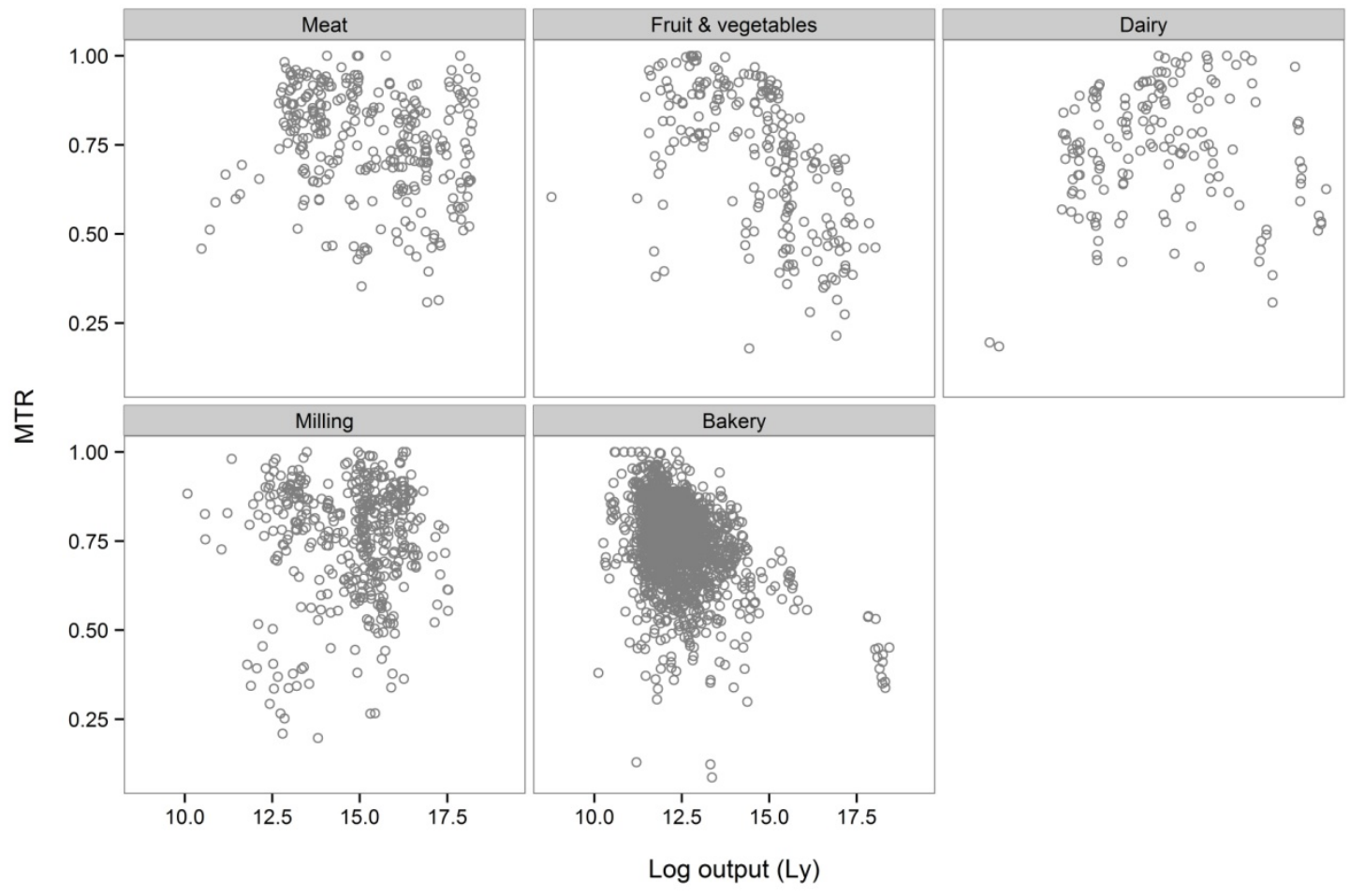

Source: Author's own calculations 


\title{
4. Testing the effect of firm performance on growth for the Chilean agribusiness
}

\begin{abstract}
Previous studies of the industrial organization field find that the relationship between firm performance and growth is weak. The objective of this paper is to test this relationship at different points of the distribution of firm growth. We also explore the impact of technology gaps and export status on growth. For this, we use Penalized Quantile Regression with Fixed Effects on a panel data of 420 Chilean agribusiness firms. Key results show that firm performance, measured as technical efficiency, has a significant and heterogeneous impact on firm growth, and that the effect is stronger on slow growing firms. Participation in international trade further increases even more positive growth rates. Hence, it then becomes relevant for researchers in the industrial organization field to use indicators for firm performance which capture the entirety of the production process. Furthermore, the non-linearity of the relationship between performance and growth should be considered in future research when analyzing this relationship.
\end{abstract}




\subsection{Introduction}

Different theoretical perspectives identify the individual features of fitness, efficiency, or productivity of firms as being determinant on explaining structural change, economic growth, and international trade (Nelson and Winter, 1982; Jovanovic, 1982; Melitz, 2003). Broadly, these theories suggest that these individual features enable firms to outperform their peers and determine their development over time. The economic benefits at the aggregated level arise from the mechanism of reshuffling resources within and between firms. Additionally, there is ample evidence that exposure to international trade speeds up this reallocation process, and thus increases the dynamics in an industry (see the reviews in Rodrik, 1995 and Ciuriak et al., 2014).

Industrial organization studies use diverse measures of firm performance to incorporate it as a determinant for firm growth. The most common measure is financial performance. This surges from the hypothesis that under imperfect capital markets, higher financial performance increases the probability that a firm will survive and also expand operations. Empirical studies have used the firm's market value or Tobin's q ratio as an indicator (Lang and Stulz, 1993; Wernetfelt and Montgomery, 1988), as well as cash flow (Oliveira and Fortunato, 2006; Fagiolo and Luzzi, 2006; Guariglia et al., 2011) and profitability (Coad, 2007; Geroski et al., 1997; Goddard et al., 2002). Recent studies have focused on estimating the effect of labor productivity, as a proxy for firm performance, on firm growth. For instance, Heshmati (2001) analyzes the effect of labor productivity on employment and asset growth of Swedish firms. He finds that the magnitude of the effect is, although statistically significant, negative and rather small: 0.0001 for both estimations. Gardebroek et al. (2010) find evidence that a $1 \%$ increase in labor productivity barely leads to $0.11 \%$ growth in assets and $0.29 \%$ growth in labor force for dairy processing firms in Europe. Similarly, Bottazzi et al. (2010) measure the effect of labor productivity on sales growth in Italian and French manufacturing firms. They find a statistically significant effect, but the magnitude of the effect is small, i.e.: $0.23 \%$ for the meat and $0.2 \%$ for the dairy sector. Based on the previous results, Bottazzi et al. (2010) conclude that the relationship between firm performance and growth is "actually very weak".

This study proposes technical efficiency (TE) as an alternative indicator of firm performance. Technical efficiency measures the ratio of observed output to the maximum feasible output from a given set of inputs and a specific technology (Kumbhakar and Lovell, 2000). Thus, TE reveals the performance of individual firms 
relative to their peers (competitors) in the sector. This is crucial because in the praxis, firms compare their business and practices against their competitors to gain market shares; particularly against those firms operating close to the production frontier or "the best performers”. If a firm is not technically efficient, TE provides a measure of the shortfall of the observed output from the maximum feasible output in the sector and the potential causes for this shortfall (Kumbhakar and Lovell, 2000). When TE is estimated using Stochastic Frontier Analysis (SFA), this shortfall can be decomposed into technical inefficiency and statistical error. We use this approach to estimate TE as a measure for firm performance and hypothesize that it has a positive effect on firm growth.

Differences in the performance of firms also arise from differences in the firms' production environment. Firms within the same industry may face different production opportunities with respect to the settings of the physical, social, or economic environment in which their production occurs (O’Donnell et al., 2008). The conventional measures of technical efficiency do not capture these effects. Battese et al. (2004) and O’Donnell et al. (2008) developed the Metafrontier framework to estimate the technology gaps for producers under different technology sets. This provides a measure of the shortfall between the observed outputs for producers under different technologies relative to the potential output defined by the industry as a whole. Furthermore, it provides a decomposition of this shortfall into group specific technical efficiency and technology gaps. We assume that shortening the technology gaps with respect to the maximum output in the industry would indicate that firms are improving their technology relative to their peers. This may contribute to an increase in output ${ }^{14}$, and presumably increased revenue.

Additionally, we consider the effect of export status on revenue growth. Exporters tend to be larger, more productive firms, paying higher wages with more skilled workers than firms only producing for the domestic market (Bernard et al., 2007). These features allow exporters to adjust more rapidly to changing market conditions and cope with intensive competition at the domestic and international level. Moreover, trading in international markets expands the market size in which firms sell their products. This can contribute to an increase in the growth rates of exporters.

Previous studies have focused on determining the effect of the independent variables on the mean of firm growth. However, recent literature has shown that the distribution of

\footnotetext{
${ }^{14}$ Or alternatively, to produce the same output using less input.
} 
firm growth has a leptokurtic shape and heavy-tails, similar to a Laplace distribution, and that this feature holds across most growth indicators (for a review see Coad, 2009). If the firm growth distribution has more observations located at the extreme of the tails than a normal distribution, it seems rather implausible that the covariates have a constant effect over the entire distribution. Furthermore, it is of interest for decision makers to know the effect of firm performance or technology gaps, especially on firms facing negative or low growth rates. In this context, the present study explores whether the effect of the covariates is heterogeneous over the entire distribution of firm growth. To answer this question, we use the Penalized Quantile Regressions with Fixed Effects (PFEQR) for panel data proposed by Koenker (2004), and provide a comparison with the Ordinary Least Square (OLS) and Within Groups (WG) estimations.

We focus our analysis on Chile because it was one of the first Latin American countries to implement a profound process of trade liberalization with an export-oriented strategy. These adjustments combined with its comparative advantage have allowed the agribusiness industry to become the second biggest exporting industry in the country. Nowadays this industry represents $24 \%$ of the Gross Domestic Product (ODEPA, 2011). Furthermore, openness to trade means more competition, higher investment, and productivity growth (Pavcnik, 2002; OECD, 2010). Thus, we expect the agribusiness in Chile to provide the conditions of a very competitive market, where firms are forced to allocate resources efficiently and have low costs to compete for market share. In this study, we center our analysis on the largest sectors within the Chilean agribusiness: meat, fruit \& vegetables, dairy, milling, and bakery. These sectors account for $71 \%$ of total agribusiness firms in 2007 and $46 \%$ of the industry revenue (INE, 2007).

This study aims to improve our understating of the empirical relationship between firm performance and firm growth and whether this relationship is constant across the distribution of growth. In this context, we analyze 420 Chilean agribusiness firms over the period 2001 to 2007 by means of the Penalized Quantile Regressions with Fixed Effects (PFEQR) regression.

This paper is organized as follows. Section 4.2 describes the data and econometric methods. Section 4.3 presents the results of the estimation and provides a comparison with other approaches. Finally, section 4.4 summarizes the results and provides the implications of the findings. 


\subsection{Methods}

To examine the effect of performance and other covariates on firm growth, we use a two-stage estimation. In the first stage, we apply the Metafrontier approach to estimate Technical Efficiency (TE) and the meta-technology ratios (MTR) for each firm. In the second step, we use these estimates to test their effect at different points of the conditional distribution of firm growth using the Penalized Fixed Effects Quantile Regression (PFEQR) proposed by Koenker (2004).

\subsubsection{Estimating technical efficiency (TE) and meta-technology ratio (MTR)}

This section summarizes the method applied to estimate TE and MTR. We use the Metafrontier model within the Stochastic Frontier Analysis (SFA) developed by Battese et al. (2004) and O'Donnell et al. (2008). This approach provides a framework to estimate the deviations between the observed outputs and the group or sector frontiers, and between the observed outputs and the Metafrontier (or industry frontier) as a single data-generating process.

We define a separate stochastic production frontier for each sector as follows:

$y_{i t}=f\left(x_{1 i t}, x_{2 i t}, \ldots x_{K i t} ; \beta^{s}\right) * \exp \left\{v_{i}^{s}-u_{i t}^{s}\right\}$,

where output $y_{i t}$ is the revenue from manufacturing of the $i$-th firm in the $s$-th sector at time $t ; x_{K i t}$ is the $k$-th input $(k=1,2, \ldots, K)$ and a dummy variable for exporting firms. The functional form $f(\cdot)$ is specified as a translog function. $\beta^{s}$ represents a vector of parameters to be estimated, associated with the $s$-th sector. The first error term $v_{i}^{s}$ is defined as a pure random error independently and identically distributed as $N\left(0, \sigma_{v}^{2}\right)$ (Aigner et al., 1977). This term captures random events that are not under the control of the producers.

The second error-term $u_{i t}^{s}$ is a systematic and nonnegative random variable for the $i$-th firm (Schmidt and Sickles, 1984); this error term is used to measure the managerial inefficiency and factors under the firm's control which contribute to the shortfall from the maximum feasible output in the given sector. We assume a half normal distribution for the inefficiency term, $u_{i} \sim N^{+}\left(0, \sigma_{u_{i t}^{s}}\right)$, and allow for heteroscedasticity of the inefficiency term by modelling $\sigma_{u_{i t}^{s}}=\exp \left(z_{j i t} \rho_{j}\right)$ as in Wang and Schmidt (2002). The $\mathrm{Z}$ vector comprises the $j$-th variables, such as the inputs and other potential drivers of technical efficiency. Details on the variables used to model the inefficiency term are presented in Chapter 3, Section 3.4 of this thesis. 
The output oriented measure of TE for any individual $i$-th firm with respect to the sector frontier is given by:

$T E_{i t}^{S}=\frac{q_{i t}}{q_{i t}^{\text {max }}}=\frac{f\left(x_{i t} ; \beta^{S}\right) \exp \left(v_{i t}-u_{i t}\right)}{f\left(x_{i t} ; \beta^{S}\right) \exp \left(v_{i t}^{S}\right)}=\exp \left(-u_{i t}^{S}\right) \in[0,1]$

TE takes values between zero and one. A firm achieves its maximum feasible output only if $\mathrm{TE}=1$. If $\mathrm{TE}<1$, it provides a measure of the shortfall of the observed output to the maximum feasible output in that sector.

The MTR estimation is based on the Metafrontier approach proposed by Battese et al. (2004) and O'Donnell et al. (2008). The Metafrontier is a function that envelops the five sector frontiers: meat, fruit \& vegetables, dairy, milling, and bakery. This enables the estimation of the gap between the individual sector frontiers and the Metafrontier, described by the meta-technology ratio (MTR):

$M T R_{i t}=\frac{\exp ^{x_{i t} \beta^{s}}}{\exp ^{x_{i t} \beta^{*}}}$

The MTR is defined as the ratio of output for the $i$-th firm in the $s$-th sector relative to the potential output defined by the Metafrontier function (Battese et al., 2004). Thus, the MTR is an index which lies between zero and one and reflects the technology gap with respect to the industry.

\subsubsection{Estimating the Penalized Quantile Regression with Fixed Effects (PFEQR)}

In this section we describe the method used to test the effect of the covariates, TE, MTR, and export status on firm growth. Classical linear regression methods enable us to estimate the effect of the covariates by changes in the mean of the response variable distribution. These estimations are based on the assumption that the variance of the error term is the same for all combinations of outcomes of the explanatory variables (Wooldridge, 2002). If this assumption is violated, consistent standard errors can be provided by specific econometric techniques. However, for certain specific cases there is an interest in exploring the effect of the covariates on the location and scale parameters of the response distribution. In this context, the quantile regression model proposed by Koenker and Basset (1978) provides a mechanism to estimate the location and scale effect of the covariates across the entire distribution of the dependent variable, without imposing assumptions on their relationship. For instance, if the variance of the error is non-constant, the conditional quantiles will have different intercepts and slopes. If the variance of the error is constant, the conditional quantiles are parallel lines with 
different intercepts. Thus, this method provides a nuanced analysis of the relationship between the independent and dependent variables. The quantile regression approach has been recently extended for the context of panel data analysis. Koenker (2004) introduces the Penalized Quantile Regression with Fixed Effects (PFEQR) regression, which is employed in the present work.

The model tested in the present study is represented by the following equation:

$Q_{\text {Revenue growth }}\left(\tau \mid x_{i t-1}, \alpha_{i}\right)=x_{i t-1}^{T} \beta(\tau)+T(\tau)+S(\tau)+\alpha_{i}+u_{i t}$

where $\tau_{j}$ is a quantile in $(0,1)$ and $Q_{\text {Revenue } \text { Growth }_{i t}}$ is the conditional quantile of the revenue growth rate from manufactured products for the $i$-th firm at time $t$. The term $x_{i t}$ is a vector of covariates for the $i$-th firm at time $t$ - 1 . These covariates are technical efficiency $\left(T E_{t-1}\right)$, the meta-technology ratio $\left(M T R_{t-1}\right)$, and a dummy variable for exporting (Exp). The lagged structure of equation (4.4) implies that previous levels of TE, MTR, and exporting explain the growth rate of revenue in the next time period. In addition, we include a linear time trend $(T)$ and sector $(S)$ dummies to control for time and sector effects; the base group is the meat sector. The $\beta(\tau)$ parameter allows for testing the effect of each covariate in the specified $(\tau)$ quantile of revenue growth. The term $\alpha_{i}$ captures unobserved heterogeneity that is time-constant and firm specific; for example, proximity to major markets. We follow Koenker (2004) and assume that these individual effects cause a location shift between the conditional quantiles of revenue. The term $u_{i t}$ refers to the idiosyncratic error or time-varying error.

Koenker (2004) proposes to solve equation (4.4) simultaneously for several quantiles by means of linear programming, as follows:

$\min _{\beta, \alpha} \sum_{j=1}^{J} \sum_{t=1}^{T} \sum_{i=1}^{N} \omega_{j} \rho_{\tau, j}\left(y_{i t}-x_{i t-1}^{\prime} \beta-\alpha_{i}\right)+\lambda \operatorname{Pen} \sum_{i=1}^{N}\left|\alpha_{i}\right|$

where $\rho_{\tau j}(u)=u\left(\tau_{j}-I(u<0)\right)$ is the quantile loss function, $\omega_{j}$ is the weight given to the $j$-th quantile and $\lambda$ is the tuning parameter. We follow the standard practice in the quantile regression literature estimating the covariate effects at five quantiles $\tau=$ $\{0.10,0.25,0.50,0.75,0.90\}$; we weighted the quantiles as $\omega=1 / j$. The standard errors are estimated by bootstrapping with 5,000 replications.

The estimation of the individual effect $\alpha_{i}$ markedly increases the variability of the estimates. To solve this, Koenker (2004) proposes the use of a penalty term $\ell_{1}$ to reduce the variability of the estimates, and the tuning parameter $\lambda$ to control the degree of 
shrinkage. Thus as $\lambda \rightarrow \infty$, the impact of the shrinkage penalty grows and the vector of individual effects shrinks towards zero, also decreasing the variability of the estimates. Nevertheless, the selection of $\lambda$ remains unclear; $\lambda$ is arbitrarily chosen. In the next section we explain how we determine the optimal value of the tuning parameter $\lambda$ for our model.

Under i.i.d. error, the coefficients of the PFEQR are vertical shifts of one another with different intercepts. While under non-i.i.d. errors, the quantiles exhibit a location and a scale shift. To test this, we use the modified Breusch-Pagan test, which has an asymptotic $\chi^{2}$ distribution. Its null hypothesis is $\mathrm{H}_{0}: \sigma_{\mathrm{i}}{ }^{2}=\sigma^{2}$. Finally, we also estimate an ordinary least squares regression (OLS) and a Within Groups (WG) regression to compare results. We also test for potential endogeneity of $T E_{t-1}$ and $M T R_{t-1}$ based on the Hausman Test.

\subsubsection{K-fold cross validation}

By means of the k-fold cross validation, we evaluate the performance of the PFEQR method under different values of $\lambda$. This analysis is based on how well the predictions match the observed data for each value of $\lambda$, and the value for which we obtain the minimum error.

For this, we split the sample into ten non-overlapping $k$ - or validation-sets. In parallel, we generate ten training sets which contain the remaining $k-1$ observations. We estimate the model in equation (4.4) for each training set and obtain the quantile regression coefficients. The preceding coefficients are used to make the predictions and we calculate the weighted sum of absolute residuals (WSR) as in equation (4.2) for each observation in the validation sets. The sum of the WSR for the ten validation sets is the so-called cross validation (CV) error:

$$
C V=\frac{1}{k} \sum_{i=1}^{k} W S R
$$

We compute the CV error as in equation (4.6) for values of $\lambda$ from zero to 500 with intervals of 0.1 Figure $4-1$ presents the results for $\lambda$ values from 0.1 to 10 . We can observe that the $\mathrm{CV}$ error decreases as $\lambda$ increases, and then flattens out. The minimum error is obtained when $\lambda=2.2$, indicated in Figure 4-1 with a cross. Therefore, we estimate the model using this result. 


\section{Figure 4-1 Cross validation error corresponding to $\lambda$ values.}

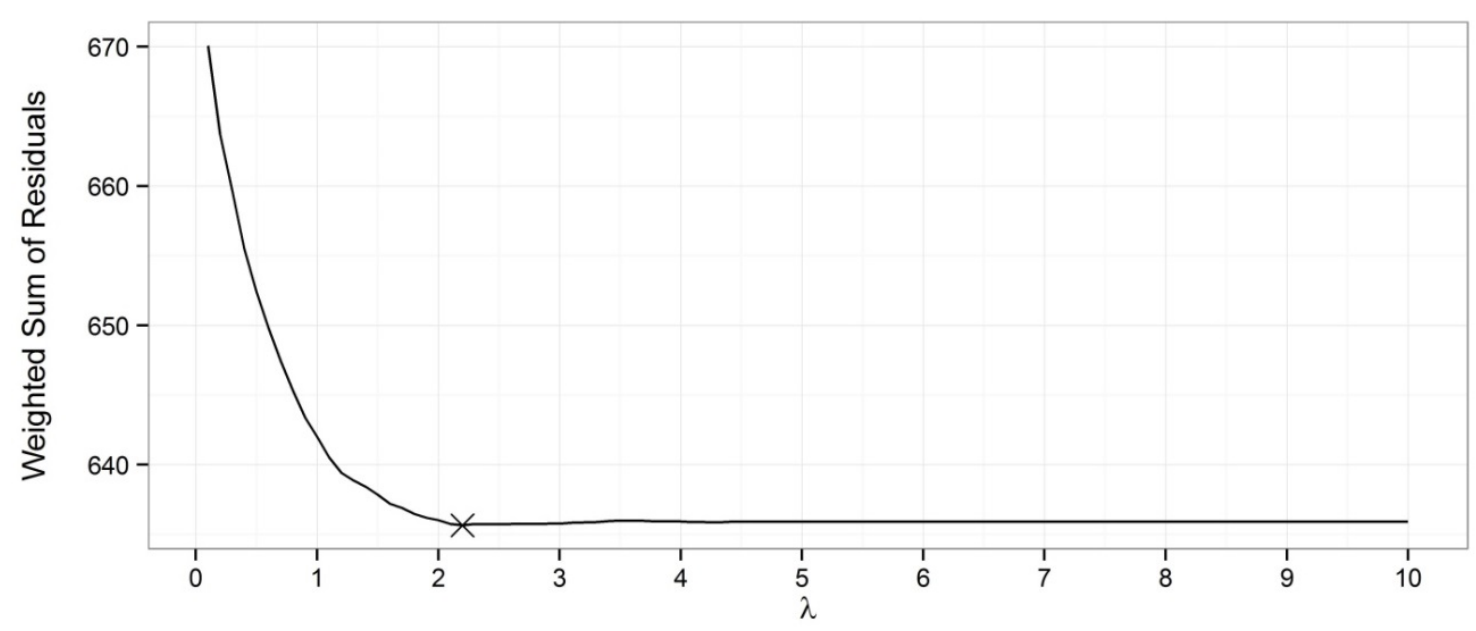

Source: Own elaboration.

\subsection{Data}

We use data from the 'Annual National Industrial Survey (ENIA)', which was conducted between 2001 and 2007 by the National Institute of Statistics in Chile (INE). The ENIA surveys the full population of manufacturing establishments with 10 or more employees (INE, 2007), based on information provided by the Internal Revenue Service. The data set covers the manufacturing of food products (division 15 of the International Standard Industrial Classification (ISIC)). The divisions are defined by the United Nations (2002) based on similarities in (i) produced goods, (ii) the uses to which the goods are put, and (iii) the inputs, the process, and the technology of production. Finally, firms are classified according to the production activity, which accounts for most of the value added. The data set consists of 2,940 observations. However, the structure of the model with lagged covariates causes the loss of one observation for each firm. Consequently, we lose 420 observations and the analysis is based on 2,520 observations. Table 4-1 shows the final structure of data set by sector. 
Table 4-1 Number of observation by sector in the data set.

\begin{tabular}{llll}
\hline ISIC Classes & Observations & Firms & Description of the sectors \\
\hline 1511 & 258 & 43 & Production, processing and preserving of meat and meat products \\
1513 & 186 & 31 & Processing and preserving of fruit \& vegetables \\
1520 & 138 & 23 & Manufacture of dairy products \\
1531 & 372 & 62 & Manufacture of grain mill products \\
1541 & 1,566 & 261 & Manufacture of bakery products \\
\hline & $\mathbf{2 , 5 2 0}$ & $\mathbf{4 2 0}$ & Total \\
\hline
\end{tabular}

Source: Author's own calculation

Descriptive statistics from the sample are presented in Table 4-2. Our dependent variable, revenue growth, is derived from the first difference in the logarithm of revenue. Revenue is measured as sales from manufactured products in Chilean Pesos. The values of this variable were deflated and are in constant prices of the year 2007 . The mean value for revenue growth rate is $2 \%$ per year. However, its standard deviation is remarkably large, $20 \%$. The variables $T E_{t-1}$ and $M T R_{t-1}$ were rescaled so that a score of 100 indicates the maximum feasible technical efficiency and metatechnology ratio, while zero indicates the minimum. The variable $T E_{t-1}$ denotes the individual technical efficiency of each firm relative to its peers within the sector and its mean is 91 . The $M T R_{t-1}$ represents the technology gap between the sectors with respect to the whole industry and has a mean of 75 . The dummy variable for exporting is equal to one if the firm exports and it shows that about $10 \%$ of the firms are exporters. However, most exporters operate in the meat, fruit \& vegetables, and dairy sectors.

Table 4-2 Description of the variables.

\begin{tabular}{lccrr}
\hline \multicolumn{1}{c}{ Variables } & Mean & Min & Max & $\begin{array}{c}\text { Standard } \\
\text { Deviation }\end{array}$ \\
\hline Revenue (CLP\$ 10 Mio.) & 426.94 & 0.65 & $22,200.00$ & $1,420.00$ \\
Revenue Growth & 0.02 & -0.98 & 1.17 & 0.20 \\
$T E_{t-1}(0-100)$ & 91.06 & 16.87 & 99.94 & 9.89 \\
$M T R_{t-1}(0-100)$ & 75.00 & 12.31 & 99.99 & 13.43 \\
Exp (0/1) & 0.10 & 0.00 & 1.00 & 0.30 \\
Years & 3 & 1 & 6 & - \\
Vector of sector dummies & & & & \\
\hline
\end{tabular}

Source: Author's own calculations 
Figure 4-2 illustrates the quantiles of revenue growth rates. The data shows that firms at the 0.90 quantile of the distribution exhibit an average revenue growth of about $23 \%$. On the contrary, firms belonging to the 0.10 quantile show negative growth rates of $18 \%$ on average. The average revenue growth at the $0.25,0.50$ and 0.75 quantile is $6 \%, 2 \%$ and $11 \%$, respectively.

Figure 4-2 Quantiles of the dependent variable, revenue growth rates.

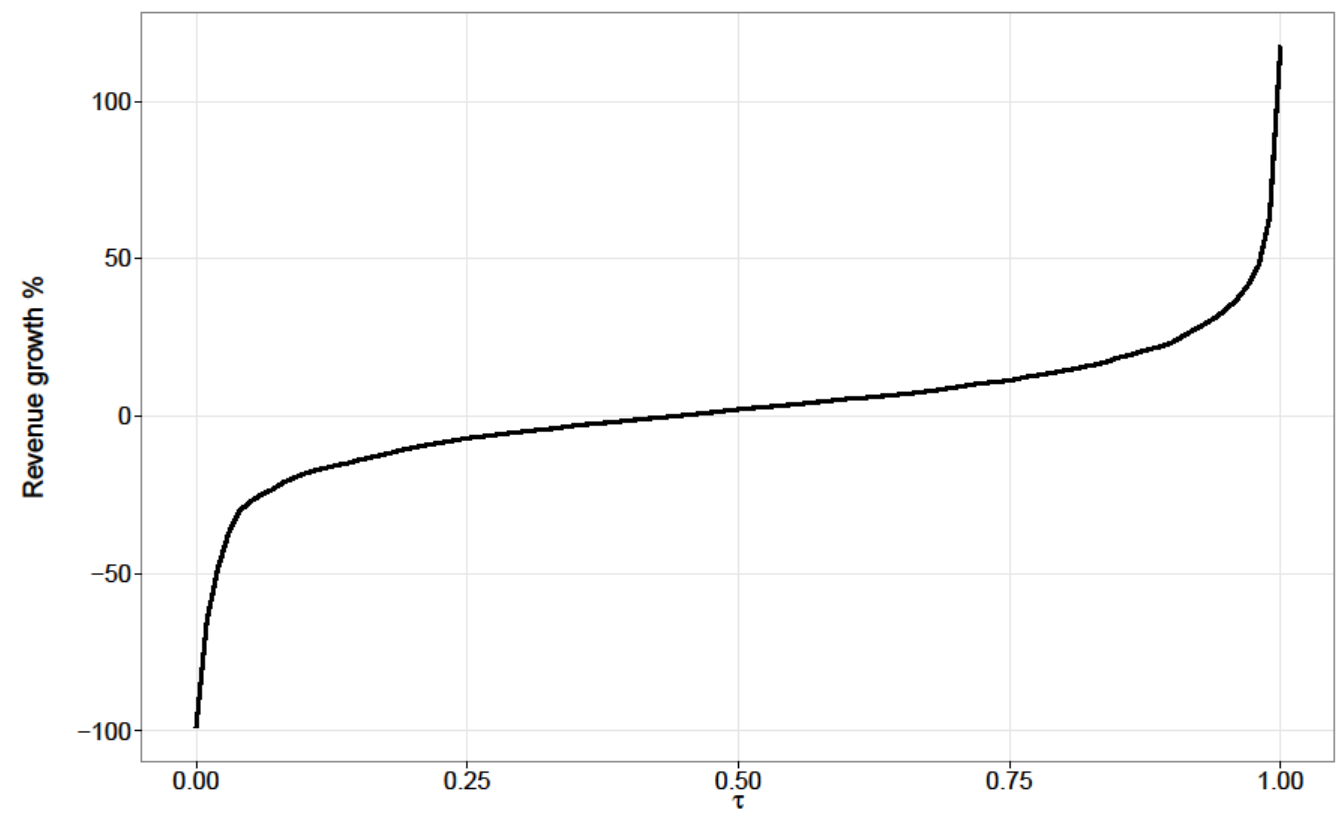

\subsection{Results}

In this section, we present the results of the estimation of equation (4.4) by means of the PFEQR and provide a comparison with the other econometric estimations, OLS and WG. The results of the TE and MTR estimates are presented and described in detail in Chapter 3, Section 3.4 of this thesis.

The estimated coefficients shown in Table 4-3 reveal substantial differences in the magnitude and significance of the coefficients. The results of the OLS estimation indicate that only $T E_{t-1}$ and the dummy for dairy firms have a statistically significant effect on revenue growth. Similarly, the results of the WG estimation suggest that the variable $T E_{t-1}$ and the time trend are statistically significant and positive; the latter indicates that firm growth has an upward trend over time. The variable $M T R_{t-1}$ shows no impact on revenue growth when its effect is measured by either OLS or the WG estimation. The PFEQR estimates reveal that the effect of $T E_{t-1}$ on revenue growth ranges from 1.2 to $0.36 \%$. Furthermore, $M T R_{t-1}$ shows a significant effect at the 0.10 
quantile and at the median of revenue growth. Additionally, exporting has a statistically significant impact at the 0.90 quantile.

The presence of heteroscedasticity in the error term is the primary reason for having differences in the magnitude of coefficient estimates at the different quantiles of the dependent variable. The result of the Breusch-Pagan Test for heteroscedasticity indicates that the variance of the error depends on the values of some of the explanatory variables, $\chi^{2}(1)=159, p$-value $<0.001$. We also tested for potential endogeneity of $T E_{t-1}$ and $\mathrm{MTR}_{\mathrm{t}-1}$ by means of the Hausman Test. Endogeneity could arise if there is reverse causality between revenue growth, $T E_{t-1}$ and $\mathrm{MTR}_{\mathrm{t}-1}$. However, the Hausman Test fails to find any evidence of endogeneity, $\mathrm{F}(2,2511)=36.96, p$-value $<0.001$.

The results of the PFEQR regression in Table 4-3 show that time effects are positive and significant for the $0.25,0.50$, and 0.75 quantile of firm growth. This implies that the growth rates have a positive trend over time at those specific quantiles. Furthermore, the dummy variables for the sectors are also significant. Since the base group is the meat sector, the results indicate that, holding constant all other variables, dairy firms have higher growth rates in revenue than meat firms at almost all quantiles $(0.10,0.25,0.50$ and 0.90). Milling firms also show higher changes in revenue at the 0.75 and 0.90 quantiles when compared to meat firms. Meanwhile, bakery firms at the 0.75 quantile grew significantly less than meat firms.

The results also reveal that technical efficiency does not have a homogenous effect on revenue growth. The magnitude of the $T E_{t-1}$ coefficient decreases across the quantiles. The estimated coefficient at the 0.10 quantile indicates that an increase of one point in $T E_{t-1}$, i.e. from 0.81 to 0.91 , increases revenue growth by $1.2 \%$. At the 0.90 quantile, the marginal effect in revenue growth is $0.4 \%$. The estimated coefficient at the 0.50 quantile approximates the OLS coefficient. 
Table 4-3 OLS, WG and quantile regression results of revenue growth.

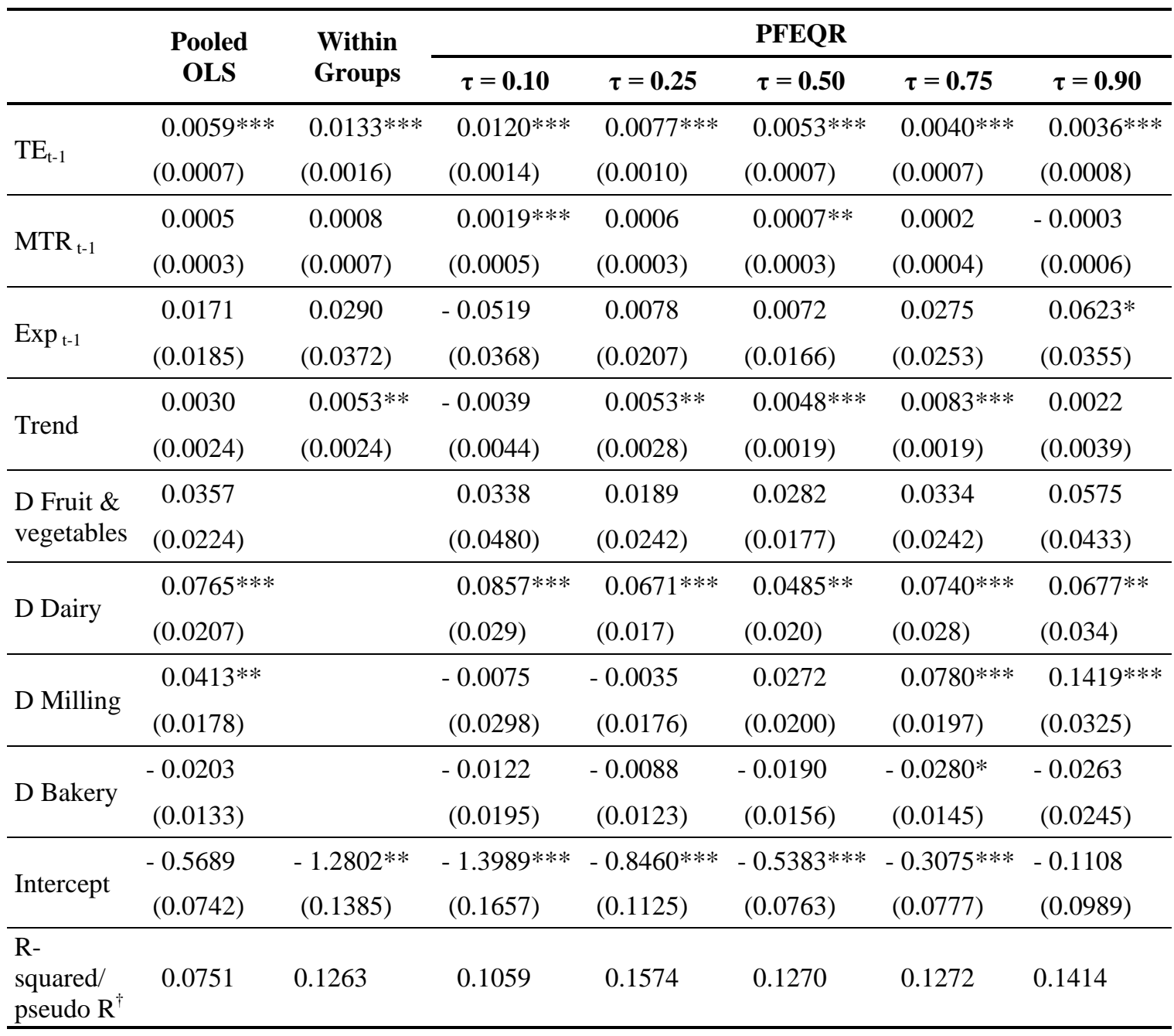

Note: Standard errors in parentheses; significance levels: $* * * / * * / *$ denote $0.01,0.05$, and 0.1

Results of the PFEQR estimation were generated using rqpd R code from Bache and Koenker (2011).

$\dagger$ : the pseudo R was calculated as in Koenker and Machado (1999) for quantile regression.

Source: Author's own calculations

We investigate whether the coefficients estimated by the PFEQR approach are statistically different than the OLS and WG coefficients. For this, we calculate if the confidence intervals of the OLS and WG estimates contain the PFEQR coefficients. We find that only the coefficient at the 0.50 quantile is not statistically different from the OLS estimate (left-hand panel of Figure 4-3). Furthermore, the right-hand panel of Figure 4-3 shows that the WG coefficient differs considerably with the PFEQR estimates, even at the median regression. With the exception of the 0.10 quantile, the PFEQR coefficients are all significantly different from the WG estimate. This result corroborates the fact that the relationship between technical efficiency and growth is non-linear and that firms facing negative revenue growth benefit more from any improvements in technical efficiency. 
Figure 4-3 Estimated effect of technical efficiency on revenue growth.
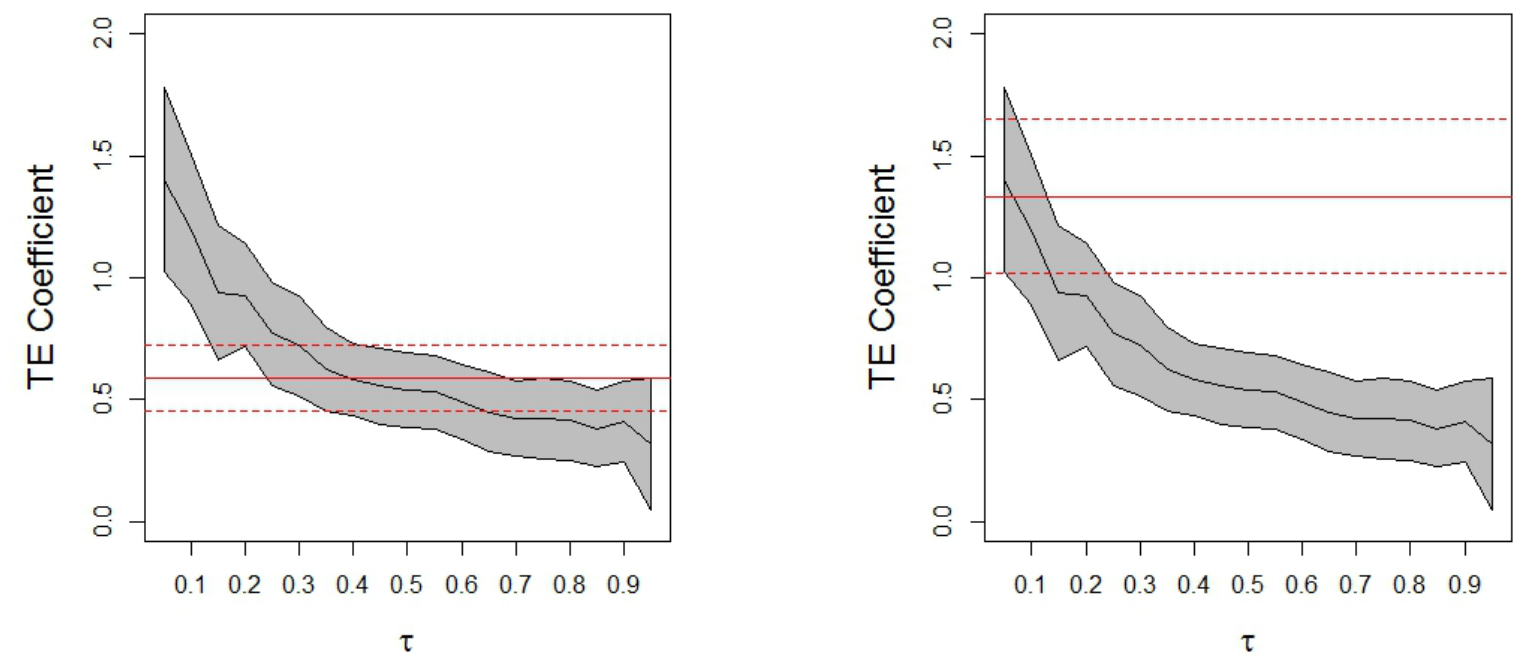

Note: The x-axis represents the quantiles of the dependent variable. The quantile coefficients are depicted with the black solid line and the gray area represents the $95 \%$ confidence interval for the quantile estimates. The red line stands for the OLS coefficients (left) and Within Groups (right), and the dashed lines for their $95 \%$ confidence interval.

Source: Author's own calculations

Additionally, we test for equality of the $T E_{t-1}$ coefficients across quantiles using pairwise T-Tests (Table 4-4). We find that all coefficients are significantly different from each other, except for the 0.75 and 0.90 quantile coefficients. This implies that there is no difference on the effect of $T E_{t-1}$ at the 0.75 and 0.90 quantile of the dependent variable; thus, the effect from technical efficiency reaches a lower plateau at the 0.75 quantile and is stable and positive afterwards. This evidence confirms that this relationship is not well explained in an average sense, as the one provided by the OLS estimates. Above all, the results are consistent with the theoretical approaches which predict that production efficiency is a driver for economic growth at the firm level. Furthermore, the results highlight the importance of performance for firms below the industry average, i.e., firms facing low and even negative growth rates. 
Table 4-4 Pairwise T-tests of equivalence of the technical efficient coefficient at the different quantiles.

\begin{tabular}{lcccc}
\hline \multicolumn{1}{c}{$\boldsymbol{\beta}_{\boldsymbol{T E}}(\boldsymbol{\tau})$} & $\boldsymbol{\tau}=\mathbf{0 . 2 5}$ & $\boldsymbol{\tau}=\mathbf{0 . 5 0}$ & $\boldsymbol{\tau}=\mathbf{0 . 7 5}$ & $\boldsymbol{\tau}=\mathbf{0 . 9 0}$ \\
\hline $\boldsymbol{\tau}=\mathbf{0 . 1 0}$ & $10.845^{* * *}$ & $19.981^{* * *}$ & $26.911^{* * *}$ & $24.653^{* * *}$ \\
& 0.001 & 0.000 & 0.000 & 0.000 \\
$\boldsymbol{\tau}=\mathbf{0 . 2 5}$ & & $7.570^{* * *}$ & $11.091^{* *}$ & $9.247^{* *}$ \\
& & 0.006 & 0.029 & 0.002 \\
$\mathbf{\tau}=\mathbf{0 . 5 0}$ & & $3.828^{*}$ & $3.038^{*}$ \\
& & & 0.051 & 0.081 \\
$\mathbf{\tau}=\mathbf{0 . 7 5}$ & & & 0.284 \\
& & & & 0.594 \\
\hline
\end{tabular}

$\mathrm{H}_{0}: \beta_{T E}\left(\tau_{i}\right)=\beta_{T E}\left(\tau_{j}\right)$

$p$-value in italics. Critical values $\chi_{1}^{2}$ at the $5 \%$ level of significance $=3.84$, at $10 \%=2.71$

Source: Author's own calculation

Therefore, firms which allocate resources efficiently are able to increase revenue at higher rates than their counterparts. Contrary to Heshmati (2001), Bottazzi et al. (2010), and Gardebroek et al. (2010), who find a weak relationship between firm's performance (measured as productivity) and growth, we demonstrate that technical efficiency has a significant and strong effect on revenue growth. The result at the 0.10 quantile confirms the hypothesis that technical efficiency spurs firm revenue in subsequent time periods, particularly when firms face severe low growth rates.

The OLS and WG estimations find no significant effect of $M T R_{t-1}$. Nevertheless, the PFEQR results reveal that $M T R_{t-1}$ is statistically significant at the 0.10 and 0.50 quantiles of revenue growth. As for the previous variable, the magnitude of the PFEQR coefficient is larger at the lower quantiles of the dependent variable. The results in Table 4-3 show that at the 0.10 quantile, an increase in $M T R_{t-1}$ of 0.10 raises revenue growth by $0.2 \%$. At the median, the marginal effect of $M T R_{t-1}$ decreases to $0.07 \%$. We also find that the PFEQR coefficient at the 0.10 quantile is statistically different than the OLS estimate (left-hand panel Figure 4-4). The $95 \%$ confidence intervals of the WG estimate contain all quantile coefficients, suggesting that there is no significant difference. Nevertheless, the PFEQR estimates exhibit a narrower confidence interval, which allows the effect of $M T R_{t-1}$ to be measured more accurately. 
Figure 4-4 Estimated effect of MTR on revenue growth.
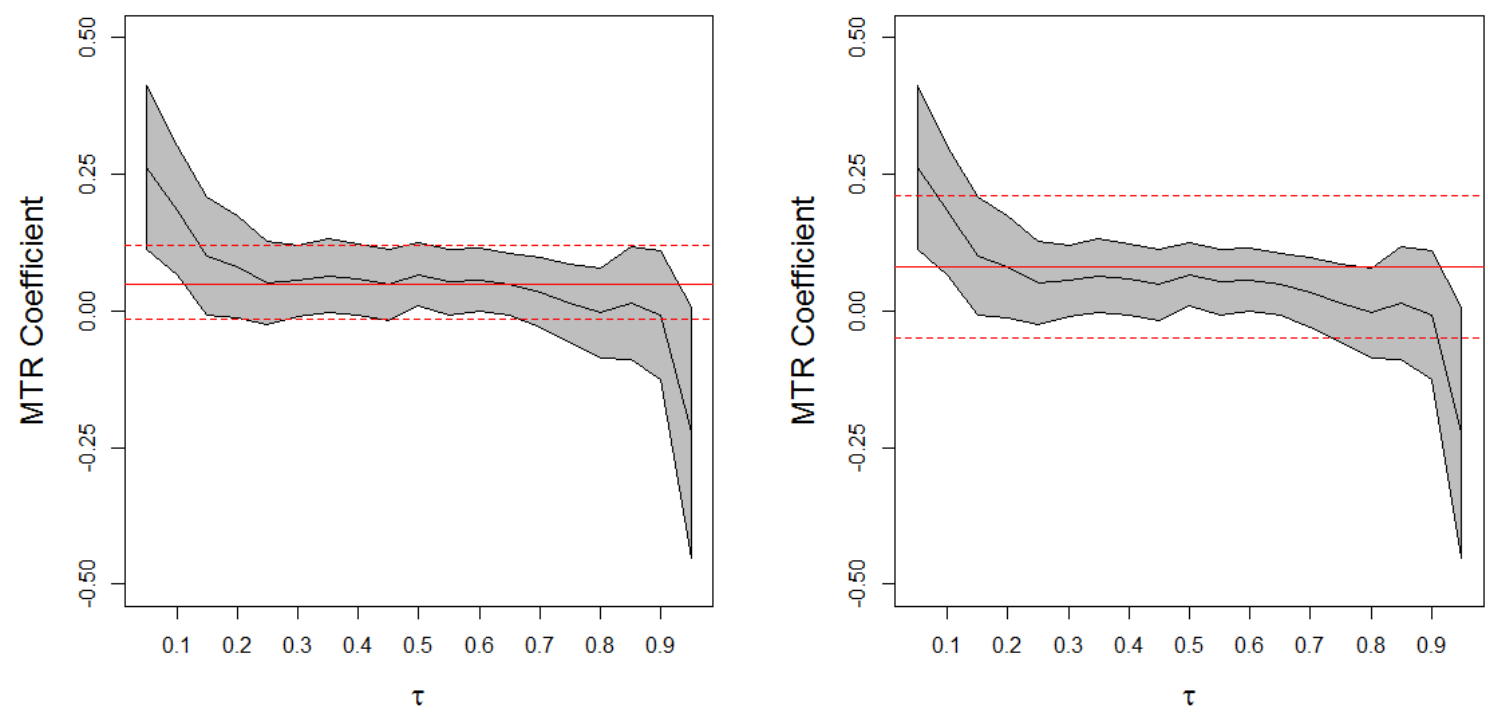

Note: The $\mathrm{x}$-axis represents the quantiles of the dependent variable. The quantile coefficients are depicted with the black solid line and the gray area represents the $95 \%$ confidence interval for the quantile estimates. The red line stands for the OLS coefficients (left) and Within Groups (right), and the dashed lines for their $95 \%$ confidence interval.

Source: Author's own calculations

A T-test indicates that the estimated effect at the 0.10 quantile is statistically different than the one at the median, $\chi 2(1)=4.80, p$-value $<0.05$. This result demonstrates that firms with low revenue growth benefit to a greater extent from the shortening of the technology gap with respect to the whole industry. Improving technological conditions with respect to other firms in the industry make firms more competitive in the market; they can lower product prices and increase market share, increasing revenue at the same time.

The OLS results suggest that the dummy variable for exporting does not have a significant effect on revenue growth. However, the PFEQR estimates point out that exporting has a positive and significant effect at the tail of the distribution. The PFEQR coefficient at the 0.90 quantile lies outside the $95 \%$ confidence interval of the OLS estimate, CI [-1.5; 5.0]. Consequently, the two coefficients are statistically different from one another. The results in Table 4-3 indicate that those exporting firms at the 0.90 quantile exhibit $6 \%$ higher growth rates in revenue than their counterparts. This might occur because output sold in foreign markets achieves larger volumes, and exporting firms can make a better utilization of the potential of the existing technology and exploit increasing returns to scale. 


\subsection{Conclusions}

The empirical analysis presented above provides a number of insights into the relationship between firm dynamics and firm performance. First, contrary to the previous literature, we confirm that there is a strong empirical relationship between firm performance and firm growth. Second, this relationship is not homogenous. We prove that the effect is positive and stronger for firms facing low or negative growth rates. The effect of technical efficiency on revenue growth varies from 1.2 to $0.4 \%$ for a one point increase in technical efficiency. These results conform to economic theory because any improvement in managerial efficiency will benefit more firms facing negative revenue growth.

Furthermore, the effect of technology gaps, although smaller in magnitude, is statistically significant at the 0.10 quantile and the median of the conditional distribution of revenue growth. We find that an increase in the meta-technology ratio by one point contributes to a rise in revenue growth by 0.2 to $0.06 \%$. Considering that the meta-technology ratio average in the sample is 75 , there is considerable scope for technological improvements, which will then benefit those firms facing negative growth rates.

The results reveal that technical efficiency and technology gaps better explain the changes in revenue for the lower quantiles. Therefore, managerial ability and technology choice are determinants for improvements in negative growth rates. Meanwhile, large positive growth rates of revenue (higher quantiles) are better explained by market-oriented variables, such as trading to foreign markets. Thus, large increases in revenue are likely to be more affected by market changes than by technological and production choices.

We acknowledge the limitations of this study. We do not provide a detailed decomposition by sector, because the number of observations at the lower and upper quantiles in most sectors is not sufficiently large to produce precise estimates. Dividing the analysis by sector produces large standard errors and imprecise estimates. Nevertheless, the results separated by sectors correspond with the results of the whole industry (see Table A 4 to Table A 8 in the Appendix). Another main constraint is the limited number of explanatory variables used in the regression. This increases the risk of omitted variable bias. This problem originates from the limited number of additional explanatory variables available in the data set. The low $\mathrm{R}^{2}$ of the OLS regression could be an indication of this problem; nevertheless the pseudo $\mathrm{R}^{2}$ value for the quantile 
estimates shows a slight improvement on the fit of the model compared with OLS. Finally, other - more influential - determinants of revenue change, such as input prices, are external factors to this analysis. Thus, future work should consider the effect of allocative efficiency on revenue growth. 


\section{References}

Aigner, D., Lovell, C. A. K., \& Schmidt, P. (1977). Formulation and estimation of stochastic frontier function analysis models. Journal of Econometrics, 6, pp. 31.

Bache, S. H., \& Koenker, R. (2011). rqpd: Regression quantiles for panel data (Version 0.5/r9) [R package]. Retrieved from http://www.r-forge.r-project.org/projects/rqpd

Battese, G. E., O’Donnell, C. J., \& Rao, D. S. P. (2004). A metafrontier production function for estimation of technical efficiencies and technology gaps for firms operating under different technologies. Journal of Productivity Analysis, 21, 91103.

Bernard, A., Jensen, B., Redding, S. \& Schott, P. (2007). Firms in International Trade, Journal of Economic Perspectives, 21(3), 105-130.

Bottazzi, G., Dosi, G., Jacoby, N., Secchi, A., \& Tamagni, F. (2010). Corporate performances and market selection. Some comparative evidence. Industrial and Corporate Change, 19, 1953-1996.

Ciuriak, D., Lapham, B., Wolfe, R., Collins-Williams, T. \& Curtis, J. ( 2014), Firms in International Trade: Trade Policy Implications of the New New Trade Theory. Global Policy. doi: 10.1111/1758-5899.12183

Coad, A. (2007). Empirical investigations into the characteristics and determinants of the growth of firms. (Doctoral dissertation, Université Paris 1 Panthéon-Sorbonne). Retrieved from: http://tel.archivesouvertes.fr/docs/00/16/33/94/PDF/Coad_alex_these.pdf

Coad, A. (2009). The growth of firms: A survey of theories and empirical evidence. Cheltenham, GL: Edward Elgar Publishing.

Coelli, T. J., Prasada Rao, D., \& O'Donnel, C. J. (2005). An introduction to efficiency and productivity analysis (2nd ed.). New York, NY: Springer

Fagiolo, G., \& Luzzi, A. (2006). Do liquidity constraints matter in explaining firm size and growth? Some evidence from the Italian manufacturing industry. Industrial and Corporate Change, 15(1), 1-39.

Gardebroek, C., Turi, K. N., \& Wijnands, J. (2010). Growth dynamics of dairy processing firms in the European Union. Journal of Agricultural Economics, 41, 285-291. 
Geroski, P. A., Machin, S. J., \& Walters, C. F. (1997). Corporate growth and profitability. The Journal of Industrial Economics, 45(2), 171-189.

Goddard, J., Tavakoli, M., \& Wilson, J. O. (2002). Dynamic panel models of firm growth and profit. Working paper. University of Wales Swansea, UK. Retrieved from: http://www.swan.ac.uk/economics/dpapers/2002/0201.pdf

Guariglia, A., Liu, X., \& Song, L. (2011). Internal finance and growth: microeconometric evidence on Chinese firms. Journal of Development Economics, 96(1), 79-94.

Heshmati, A. (2001). On the growth of micro and small firms: evidence from Sweden. Small business economics, 17(3), 213-228.

INE (Instituto Nacional de Estadisticas) (2007). Antecedentes metódologicos de la Encuesta Naciona Industrial Anual (ENIA). Santiago, Chile.

Jovanovic, B. (1982). Selection and the evolution of industry. Econometrica 50 (3), 649-670.

Koenker, R., \& Bassett Jr, G. (1978). Regression quantiles. Econometrica: journal of the Econometric Society, 33-50.

Koenker, R., \& Machado, J. A. (1999). Goodness of fit and related inference processes for quantile regression. Journal of the american statistical association, 94(448), 1296-1310.

Koenker, R., (2004). Quantile regression for longitudinal data. Journal of Multivariate Analysis, $\quad 91, \quad 74 \quad$ - $\quad 89 . \quad$ Retrieved from: http://www.econ.uiuc.edu/ roger/research/panel/long.pdf

Kumbhakar, S. C., \& Lovell, C. K. (2000). Stochastic frontier analysis. Cambridge University Press.

Lang, L. H., \& Stulz, R. M. (1993). Tobin's q, corporate diversification and firm performance (No. w4376). National Bureau of Economic Research.

Melitz, M.J., (2003). The Impact of Trade on Intra-Industry Reallocations and Aggregate Industry Productivity. Econometrica, 71, 1695-1725.

Nelson, R., \& Winter S. G., (1982). An evolutionary theory of economic change. Harvard Business School Press, Cambridge.

OECD (2010). Trade and Agriculture Directorate: Benefits of Trade Liberalization, document from Organization of Economic Co-operating and Development 
(OECD), $\quad$ Retrieved from: http://www.oecd.org/about/0,3347,en_2649_36442957_1_1_1_1_1,00.html

O’Donnell, C.J., Rao, D.S.P., \& Battese, G.E. (2008). Metafrontier Frameworks for the study of firm level efficiencies and technology ratios. Empirical Economics, 34, 231-255.

Oficina de Estudios y Políticas Agrarias. (2011). Identificación y análisis de las fortalezas y restricciones del crecimiento agroalimentario chileno al año 2017 (ODEPA Publication No. 688-29-LE11). Retrieved from http://www.odepa.cl/wpcontent/files_mf/1369835785Crecimiento_agroalimentario_chileno.pdf

Oliveira, B., \& Fortunato, A. (2006). Firm growth and liquidity constraints: A dynamic analysis. Small Business Economics, 27(2-3), 139-156.

Pavcnik, N. (2002). Trade Liberalization, Exit, and Produtivity Improvements: Evidence from Chilean Plants. The Review of Economic Studies Limited, 69, 245276

Rodrik, D. (1995). Trade and industrial policy reform. In: J. Behrman and T.N. Srinivasan (Eds), Handbook of development economics, vol. 3 B, 2925-2982.

Schmidt, P. \& Sickles, R.C. (1984). Production frontiers and panel data. Journal of Business and Economic Statistics, 2, 367-374.

United Nations. (2002). International Standard Industrial Classification of All Economic Activities. Series M, Nr. 4, Rev. 3.1, New York

Wang, H.-J., \& Schmidt, P. (2002). One-Step and Two-Step Estimation of the Effects of Exogenous Variables on Technical Efficiency Levels. Journal of Productivity Analysis, 18, 129-144.

Wernerfelt, B., \& Montgomery, C. A. (1988). Tobin's q and the importance of focus in firm performance. The American Economic Review, 246-250.

Wooldridge, J. (2002). Introductory Econometrics: A Modern Approach: Cincinnati. Ohio: South-Western College Pub, 218-220. 


\section{Appendix}

Table A 4 PFEQR estimates for the meat sector.

\begin{tabular}{lccccc}
\hline & \multicolumn{5}{c}{ PFEQR } \\
\cline { 2 - 6 } & $\boldsymbol{\tau}=\mathbf{0 . 1 0}$ & $\boldsymbol{\tau}=\mathbf{0 . 2 5}$ & $\boldsymbol{\tau}=\mathbf{0 . 5 0}$ & $\boldsymbol{\tau}=\mathbf{0 . 7 5}$ & $\boldsymbol{\tau}=\mathbf{0 . 9 0}$ \\
\hline \multirow{2}{*}{$\mathrm{TE}_{\mathrm{t}-1}$} & $0.0086^{* * *}$ & $0.0077^{* * *}$ & $0.0073^{* * *}$ & $0.0056^{*}$ & 0.0022 \\
& $(0.0034)$ & $(0.0018)$ & $(0.0026)$ & $(0.0033)$ & $(0.0040)$ \\
\hline \multirow{2}{*}{ MTR $_{\mathrm{t}-1}$} & 0.0019 & 0.0009 & 0.0000 & -0.0001 & 0.0001 \\
& $(0.0013)$ & $(0.0012)$ & $(0.0011)$ & $(0.0011)$ & $(0.0018)$ \\
\hline \multirow{2}{*}{ Exp } & -0.0061 & 0.0296 & 0.0274 & 0.0194 & 0.0388 \\
\hline \multirow{2}{*}{ Trend } & $(0.0573)$ & $(0.0355)$ & $(0.0344)$ & $(0.0501)$ & $(0.0634)$ \\
\hline \multirow{2}{*}{ Intercept } & -0.0037 & 0.0105 & 0.0020 & -0.0041 & -0.0136 \\
& $(0.0127)$ & $(0.0087)$ & $(0.0091)$ & $(0.0108)$ & $(0.099)$ \\
\hline
\end{tabular}

Note: Standard errors in parentheses; significance levels: $* * * / * * / *$ denote $0.01,0.05$, and 0.1

Results of the PFEQR estimation were generated using rqpd R code (Bache and Koenker, 2011)

Source: Author's own calculations

Table A 5 PFEQR estimates for the fruit \& vegetables sector.

\begin{tabular}{|c|c|c|c|c|c|}
\hline & \multicolumn{5}{|c|}{ PFEQR } \\
\hline & $\tau=\mathbf{0 . 1 0}$ & $\tau=0.25$ & $\tau=\mathbf{0 . 5 0}$ & $\tau=0.75$ & $\tau=0.90$ \\
\hline \multirow{2}{*}{$\mathrm{TE}_{\mathrm{t}-1}$} & $0.1208 * *$ & 0.0048 & $0.0030 * *$ & 0.0008 & 0.0037 \\
\hline & $(0.0061)$ & (0.0039) & $(0.0014)$ & $(0.0020)$ & $(0.0033)$ \\
\hline \multirow{2}{*}{$\operatorname{MTR}_{\mathrm{t}-1}$} & -0.0001 & 0.0015 & 0.0011 & 0.0010 & 0.0021 \\
\hline & (0.0018) & $(0.0015)$ & $(0.0008)$ & $(0.0016)$ & $(0.0022)$ \\
\hline \multirow{2}{*}{$\operatorname{Exp}_{t-1}$} & -0.1221 & -0.0621 & -0.0180 & 0.0321 & 0.0988 \\
\hline & $(0.0844)$ & $(0.0463)$ & $(0.0230)$ & $(0.0598)$ & $(0.0934)$ \\
\hline \multirow{2}{*}{ Trend } & -0.0099 & -0.0124 & -0.0033 & -0.0033 & -0.0020 \\
\hline & $(0.0204)$ & $(0.0151)$ & (0.0077) & $(0.0131)$ & $(0.0241)$ \\
\hline \multirow{2}{*}{ Intercept } & $-1.1381 *$ & -0.5085 & $-0.2866^{* *}$ & -0.0011 & -0.2512 \\
\hline & (0.5980) & (0.3189) & $(0.1142)$ & (0.1933) & $(0.3434)$ \\
\hline
\end{tabular}

Note: Standard errors in parentheses; significance levels: $* * * * * * *$ denote $0.01,0.05$, and 0.1

Results of the PFEQR estimation were generated using rqpd R code (Bache and Koenker, 2011)

Source: Author's own calculations 
Table A 6 PFEQR estimates for the dairy sector.

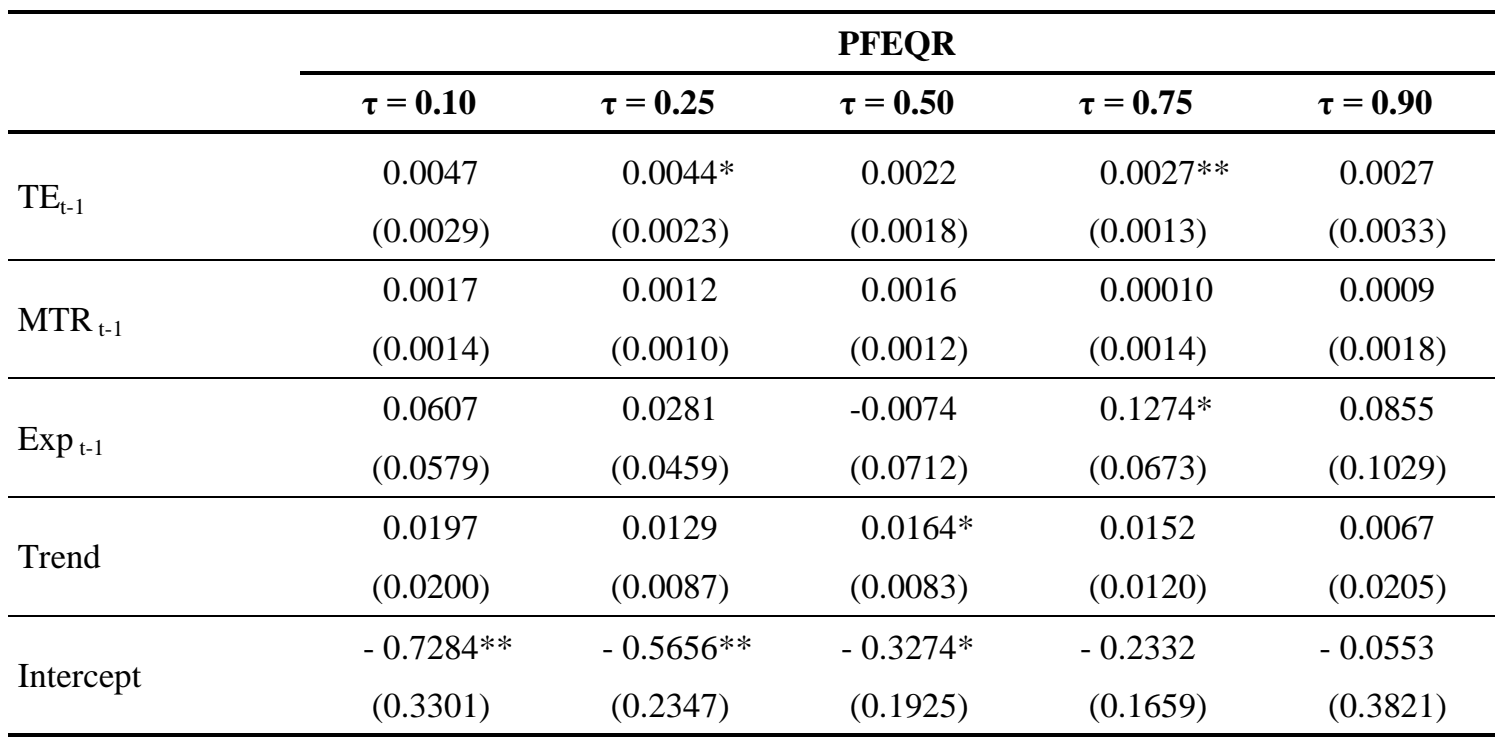

Note: Standard errors in parentheses; significance levels: $* * * / * * / *$ denote $0.01,0.05$, and 0.1

Results of the PFEQR estimation were generated using rqpd R code (Bache and Koenker, 2011)

Source: Author's own calculations

Table A 7 PFEQR estimates for the grain sector.

\begin{tabular}{lccccc}
\hline & \multicolumn{5}{c}{ PFEQR } \\
\cline { 2 - 5 } & $\boldsymbol{\tau}=\mathbf{0 . 1 0}$ & $\boldsymbol{\tau}=\mathbf{0 . 2 5}$ & $\boldsymbol{\tau}=\mathbf{0 . 5 0}$ & $\boldsymbol{\tau}=\mathbf{0 . 7 5}$ & $\boldsymbol{\tau}=\mathbf{0 . 9 0}$ \\
\hline \multirow{2}{*}{$\mathrm{TE}_{\mathrm{t}-1}$} & 0.0098 & 0.0097 & 0.0057 & 0.0040 & 0.0003 \\
& $(0.0015)$ & $(0.0015)$ & $(0.0021)$ & $(0.0014)$ & $(0.0024)$ \\
\hline \multirow{2}{*}{ MTR $_{\mathrm{t}-1}$} & -0.0005 & -0.0004 & 0.0008 & -0.0002 & -0.0044 \\
\hline \multirow{2}{*}{ Exp $_{\mathrm{t}-1}$} & $(0.0018)$ & $(0.0013)$ & $(0.0013)$ & $(0.0010)$ & $(0.0018)$ \\
\hline \multirow{2}{*}{ Trend } & 0.0287 & 0.0424 & 0.0149 & -0.0689 & -0.0216 \\
& $(0.0784)$ & $(0.0523)$ & $(0.0536)$ & $(0.0432)$ & $(0.0845)$ \\
\hline \multirow{2}{*}{ Intercept } & -0.0337 & -0.0069 & 0.0210 & 0.0289 & 0.0253 \\
& $(0.0141)$ & $(0.0104)$ & $(0.0111)$ & $(0.0074)$ & $(0.0084)$ \\
\hline
\end{tabular}

Note: Standard errors in parentheses; significance levels: $* * * / * * / *$ denote $0.01,0.05$, and 0.1

Results of the PFEQR estimation were generated using rqpd R code (Bache and Koenker, 2011)

Source: Author's own calculations 
Table A 8 PFEQR estimates for the bakery sector.

\begin{tabular}{lccccc}
\hline & \multicolumn{5}{c}{ PFEQR } \\
\cline { 2 - 6 } & $\boldsymbol{\tau}=\mathbf{0 . 1 0}$ & $\boldsymbol{\tau}=\mathbf{0 . 2 5}$ & $\boldsymbol{\tau}=\mathbf{0 . 5 0}$ & $\boldsymbol{\tau}=\mathbf{0 . 7 5}$ & $\boldsymbol{\tau}=\mathbf{0 . 9 0}$ \\
\hline \multirow{2}{*}{$\mathrm{TE}_{\mathrm{t}-1}$} & $0.153^{* * *}$ & $0.0114^{* * *}$ & $0.0078^{* * *}$ & $0.0068^{* * *}$ & $0.0063^{* *}$ \\
& $(0.0021)$ & $(0.0020)$ & $(0.0013)$ & $(0.0013)$ & $(0.0022)$ \\
\hline \multirow{2}{*}{ MTR $_{\mathrm{t}-1}$} & $0.0029 * * *$ & $0.0011^{* *}$ & $0.0007^{*}$ & 0.0002 & -0.0002 \\
& $(0.0009)$ & $(0.0005)$ & $(0.0004)$ & $(0.0005)$ & $(0.0010)$ \\
\hline \multirow{2}{*}{ Exp $\mathrm{t}-1$} & -0.0371 & -0.0026 & -0.0393 & -0.0479 & 0.0843 \\
& $(0.0636)$ & $(0.0332)$ & $(0.0462)$ & $(0.0576)$ & $(0.1208)$ \\
\hline \multirow{2}{*}{ Trend } & -0.0039 & 0.0049 & $0.0051^{* *}$ & $0.0053^{* * *}$ & -0.0002 \\
& $(0.0048)$ & $(0.0035)$ & $(0.0020)$ & $(0.0020)$ & $(0.0045)$ \\
\hline \multirow{2}{*}{ Intercept } & $-1.7981^{* * *}$ & $-1.2394 * * *$ & $-0.7897^{* * *}$ & $-0.5873 * * *$ & -0.3907 \\
& $(0.2269)$ & $(0.2069)$ & $(0.1368)$ & $(0.1421)$ & $(0.2381)$ \\
\hline
\end{tabular}

Note: Standard errors in parentheses; significance levels: $* * * / * * / *$ denote $0.01,0.05$, and 0.1

Results of the PFEQR estimation were generated using rqpd R code (Bache and Koenker, 2011)

Source: Author's own calculations 


\section{Concluding remarks}

This thesis presents three selected studies on the topic of performance and dynamics of agricultural firms. Chapter 2 analyzes the factors driving the dynamics of agricultural firms operating in the sector of organic agriculture. Chapter 3 determines firm performance of agricultural firms accounting for within-industry heterogeneity. Finally, Chapter 4 connects the previous chapters and analyzes the effect of performance on a firm's dynamics. In this section, each of the three preceding chapters is discussed individually, summarizing the main results and their implications, discussing the challenges of the estimations, and presenting research topics for future work.

\subsection{What influences the growth of organic farms in Southern Germany?}

Chapter 2 analyzes the dynamics of agricultural firms engaged in organic agricultural production in Bavaria and Baden-Württemberg. The results are based on the System Generalized Method of Moments estimator (SGMM) proposed by Arellano and Bover (1995) and further developed by Blundell and Bond (1998). This approach does not only control for unobserved heterogeneity in the context of panel data, but also for potential endogeneity and persistence of the series when using the lagged dependent variable as regressor. Therefore, it has the advantage of producing consistent estimates by allowing dynamics in the model and testing the effect of initial firm size on firm growth. This chapter refines the SGMM estimation with a probability transition matrix, which provides the absolute changes in agricultural land by predefined farm size categories.

Chapter 2 has shown that when farm size is measured in terms of output, farms with lower output have higher growth rates than their peers in the sector. This is consistent with economic theory which predicts that small firms grow at higher rates than their peers because they adjust towards more efficient (larger) farm sizes. We do not find the same tendency when farm size is measured in terms of agricultural land. The results of the SGMM estimation do not find empirical evidence that smaller farms are growing at larger rates than their peers and the coefficient does not have the expected sign. We complemented this analysis with a transition probability matrix which analyzes the absolute changes in area by farm size categories. The results from the transition probability matrix revealed that, firstly, increases in the area farmed organically are less than 10 ha for all farms. Second, larger farm sizes tend to increase acreage more 
frequently than smaller sizes. These two results indicate that small farms are not adjusting their scale of operation as predicted by economic theory. Chavas (2001) and Huettel and Margarian (2009) explain that farm size persistence is often found in the literature and it is caused by a reluctance to leave the sector and decline or expand the scale of operation, sunk costs, uncertain future revenues, and the presence of imperfect input markets.

In organic farming, reluctance to exit or grow can arise as a result of "hobby farming", where farming is seen as a leisure activity from holders with a secured monthly income and special interest in organic agriculture. Certainly for these farms, the economic premises of maximizing profits or minimizing costs are at the background and they are less likely to be affected by market pressures to move towards more efficient sizes or exiting the sector. Thus, it is tempting to speculate that the reluctance to grow from small farms in the data set comes from this type of farming. However, this is not the case for work presented in Chapter 2: small farms ( $<10$ ha) are managed in $81 \%$ of the cases by full-time farmers. The former supports the assumption that farms in the data set correspond to commercial organic farms and that the persistence of farms in a small size category is caused by reasons other than "hobby farming”.

In organic farming, sunk costs arise from the conversion costs from learning the technology, restoring and converting the soil into organic, and any other investment to improve buildings and equipment to comply with the standards for organic farming. In case of exiting the organic sector and reverting to conventional agriculture, the conversion costs are reduced by selling redundant machinery and equipment (Mußhoff and Hirschauer, 2008). Therefore, sunk costs do not appear to be the main reason for persistence of size in organic farming.

Uncertain future revenue can play an important role in inhibiting dynamics, particularly for small organic farms that mainly depend on agricultural revenue. Purchasing (or renting) additional land to restore and convert it into organic is a long-term investment decision, whereas there are factors beyond farmers' control which can create uncertainty. The first one is policy support through area based payments for the introduction and maintenance of organic farming. The amount and the subsidies themselves are subject to political objectives and economic decisions taken at different levels, i.e. European, Federal and State levels. This support can be changed in the midterm as it occurred in 2007, when the funding period 2007-2013 came into force and 
the financial resources from the EU were reduced (Nieberg et al., 2011). The reduction of the EU funding resulted in a decrease in the Federation States' relative share of the payments. As a consequence, the amount paid for conversion and maintenance of organic farms was reduced from 2007 to 2008 in most Federal States in Germany. Several studies show that these subsidies are crucial for conversion to organic farming (Oude Lansik and Jensma, 2003; Kumbhakar et al. 2009; Offermann and Nieberg, 2001; Offermann et al., 2009). Moreover, Chapter 2 of this thesis has shown that subsidies for organic farming also contribute to acreage expansion. Therefore, such an event as in 2007 gives rise to uncertainty for organic farmers with respect to whether the subsidies will remain stable, decrease, or cease to exist. This uncertainty can discourage some farms to invest in new areas, especially during times of political change. Another source for uncertainty in future revenues is the market; specifically, the issues regarding whether the demand for organic products will keep growing, stagnate or decrease, and whether the prices will remain higher than for conventional products. The potential changes of these two factors are crucial when a small farm considers whether to keep its current farm size or expand its scale of operation.

Imperfect capital markets can be a determinant of this status quo in small organic farms if they face a higher capital cost than the largest farms. This is suggested by the finding in Chapter 2 that larger organic farms appear to cope better with the investment costs for additional land. Additionally, the findings also revealed that holdings operated by part-time farmers report $2.8 \%$ higher growth rates (in terms of land) than full-time farmers. It appears that off-farm employment work is a stabilizer of the household income when agricultural income is irregular during the first years of conversion. and it also creates the financial basis for further investments, either by self-financing or as startup capital for acquiring credit.

Area-based payments for conversion and maintenance of organic farms can also contribute to create persistence for small farms, where small farms may not leave the organic sector because they receive the financial support and the price premium, but either increase size due to the effect of the uncertainty or the capital-market imperfections. Determining whether this happens is beyond the scope of this work and the data available, nevertheless it remains a subject for future work. 
Two important events in the years following this investigation have changed the context of organic farming in Germany. First, the policy support offered for conversion and maintenance of organic farming underwent modifications. As mentioned above, most Federal States reduced the payments for conversion and maintenance of organic farming in 2007. Bavaria reduced the payment for arable farms by $25 \%$ and Baden Württemberg by 12 \% (Nieberg et al., 2011). The reduction in these two Federal States was not as severe as it was, for instance, in Lower Saxony where the payments for organic arable farms decreased by $51 \%$. Thus, this reduction presumably did not have as drastic an effect in the southern region as it did in other regions of Germany. Besides this, in 2009 the payments in Bavaria and Baden Württemberg returned to the levels seen prior to 2007. A second important event is the launch of the German Renewable Energy Act (Erneuerbare-Energien-Gesetz), which was introduced in 2000. This has created more competition for the agricultural land market, especially with the subsequent amendment in 2004. The aim of this law is to encourage energy supply from renewable sources including, among others, biomass i.e. energy crops, crop residues, and manure (BMWI, 2014). Habermann and Breustedt (2011) report that agricultural biogas production increased rental rates in Western Germany for new negotiated contracts in 2006 and 2007. The effects of this law are unfavorable for conventional and organic farms which seek to expand their agricultural area but do not take part in the biogas business. Kuhnert et al. (2013) state that organic farms participate less in this business than conventional farms do, indicating that they may be more affected by this policy than conventional farms. Therefore, it remains a topic for future empirical research to analyze the extent to which the dynamic of organic farms is affected by this law.

Finally, it should be borne in mind that the data set is not representative of organic farming in Germany. These results are situation specific and shall not be extrapolated to other regions or countries with different conditions. There are large differences across the regions in Germany with respect to farm structure, regional land market, policy support as well as in the demand for organic products. The results of a similar study in other regions of Germany might differ compared to those presented in Chapter 2, depending on the context.

The use of two dependent variables, land and output, appears ambiguous at first glance. However, we believe that they complement each other. The majority of the studies that 
analyze farm size and growth in agriculture coincide with finding a negative relationship between farm size and growth and often this relationship is non-linear. This holds across different indicators of farm size: acres and sales in Canada (Shapiro, 1987), livestock units in Austria (Weiss, 1999), hectares (Rizov and Mathijs, 2003) and sales (Bakucs and Fertö, 2009) in Hungary, and sales and number of employees in various European countries (Gardebroek et al., 2010). Therefore, we assumed that the effect of the lag dependent variable (regardless of the measure) shall be similar in the two equations, or at least have the same sign. Thus, using the two regressions allows results to be compared and the sources of differences to be analyzed. The estimation using land as an indicator for farm size reveals the spatial sense of growth. The output oriented estimation provides information about the factors contributing to increased output, which is a fundamental matter when there is a limited availability of land for purchase or lease.

An important issue in the empirical analysis of firm growth is whether attrition bias is present in the data. The causes and consequences of attrition remain a very important issue to consider, since it causes biased estimates. Selection bias due to attrition arises if a specific group is more likely to remain or to drop out of the data set. Previous studies on farm size indicate that small farms are more likely to cease operations than large operations (Kimhi and Bollman, 1999; Weiss, 1999; Rivoz and Mathijs, 2003; Glauben, 2006). Consequently, small farms performing well select themselves and, over time, can be overrepresented in the data set. Therefore, estimating growth rates on incumbents (surviving farms) produces bias estimates. The approach to address this problem is to model the survival probability from one period to the next, using the Heckman sample selection procedure and then adding the inverse Mills ratio on the firm growth regression. This correction is not statistically significant in all cases; for instance, the seminal work by Weiss (1999) finds significant effects when analyzing only the parttime farms from the sample. Therefore, the remaining questions are whether sample selection bias exists in the data set of organic farms and, if so, how severe the bias is and which direction it takes. In general, the data set does not provide evidence of selection bias. First, besides having dropouts, the data set also includes yearly newcomers, thus, both good and bad performers have the potential to enter the data set every year. Second, as described in Chapter 2, none of the tests proposed by Verbeek and Nijman (1992) were statistically significant. Therefore, sample attrition appears to be correlated to other factors rather than the farm growth rates. Attrition appears to 
depend on external circumstances such as changing the bookkeeping company. Finally, the direction of the bias (if any) would be upwards, resulting in unfavorable estimates for small organic farms.

The two-step SGMM estimation provides consistent and unbiased estimates under three settings: unobserved heterogeneity, endogeneous variables, and when the coefficient of the lagged dependent variable in equation (2.1) approaches one, i.e. the series is persistent. The last setting is not discussed in many studies that use dynamic models and the SGMM estimator is applied without concern. If the lagged dependent variable is not persistent, the use of the SGMM is not justified and the First-Differenced GMM (DIFGMM) provides efficient and unbiased estimates. If the coefficient of the lagged dependent variable approaches one, simulation results have shown that the DIFGMM estimator is subject to downward bias, especially when the number of time periods is short (Bond et al., 2001). A DIFGMM estimator close to or below the Within Groups estimate may denote serious finite sample bias associated with weak instruments (ibid.). In this context, the results of the DIFGMM on the data of organic farms show that both lagged dependent variables, land and revenue, are below the Within Groups estimation, confirming persistence in the series, (see Table 5-1). Thus, the SGMM is required to obtain unbiased estimates; moreover the standard errors of SGMM also decreased in comparison with the DIFGMM, which improves the estimation efficiency.

Table 5-1 Comparison of coefficients for the lagged dependent variables of land and revenue.

\begin{tabular}{lccc}
\hline & Within Groups & DIFGMM & SGMM \\
\hline Revenue $_{i t-1}$ & $-0.83^{* * *}$ & $-1.00^{* * *}$ & $-0.42^{* * *}$ \\
& $(0.03)$ & $(0.10)$ & $(0.05)$ \\
Land $_{i-1}$ & $-0.49^{* * *}$ & $-0.72^{* * *}$ & 0.08 \\
& $(0.03)$ & $(0.16)$ & $(0.06)$ \\
\hline
\end{tabular}

One problem inherent to the SGMM estimation is the proliferation of instruments. This could occur in particular when one uses all available lags to instrument the endogenous variables. Proliferation of instruments can cause over-fitting and weakens the Hansen Test (Roodman, 2009), which leads to erroneously failing to reject the null hypothesis that the instruments are exogenous. This is particularly important because it can lead to invalid conclusions being drawn. For the estimations of Chapter 2 in which the model was estimated using the full set of available lags for the endogenous variables, the Hansen Tests show $p$-values $=1.00$ for the revenue growth estimation and $p$-value $=$ 
0.83 for land growth. Therefore, we restricted the instruments to the third lag of the dependent variables. This provided both more plausible results for the Hansen test (see Chapter 2, Section 2.5) and lower standard errors. We can therefore deduce that the risk of suffering from proliferation of instruments, if any, is low.

We also considered the effects of other potential variables to determine farm growth. We tested for the effect of farm size squared, the Federal States (Bayern and BadenWürttemberg), and farmer's education (with or without agricultural education). However, none of these sets of variables were statistically significant and for the sake of parsimony were not included in the final estimations.

Finally, the SGMM estimation provides an appropriate framework to analyze the determinants of changing farm size, but certainly cannot capture all aspects of this process. For instance, from the SGMM estimation it was not possible to derive the absolute change in hectares, a crucial matter when analyzing farm growth in terms of land. For this reason we found that the transition probability matrix was an appropriate complement to the SGMM estimation. Moreover, the SGMM estimation ignores those farms which do not change their size, because the dependent variable is zero. This information is crucial to determine why farms persist in a specific farm size category. Furthermore, farm growth and size persistence can be driven by different factors. Therefore, future research should consider these issues for further analysis. Lastly, the simultaneous analysis of both organic and conventional farms is another subject for further research; this is the only way that we can compare the patterns of growth between conventional and organic farms. Furthermore, by extending the research topic addressed in Chapter 2 to other regions in Germany under different conditions of the land market, farm structure, and policy support, we can shed some light on regional differences in the development of organic farming. Additionally, further research is also needed to understand the impact of uncertainty on investment decisions in the context of organic farming. In this line, some work has already been done using aggregated national data from Germany (see Mußhoff and Hirschauer, 2008). However, the effect on individual decisions remains open for further study. 


\subsection{Technical efficiency in Chilean agribusiness - a Stochastic Metafrontier Approach}

Chapter 3 analyzes the performance of agricultural firms operating in the Chilean agribusiness industry. Previous studies about Chile analyze the agribusiness as a whole, without any consideration of the differences within the industry. Chapter 3 addresses this problem by accounting for differences in the technology sets in the estimation of technical efficiency. For doing this, we require the assumption that the sectors share a hypothetical common frontier, which can be questionable but is also unavoidable if we are to compare the differences in performance. Overall, the results support theoretical models, suggesting that the heterogeneity in structure and production characteristics define the sectoral performance and the magnitude of effects of exposure to international trade. The general results of the industry reveal that the sectors are relatively efficient with respect to the technologies they currently use. However, in general, if they were to further improve their technologies, significant efficiency gains could be made. This is a crucial issue for Chile if it seeks to achieve its goal to position itself as a food power on the global market.

Chapter 3 finds strong evidence that the sectors exposed to international trade achieve higher rates of technological progress than those trading mostly domestically. Moreover, exposure to international trade contributes to a better utilization of current technologies if firms operate under strong competition. In this sense, the open-economy policy followed by Chile and the strong efforts for signing free trade agreements with other countries and regions has created the possibility to expand into new markets and develop new products. Furthermore, this policy has also allowed new economic sectors, such as meat processing, to develop, contributing to the technological improvements shown in the present work.

The results presented in Chapter 3 provide evidence of an imperfect market structure within the dairy products processing sector in Chile. The results reveal that poor competition prevents the transfer of the benefits of international trade to non-exporting firms and the efficient allocation of resources within the largest firms. The existence of imperfect market structures is harmful not only for primary milk producers, but also for consumers: it can create welfare losses for both. In fact, milk farmers have lodged complaints with the Court for the Protection of Free Competition in 1997, 2001, and 2015 against the three largest milk processors in Chile for agreeing on market-shares, fixing prices, and price discrimination (OECD, 2006; TDLC, 2015). The Court did not 
find evidence of agreement in the first two cases but the last case is still ongoing. Furthermore, Chile has concentrated efforts to enhance the productivity of the dairy primary production business by promoting investments in new technologies and implementing programs for genetic improvements (ODEPA, 2011). However, the gains of these governmental efforts will not be transmitted entirely to the society if the next component of the value chain does not operate efficiently. This is relevant for policy makers because it can serve as an indication to improve the mechanisms for detecting and controlling this type of inefficient market structure. Improving these mechanisms can contribute to efficiency gains in the processing sector and lead to a more effective transmission of the efforts made by the government to improve the dairy primary production business.

The results presented in Chapter 3 show that large firms in the fruit \& vegetables sector exhibit lower MTR scores than their peers. This indicates that the course of action to enhance the performance of the sector shall be directed towards supporting the largest firms to improve their current technologies, primarily because they make the most of the sectoral output. This is crucial for the Chilean fruit \& vegetables sector because new competitors in the region are emerging and also moving towards more open economies. One example is Peru, which is experiencing a dynamic growth in agricultural exports and gaining ground in the United States in canned vegetables and table grapes, the main market for Chilean products (ODEPA, 2013). Although primary production in Peru is not as technologically advanced as is in Chile, labor is cheaper and the climatic conditions of the country allow the products to be harvested and positioned in the market before Chile (ibid.). This poses a risk for the fruit \& vegetables sector in the long term.

There are some challenges regarding the estimation procedure of the MF analysis. The first one is to find a single model which adequately fits to all sectors. In doing so, there are some singularities for each sector which cannot be considered in the MF approach because not all sectors share the same components. In this context, one important issue when analyzing Chile is its geographical characteristic of being a narrow and long country. There is much discussion on the uneven economic development of the country and the concentration of most business in the metropolitan region; it is often claimed that others regions are ignored. Therefore, one can assume that the location of a firm has an effect on its performance. However, the differences in the characteristics of the 
sectors make it problematic to incorporate the geographical location into the MF estimation. For example, more than $50 \%$ of meat firms are located between the $8^{\text {th }}$ and $10^{\text {th }}$ regions, corresponding to the area where cattle production is concentrated. Meanwhile, $58 \%$ of the milling firms are concentrated between the $7^{\text {th }}$ and $10^{\text {th }}$ regions, and $53 \%$ of the bakeries are located in the metropolitan region (Santiago). Consequently, not all sectors had enough observations in all regions.

Furthermore, we tested clustering the regions in the north, center and south. A supplementary approach was classifying observations in metropolitan and nonmetropolitan regions. However, these variations were not significant and point out that for processing of agricultural products, the location at regional level is not as relevant as it may be for primary agricultural production. An analysis based on more precise scales such as county level may be of interest for further research.

The estimation in Chapter 3 relies on the assumption that the output within the sectors is homogenous. Indeed, within each sector there is a certain heterogeneity (subspecializations) which the data set does not capture, for example, the meat sector consists of poultry and beef slaughterhouses and meat processing firms, while bakeries include processing and bread, pasta, or snack product production. This problem is less important for the milling sector where the technology and products are rather homogenous. This heterogeneity will probably be reflected in the dispersion of the $\mathrm{TE}^{\mathrm{G}}$ scores due to the differences in technology. Nevertheless, the standard deviation of technical efficiency is relatively low for bakery, meat, and milling. The largest dispersion is found in the dairy processors. However, this fact is related to the inherent structure of this sector. Although we cannot rule out the presence of a certain degree of heterogeneity in data, we consider that most of the variation in the efficiency scores derives from managerial inefficiency and measurement errors (which we accounted for).

More research should be done with respect to explaining the potential determinants of the meta-technology ratios for each sector rather than only measuring MTR. This will shed light on the sources of the differences in the technology gaps. Further research should also be done regarding the total factor productivity growth decomposition for Chilean agribusiness. This way we could obtain a nuanced analysis of the sources of productivity growth: technical change, technical efficiency change, and returns to scale. 


\subsection{Testing the effect of firm performance on growth for the Chilean agribusiness.}

Chapter 4 has shown the empirical relationship of firm performance and growth. The contribution of this chapter is the validation of the positive effect that firm performance (measured as technical efficiency) has on firm growth. Moreover, Chapter 4 has shown that the effect of firm performance is higher on slow-growing firms. These results are relevant to researchers because they demonstrate the importance of accounting for an appropriate indicator of firm performance such as technical efficiency, which captures the entirety of production process. Furthermore, the non-linearity of the relationship between performance and growth should be considered in future studies. Secondly, the findings are also relevant to managers because they stress the positive effect of firm performance to stimulating revenue growth.

The results presented in Chapter 4 also indicate that exporting status contributes to explaining large positive growth rates. Chapter 4 provides empirical evidence that trading to international markets offers the possibility to firms of experiencing large increases in revenue and coincides with extensive literature which also finds positive effects of free trade in individual firms. Thus, these results corroborate the dynamic effects of trade liberalization policies at the firm level.

Improvements to the estimation in Chapter 4 can be done by centering the data of the covariates on the mean. This will provide a more practical interpretation of the coefficients of technical efficiency and the meta-technology ratio. Furthermore, the use of an alternative measurement for firm performance such as total factor productivity can be of interest. 


\section{References}

Arellano, M., \& Bover, O. (1995). Another look at the instrumental variable estimation of error-components models. Journal of econometrics, 68(1), 29-51.

Bakucs, L.Z. \& Fertő, I. (2009). The growth of family farms in Hungary. Agricultural Economics. 40(S), 789-795.

Blundell, R. \& Bond, S. (1998). Initial conditions and moment restrictions in dynamic panel data models. Journal of Econometrics 87 (1), 115-143.

Bond, S., Hoeffler, A. \& Temple, J. (2001). GMM estimation of empirical growth models. London: Centre for Economic Policy Research (CEPR) Discussion Paper No. 2048.

BMWI (Bundesministerium für Wirtschaft und Energie) (2014). Act on the Development of Renewable Energy Sources. Retrieved from: http://www.bmwi.de/English/Redaktion/Pdf/renewable-energy-sources-act-eeg2014,property=pdf,bereich=bmwi2012, sprache=en,rwb=true.pdf

Chavas, J. P. (2001). Structural change in agricultural production: Economics, technology and policy. Handbook of agricultural economics, 1, 263-285.

Gardebroek, C., Turi, K.N. \& Wijnands, J. (2010). Growth dynamics of dairy processing firms in the European Union. Journal of Agricultural Economics 41 (34), 285-291.

Glauben, T., Tietje, H., \& Weiss, C. (2006). Agriculture on the move: Exploring regional differences in farm exit rates in Western Germany. Jahrbuch für regionalwissenschaft, 26(1), 103-118.

Habermann, H., \& Breustedt, G. (2011) Einfluss der Biogaserzeugung auf landwirtschaftliche Pachtpreise in Deutschland. German Journal of Agricultural Economics, 60, 85-100.

Huettel, S. \& Margarian, A. (2009). Structural change in the west German agricultural sector. Agricultural Economics 40 (Supplement), 759-772.

Kimhi, A., \& Bollman, R. (1999). Family farm dynamics in Canada and Israel: the case of farm exits. Agricultural Economics, 21(1), 69-79.

Kuhnert, H., Behrens, G., Hamm, U., Müller, H., Nieberg, H., Sanders, J. \& Strohm, R. (2013). Ausstiege aus dem ökologischen Landbau: Umfang - Gründe Handlungsoptionen. Johann Heinrich von Thünen-Institut. 
Kumbhakar, S. C., Tsionas, E. G., \& Sipiläinen, T. (2009). Joint estimation of technology choice and technical efficiency: an application to organic and conventional dairy farming. Journal of Productivity Analysis, 31(3), 151-161.

Musshoff, O., \& Hirschauer, N. (2008). Adoption of organic farming in Germany and Austria: an integrative dynamic investment perspective. Agricultural Economics, 39(1), 135-145.

Nieberg, H., Kuhnert, H. \& Sanders, J. (2011). Förderung des ökologischen Landbaus in Deutschland - Stand, Entwicklung und internationale Perspektive. 2., überarbeitete und aktualisierte Auflage, Special Issue No. 347. Braunschweig: vTI, Johann Heinrich von Thünen-Institut.

ODEPA (Oficina de Estudios y Politicas Agrarias) (2011). Identificación y análisis de las fortalezas y restricciones del crecimiento agroalimentario chileno al año 2017. Santiago, Chile.

ODEPA (2013). Mercado de lashortalizas procesadas. Retrieved from: http://www.odepa.cl/odepaweb/publicaciones/doc/9593.pdf

OECD (2006). Competition Law and Policy in Latin America: Peer Reviews of Argentina, Brazil, Chile, Mexico and Peru, OECD Report November 9, 2006.

Offermann, F. \& Nieberg, H. (2001). Economic Performance of Organic Farms in Europe. Organic Farming in Europe: Economics and Policy. Stuttgart-Hohenheim: University of Hohenheim, Department of Farm Economics.

Offermann, F., Nieberg, H. \& Zander, K. (2009). Dependency of organic farms on direct payments in selected EU member states: Today and tomorrow. Food Policy 34 (3), 273-279.

Oude Lansink, A. G., \& Jensma, K. (2003). Analysing profits and economic behaviour of organic and conventional Dutch arable farms. Agricultural Economics Review, $4(2)$.

Rizov, M. \& Mathijs, E. (2003). Farm survival and growth in transition economies: Theory and empirical evidence from Hungary. Post Communist Economies 15(2), 227-242.

Roodman, D. (2009). A note on the theme of too many instruments. Oxford Bulletin of Economics and Statistics 71 (1), 135-158.

Shapiro, D., Bollman, R. D. \& Ehrensaft, P. (1987). Farm size and growth in Canada. American Journal of Agricultural Economics 69 (2), 477-483. 
TDLC (Tribunal de Defensa de la Libre Competencia) (2015). Procesos en Curso: Demanda de Fedeleche contra Soprole S.A. Retrieved from http://www.tdlc.cl/DocumentosMultiples/C\%20291-15\%20\%20FEDELECHE.pdf

Verbeek M. \& Nijman, T.E. (1992). Testing for selectivity bias in panel data models. International Economic Review 33 (3), 681-703.

Weiss, C. (1999). Farm growth and survival: Econometric evidence for individual farms in Upper Austria. American Journal of Agricultural Economics 81 (1), 103-116. 


\section{List of scientific presentations}

Lakner, S., Brenes-Muñoz, T., Rivera-Aedo, E. and Brümmer, B. (2014). Technical Efficiency in the Chilean Agribusiness Sector? A Stochastic Meta-Frontier Approach. Paper presented at the $8^{\text {th }}$ North American Productivity Workshop, Ottawa, Canada.

Lakner, S., Brenes-Muñoz, T., Rivera-Aedo, E. and Brümmer, B. (2014). Technical Efficiency in the Chilean Agribusiness Sector? A Stochastic Meta-Frontier Approach, Poster session presented at the $14^{\text {th }}$ EAAE Congress, Ljubljana, Slovenia.

Lakner, S., Brenes-Muñoz, T., Rivera-Aedo, E. and Brümmer, B. (2013). Technical Efficiency in the Chilean Agribusiness Sector - a Stochastic Meta-Frontier Approach. Paper presented at the IATRC Symposium "Productivity and Its Impacts on Global Trade", Sevilla, Spain.

Brenes-Muñoz, T., Lakner, S. and Brümmer, B. (2012). Economic growth of farms: An empirical analysis on organic farming, Paper presented at the $28^{\text {th }}$ International Conference of Agricultural Economists (ICAE), Foz do Iguaçu, Brazil

Brenes-Muñoz, T., Lakner, S. and Brümmer, B. (2011). Determinants of economic growth in organic farming: the case of Bavaria and Baden-Wuerttemberg, Contributed Paper presented at the $13^{\text {th }}$ Congress of the European Association of Agricultural Economists (EAAE), Zürich, Switzerland.

Brenes-Muñoz, T., Lakner, S. and Brümmer, B. (2011). Determinants of economic growth in organic farming: the case of Bavaria and Baden-Württemberg, Paper presented at the $11^{\text {th }}$ Scientific Conference on Organic Agriculture (Wissenschaftstagung Ökologischer Landbau), Justus-Liebig-Universität Gießen, Germany. 


\section{Acknowledgements}

I would like to offer my special thanks to my supervisor, Prof. Dr. Stephan von Cramon-Taubadel to grant me the opportunity to pursue the $\mathrm{PhD}$ Degree, for his enthusiastic encouragement and useful suggestions during my study time. My grateful thanks are also extended to Prof. Dr. Bernhard Brümmer for his accurate comments, guide and above all for his time and contributions to develop this research work.

In addition, a thank you to all the colleagues at the Chair of Agricultural Policy and the Chair of Agricultural Market Analysis for the lively discussions and support during these years: Antje Wagener, Barbara Heinrich, Carsten Holst, Cordula Hundeshagen, Daniel Castro, Karla Hernandez, Friederike Greb, Jorge Carcamo, Jonathan Holtkamp, Nadine Würriehausen, Nina Enke, Sebastian Lakner, Sergio Araujo and Rico Ihle.

To the friends I have made along the way in Göttingen and Chile: Arlen Arbizu, Ayme Muzo, Edison Rivera, Grace Morrison, Lisbet Yañez, Sandra Gonzalez, Victor Aguilera, and Wendy Sanchez.

Thanks to my beloved family, first to my mother and my grandfather, Thelma Muñoz and Jose Muñoz for instilling in me a love for science and nature from early age. Thanks as well to my father, Carlos Brenes for teaching me that I could achieve anything I propose myself to do with hard work and for encouraging me to follow my goals. Thanks to my sister Nadia and brother Carlos for your unconditional support and love. Special thanks to my husband, Steven Parchwitz without your support, love and patience this work would not have been possible. Este logro también es de todos ustedes. 